\title{
Dental Pulp Stem Cells: an Alternative Source of Mesenchymal Stem Cells with Potential Osteogenic Regenerative Capacities
}

\section{Arkaitz Mucientes}

IdISSC

Eva Herranz

IdISSC

Enrique Moro

Hospital Clinico San Carlos

Aranzazu González-Corchón

Hospital Clinico San Carlos

María Jesús Peña-Soria

Hospital Clínico Universitario San Carlos Instituto Cardiovascular: Hospital Clinico Universitario San

Carlos Instituto Cardiovascular

\section{Pilar Pena}

Instituto de Cerámica y Vidrio: Instituto de Ceramica y Vidrio

Carmen Baudín

Instituto de Cerámica y Vidrio: Instituto de Ceramica y Vidrio

Lydia Abasolo

IdISSC

Luis Rodriguez-Rodriguez

IdISSC

José Ramón Lamas

IdISSC

Benjamin Fernandez-Gutierrez ( $\nabla$ benjamin.fernandez@salud.madrid.org)

Hospital Clinico San Carlos https://orcid.org/0000-0002-6126-8786

\section{Research}

Keywords: Mesenchymal stem cell, osteogenesis, osteogenic differentiation, dental pulp

Posted Date: November 12th, 2020

DOI: https://doi.org/10.21203/rs.3.rs-102952/v1 
License: (c) (i) This work is licensed under a Creative Commons Attribution 4.0 International License. Read Full License 


\section{Abstract}

Background: Bone innate ability to repair without scaring is surpassed by major bone damage. Current gold-standard strategies do not achieve a full recovery of the bone biomechanical properties. To bypass these limitations, tissue engineering techniques based on hybrid materials made up of osteoprogenitor cells, like mesenchymal stem cells (MSCs), and bioactive ceramic scaffolds, like calcium phosphatebased (CaPs), are promising. Biological properties of the MSCs, including osteogenic potential, are influenced by the tissue source. The aim of this study is to define the MSC source and construct (MSC and scaffold combination) most interesting for its clinical application in the context of bone regeneration.

Methods: MSCs of 9 healthy donors were isolated from adipose tissue, bone marrow and dental pulp. MSCs were cultured both on plastic surface and on CaPs (hydroxyapatite and $\beta$-tricalcium phosphate) to compare their biological features: proliferation rate, osteogenic potential, cell viability and activity, ability to colonize the CaPs and ALP activity.

Results: ITRAQ results generated the hypothesis that anatomical proximity to bone has a direct effect on MSC phenotype. On plastic, MSCs isolated from dental pulp (DPSCs) were the MSCs with the highest proliferation capacity and the greatest osteogenic potential. On both CaPs, DPSCs are the MSCs with the greatest capacity to colonize bioceramics. Furthermore, results show a trend for DPSCs are the MSCs with the most robust increase in the ALP activity.

Conclusion: Based in our results, we propose DPSCs as a suitable MSCs for bone/dental regeneration cell-based strategies.

\section{Background}

Bone regeneration and bone remodelling can be considered as two sides of the same coin. While bone remodelling is a life-long process, bone regeneration occurs mainly during bone healing. [1] It is known that for small fractures or injuries, the bone has an innate ability to repair without scaring. [2] These regenerative processes are largely surpassed by major bone damage such as skeletal reconstruction surgeries, bone defects of varied origins (traumatic, infectious and tumoral) or congenital skeletal dysplasias. Current orthopaedic surgery strategies are mostly bone grafting (both autologous and allogenic) and osteodistraction. [3] They can be combined with the use of growth factors or osteoinductive scaffolds. However, the successful recovery of the bone biomechanical properties is limited. To bypass these limitations, novel strategies have been developed. Among those, hybrid materials consisting of osteoprogenitor cells, like mesenchymal stem cells (MSCs), and bioactive ceramic scaffolds have been proposed as promising tools. [4]

Calcium phosphate-based (CaPs) bioceramics have been used both in maxillo-facial surgeries and dentistry for over 30 years. CaPs are biocompatible, osteoconductive, osteoinductive and, in some cases, bioactive. Due to these properties, CaPs are widely used as scaffolds for bone regeneration and tissue engineering. Among the different CaPs bioceramics, hydroxyapatite $(\mathrm{HA})$ and $\beta$-tricalcium phosphate ( $\beta$ - 
TCP) have been widely used. [5] The Ca:P ratio determines properties such as the solubility and tendency for resorption in the body. [6] HA is considered relatively non-biodegradable while $\beta$-TCP degrades readily and can be completely replaced by newly formed bone.

Adult MSCs can be isolated from almost every tissue. [7] They have multipotential capacities and can differentiate into cells of several mesenchymal lineages (cartilage, bone, tendons, muscles, and adipocytes) among other cell type. [8] Besides, MSCs have migratory and homing abilities which enhances their immunomodulatory and immunological tolerance induction potential. [9] Although MSCs derived from different sources present similar phenotypic characteristics, the intensity of these vary depending on the tissue source. [10]

Bone Marrow MSCs (BM-MSCs) were the first described MSCs and are often considered as the goldstandard in MSCs. [11] They have been widely used and studied in trials looking for potential regenerative therapies in the last years. Adipose-derived MSCs (ASCs) present several advantages compared to MSCs obtained from other sources: adipose depots are ubiquitous in the body, easily accessible with minimum invasion and contain a large number of stem cells. [12] Furthermore, their capacity to promote osteogenesis in animal models has been described. [13] MSCs isolated from dental pulp (DPSCs) are usually isolated after surgical removal of wisdom teeth, so they are considered as a non-invasive source of MSCs. DPSCs present a high proliferative capacity and easily differentiate into odontoblasts, osteoblasts and chondrocytes. [14] DPSCs have been recently proposed to be used in regenerative therapies for bone diseases, among other condition. [15]

Considering the osteogenic potential as a property influenced by the tissue, several comparative studies of MSCs derived from various sources on different surfaces have been published. [16-21] Despite these, a clarification is still needed regarding the influence of the cell source and surface in the osteogenic potential. Osteogenic potential maximization in a context of the bone-regeneration process would be an important step. The aim of this study is to define the MSC source and construct (MSC and scaffold combination) with the highest osteogenic potential.

\section{Methods}

\section{Proteomic analysis by ITRAQ labelling}

Data obtained in a previous proteomic analysis where MSCs from subchondral bone and cartilage were compared (not published). Specifically, results obtained after comparing these locations in healthy individuals were analysed.

Briefly, MSCs were obtained surgically from subchondral bone and cartilage of a donor without osteoporotic or osteoarthritis signs. Total protein content was isolated, dried in air and then re-suspended in $25 \mu \mathrm{l}$ of iTRAQ dissolution buffer (ABSciex, Foster City, CA, USA). Protein concentrations were determined by Bradford assay (Sigma-Aldrich, St. Louis, MO, USA). TRAQ labelling (ABSciex, Foster City, CA, USA) was performed with $\mathrm{SB}(116)$ and $\mathrm{C}(117)$ mass tags and desalted with home-made C-18 Stage- 
tips. Fractions separated in a nanoLC system (Tempo, Eksigent) were automatically deposited on a MALDI plate and analysed by MSMS (4800 MALDI-TOF/TOF system. ABSciex). Relative quantitative analysis was done using ProteinPilot software (ABSciex) using the Paragon ${ }^{\text {TM }}$ Algorithm for protein identification and quantification. Only proteins identified with at least $95 \%$ confidence, a Prot Score of at least 1.3 , a $p$-value $\leq 0.05$ and ratio $(\neq 1)$ were considered as modulated.

\section{Samples}

MSCs from 3 different localizations (bone marrow, dental pulp, and adipose tissue), obtained from healthy donors (Table 1), were used for in vitro biological studies. Written informed consent was obtained from all donors before sample collection. The study was approved following the guidelines of the institutional ethics committee (Comité Ético de Investigación Clínica Hospital Clínico San Carlos) and the principles expressed in the Declaration of Helsinki.

Table 1

Main characteristics of healthy donors

\begin{tabular}{|llll|}
\hline Donor & Cell type & Sex & Age \\
\hline Donor 1 & BM-MSC & F & 57 \\
\hline Donor 2 & BM-MSC & M & 56 \\
\hline Donor 3 & BM-MSC & M & 55 \\
\hline Donor 4 & ASC & F & 53 \\
\hline Donor 5 & ASC & F & 56 \\
\hline Donor 6 & ASC & M & 50 \\
\hline Donor 7 & DPSC & F & 44 \\
\hline Donor 8 & DPSC & M & 58 \\
\hline Donor 9 & DPSC & M & 59 \\
\hline
\end{tabular}

Discs of CaPs bioceramics used in this study were synthesised, sintered, and polished if needed. They were kindly supplied by Instituto de Cerámica y Vidrio (ICV-CSIC). Discs had a diameter of $18 \mathrm{~mm}$ and $4 \mathrm{~mm}$ thickness. Sintering temperature employed for $\beta$-TCP was $1130^{\circ} \mathrm{C}$ and for HA was $1250^{\circ} \mathrm{C}$.

\section{Cell isolation and culture}

ASCs were obtained from adipose tissue after surgical biopsies, according to Yang et al. [22] DPSCs were isolated after dental pulp mechanical extraction from wisdom exodontias, as described by Huang et al. 
[23] Finally, BM-MSCs were obtained from femoral channel aspirates of bone marrow, taken during joint replacement surgery, in a Ficoll density gradient and cultured directly as described by Gudlevicine et al. [24]

Once isolated, cells were expanded in growth medium: DMEM supplemented with $10 \%$ FBS and antibiotics; DPSCs required $20 \%$ FBS instead of the $10 \%$ usually established as described by Alkhalil et al. [25] Cell cultures were expanded at $37^{\circ} \mathrm{C}$ in a $5 \% \mathrm{CO}_{2}$ atmosphere. The medium was changed every 3 days until cell confluence at passage 3 .

\section{Cell characterization}

In order to confirm that cells satisfied the minimal criteria for the definition of MSC proposed by the International Society for Cellular Therapy, [26] flow cytometry and histochemistry assays were carried out as we previously described. [27]

\section{Biological features on plastic surface}

\section{MSC proliferation rate}

During cell expansion, cell proliferation was evaluated by calculating the population doubling time (Dt), which is defined by:

$\mathrm{Dt}=\mathrm{T} \ln 2 / \ln (\mathrm{Nf} / \mathrm{Ni})$

Where " $\mathrm{T}$ " represents the time elapsed between determinations of the final number of cells (Nf) obtained from an initial cell number $(\mathrm{Ni})$.

\section{Osteogenic commitment of each MSC}

Alizarin Red staining was carried out along culture on plastic. The coloured area of cell cultures after alizarin red staining was quantified, in terms of percentage, with ImageJ $1.43 \mathrm{v}$ software (National Institutes of Health, free available: https://imagej.nih.gov/ij/index.html).

\section{Cell behaviour on CaPs}

\section{Cell activity/viability}

Prior to cell seeding, the scaffolds were previously submerged in growth medium for 24 hours and then seeded with $1 \mathrm{ml}$ of a cellular suspension containing 50000 cells.

Monitorization of cell viability was performed using the colourimetric indicator AlamarBlue ${ }^{\mathrm{TM}}$ (Cat\#Y00100. Thermo Fisher Scientific, Waltham, MA USA). The variation of absorbance at $570 \mathrm{~nm}$ was measured at 24 hours, 4 and 7 days using Heales MB-580 microplate reader (Shenzhen Heales Technology 
Development Co. Ltd. Guangdong. China). The amount of absorbance corresponds to cell metabolic activity.

\section{Scanning Electronic Microscopy (SEM)}

The cellular organization, adhesion and colonization of the scaffolds were assessed at 24 hours and 7 days. Each sample was subjected to fixation with a phosphate buffer solution containing $4 \%$ paraformaldehyde and $2.5 \%$ glutaraldehyde for 30 minutes. After fixation, samples were washed 3 times with phosphate-buffered saline (PBS) for 20 minutes followed by incubation for 45 minutes with a solution of $1 \%$ osmium tetraoxide and, finally, washed again with PBS 3 times for 10 minutes. The next step was the dehydration of the samples by immersing them in increasing ethanol concentrations: $30 \%$, $50 \%, 70 \%, 96 \%$ and $100 \%$. The final step was to introduce the samples into the critical-point device and cover them with vaporized gold. Samples were observed and analysed by scanning electron microscopy (SEM JEM 6400, JEOL, Japan).

\section{ALP activity}

Early osteoblast differentiation was evaluated by measuring the alkaline phosphatase (ALP) activity, which is expressed just before the matrix mineralization occurs and its role as osteogenic activity marker is established [28]. The evaluation was made using 24-well plates and 3 conditions for each sample were evaluated: cell in plastic with growth medium as an internal control; cells seeded on HA with osteogenic medium and $\beta$-TCP with osteogenic medium. Duplicates for each experimental condition were made.

Osteogenesis progression was measured between $24 \mathrm{~h}$ and 7 days, at this time points media was discarded and ceramic discs recovered, washed with PBS and stored at $-20^{\circ} \mathrm{C}$ soaked in lysis buffer $(0.1$ wt\%, Triton-X 100, $1 \mathrm{mM} \mathrm{MgCl} 2,0.1 \mathrm{mM} \mathrm{ZnCl} 2$ ). The ALP activity was determined by a colourimetric method using a commercial kit (Thermo Fisher Scientific, Cat\#37629), following the manufacturer instructions, and measuring the absorbance at $405 \mathrm{~nm}$.

\section{Statistical analysis}

Statistical analysis was performed using GraphPad Prism version 7.00 for Windows, (GraphPad Software, La Jolla California USA, www.graphpad.com). We have used two-tailed paired/unpaired Student's t-test for comparison of normal variables. Normal variables were presented as mean $\pm S D$ (standard deviation). The level of significance $p<0.05$ was considered statistically significant. Each experiment was done with replicates.

\section{Results}

\section{ITRAQ results analysis}

The different protein components between MSCs from subchondral bone and cartilage were analysed using an iTRAQ-based comparative analysis. We have previously performed this ITRAQ in the context of 
osteoarthritis vs control patients and in this case we have analysed quantitative differences between subchondral bone and cartilage only from healthy control individuals.

Results obtained revealed the identification of 1012 unique proteins in samples. Fifty of those proteins display statistically significant differences (Table 2). Among those, 5 proteins have been previously associated with the osteoblast differentiation process: PALLD, HSPA5/GRP78, FLNA, IGFBP3 and DSTN. 


\section{Table 2 - Differentially expressed proteins identified in MSC isolated from subchondral bone compared to MSC from cartilage}

\begin{tabular}{|c|c|c|c|c|c|c|}
\hline Uniprot ID & Gene & Protein & Coverage & Peptides & $\begin{array}{l}\text { Fold } \\
\text { change }\end{array}$ & $\begin{array}{l}\mathrm{p}- \\
\text { value }\end{array}$ \\
\hline AMPN_HUMAN & ANPEP & Aminopeptidase $\mathrm{N}$ & 38,1 & 27 & 11,272 & 0,0001 \\
\hline PALLD_HUMAN & PALLD & Palladin & 13,4 & 4 & 4,6989 & 0,0145 \\
\hline K2C1_HUMAN & KRT1 & $\begin{array}{l}\text { Keratin, type II } \\
\text { cytoskeletal } 1\end{array}$ & 30,6 & 11 & 4,3652 & 0,0164 \\
\hline TPM1_HUMAN & TPM1 & $\begin{array}{l}\text { Tropomyosin alpha-1 } \\
\text { chain }\end{array}$ & 41,6 & 13 & 4,3652 & 0,0173 \\
\hline TAGL_HUMAN & TAGLN & Transgelin & 68,2 & 13 & 4,2855 & 0,0001 \\
\hline K1C10_HUMAN & KRT10 & $\begin{array}{l}\text { Keratin, type I } \\
\text { cytoskeletal } 10\end{array}$ & 26,5 & 8 & 3,5645 & 0,0085 \\
\hline FRIH_HUMAN & FTH1 & Ferritin heavy chain & 45,9 & 3 & 3,4356 & 0,034 \\
\hline DHB4_HUMAN & HSD17B4 & $\begin{array}{l}\text { Peroxisomal } \\
\text { multifunctional } \\
\text { enzyme type } 2\end{array}$ & 19,2 & 5 & 3,4041 & 0,0078 \\
\hline VIME_HUMAN & VIM & Vimentin & 91,6 & 235 & 3,342 & 0,0291 \\
\hline SQRD_HUMAN & SQRDL & $\begin{array}{l}\text { Sulfide:quinone } \\
\text { oxidoreductase, } \\
\text { mitochondrial }\end{array}$ & 29,3 & 10 & 2,9923 & 0,003 \\
\hline PDIA1_HUMAN & $\mathrm{P} 4 \mathrm{HB}$ & $\begin{array}{l}\text { Protein disulfide- } \\
\text { isomerase }\end{array}$ & 71,3 & 48 & 2,729 & 0,0028 \\
\hline KPYM_HUMAN & PKM2 & $\begin{array}{l}\text { Pyruvate kinase } \\
\text { isozymes M1/M2 }\end{array}$ & 76,5 & 69 & 2,6062 & 0,0123 \\
\hline ATPB_HUMAN & ATP5B & $\begin{array}{l}\text { ATP synthase } \\
\text { subunit beta, } \\
\text { mitochondrial }\end{array}$ & 65,6 & 21 & 2,5351 & 0,0118 \\
\hline GRP78_HUMAN & HSPA5 & $\begin{array}{l}78 \mathrm{kDa} \text { glucose- } \\
\text { regulated protein }\end{array}$ & 69 & 53 & 2,5119 & 0,0001 \\
\hline GLCM_HUMAN & GBA & Glucosylceramidase & 16 & 4 & 2,421 & 0,0472 \\
\hline DPYL3_HUMAN & DPYSL3 & $\begin{array}{l}\text { Dihydropyrimidinase- } \\
\text { related protein } 3\end{array}$ & 47 & 14 & 2,3768 & 0,0232 \\
\hline SPTB2_HUMAN & SPTBN1 & $\begin{array}{l}\text { Spectrin beta chain, } \\
\text { brain } 1\end{array}$ & 28,2 & 31 & 2,0512 & 0,0251 \\
\hline GDIR1_HUMAN & ARHGDIA & $\begin{array}{l}\text { Rho GDP- } \\
\text { dissociation inhibitor } \\
1\end{array}$ & 59,8 & 8 & 2,0137 & 0,0105 \\
\hline
\end{tabular}




\section{Table 2 - Differentially expressed proteins identified in MSC isolated from subchondral bone compared to MSC from cartilage}

\begin{tabular}{|c|c|c|c|c|c|c|}
\hline ACADV_HUMAN & ACADVL & $\begin{array}{l}\text { Very long-chain } \\
\text { specific acyl-CoA } \\
\text { dehydrogenase, } \\
\text { mitochondrial }\end{array}$ & 28,7 & 7 & 1,8707 & 0,0486 \\
\hline ATPA_HUMAN & ATP5A1 & $\begin{array}{l}\text { ATP synthase } \\
\text { subunit alpha, } \\
\text { mitochondrial }\end{array}$ & 57,7 & 24 & 1,8535 & 0,007 \\
\hline MYL6_HUMAN & MYL6 & $\begin{array}{l}\text { Myosin light } \\
\text { polypeptide } 6\end{array}$ & 86,8 & 16 & 1,7865 & 0,0487 \\
\hline LMO7_HUMAN & LMO7 & $\begin{array}{l}\text { LIM domain only } \\
\text { protein } 7\end{array}$ & 28,4 & 11 & 1,6144 & 0,0436 \\
\hline 5NTD_HUMAN & FLNA & 5'-nucleotidase & 53,5 & 22 & 1,5704 & 0,044 \\
\hline FLNA_HUMAN & FLNA & Filamin-A & 61,4 & 126 & 1,5276 & 0,0036 \\
\hline HS90A_HUMAN & HSP90AA1 & $\begin{array}{l}\text { Heat shock protein } \\
\text { HSP } 90 \text {-alpha }\end{array}$ & 56,4 & 29 & 1,5276 & 0,0351 \\
\hline H32_HUMAN & HIST2H3A & Histone H3.2 & 36 & 7 & 0,8872 & 0,0298 \\
\hline H2AJ_HUMAN & H2AFJ & Histone H2A.J & 41,1 & 7 & 0,7798 & 0,0365 \\
\hline PDLI7_HUMAN & PDLIM7 & $\begin{array}{l}\text { PDZ and LIM domain } \\
\text { protein } 7\end{array}$ & 12,9 & 1 & 0,7311 & 0,0042 \\
\hline ALDR_HUMAN & AKR1B1 & Aldose reductase & 37 & 5 & 0,6918 & 0,0237 \\
\hline FLNC_HUMAN & FLNC & Filamin-C & 14,8 & 14 & 0,631 & 0,0145 \\
\hline MVP_HUMAN & MVP & Major vault protein & 49,7 & 23 & 0,5649 & 0,0078 \\
\hline VINC_HUMAN & VCL & Vinculin & 41,5 & 23 & 0,5546 & 0,0245 \\
\hline RS15A_HUMAN & RPS15A & $\begin{array}{l}40 S \text { ribosomal } \\
\text { protein S15a }\end{array}$ & 47,7 & 4 & 0,5248 & 0,0221 \\
\hline SFPQ_HUMAN & SFPQ & $\begin{array}{l}\text { Splicing factor, } \\
\text { proline- and } \\
\text { glutamine-rich }\end{array}$ & 21,1 & 3 & 0,4966 & 0,0205 \\
\hline PLIN3_HUMAN & PLIN3 & Perilipin-3 & 55,8 & 14 & 0,4875 & 0,0418 \\
\hline NNMT_HUMAN & NNMT & $\begin{array}{l}\text { Nicotinamide } \mathrm{N}- \\
\text { methyltransferase }\end{array}$ & 31,8 & 6 & 0,4742 & 0,04 \\
\hline 1433Z_HUMAN & YWHAZ & $\begin{array}{l}\text { 14-3-3 protein } \\
\text { zeta/delta }\end{array}$ & 71,8 & 14 & 0,4699 & 0,0217 \\
\hline PRDX1_HUMAN & PRDX1 & Peroxiredoxin-1 & 70,9 & 21 & 0,4169 & 0,0199 \\
\hline
\end{tabular}




\section{Table 2 - Differentially expressed proteins identified in MSC isolated from subchondral bone compared to MSC from cartilage}

\begin{tabular}{|c|c|c|c|c|c|c|}
\hline ANX11_HUMAN & ANXA11 & Annexin A11 & 36,4 & 9 & 0,3733 & 0,0014 \\
\hline G6PD_HUMAN & G6PD & $\begin{array}{l}\text { Glucose-6-phosphate } \\
\text { 1-dehydrogenase }\end{array}$ & 43,5 & 15 & 0,3664 & 0,0006 \\
\hline HYEP_HUMAN & EPHX1 & Epoxide hydrolase 1 & 19,6 & 7 & 0,3467 & 0,0069 \\
\hline 6PGD_HUMAN & PGD & $\begin{array}{l}\text { 6-phosphogluconate } \\
\text { dehydrogenase, } \\
\text { decarboxylating }\end{array}$ & 38,3 & 10 & 0,2911 & 0,004 \\
\hline CALU_HUMAN & CALU & Calumenin & 53,3 & 14 & 0,2655 & 0,0057 \\
\hline NQ01_HUMAN & NQ01 & $\begin{array}{l}\mathrm{NAD}(\mathrm{P}) \mathrm{H} \\
\text { dehydrogenase } \\
\text { [quinone] } 1\end{array}$ & 46 & 11 & 0,2512 & 0,0153 \\
\hline TKT_HUMAN & TKT & Transketolase & 56 & 21 & 0,1486 & 0,0051 \\
\hline ANXA5_HUMAN & ANXA5 & Annexin A5 & 78,4 & 38 & 0,1294 & 0,0002 \\
\hline ENOA_HUMAN & EN01 & Alpha-enolase & 84,3 & 54 & 0,1 & 0,0419 \\
\hline ANXA2_HUMAN & ANXA2 & Annexin A2 & 87,6 & 74 & 0,0871 & 0,0019 \\
\hline IBP3_HUMAN & IGFBP3 & $\begin{array}{l}\text { Insulin-like growth } \\
\text { factor-binding protein } \\
3\end{array}$ & 39,9 & 5 & 0,0802 & 0,0424 \\
\hline DEST_HUMAN & DSTN & Destrin & 65,5 & 8 & 0,0614 & 0,0245 \\
\hline
\end{tabular}

\section{Scanning Electronic Microscopy}

Cell morphology and behaviour when growing on $\beta$-TCP and HA scaffolds were studied by SEM at both 24 hours and 7 days after culture. In all cases, cells do not show visual signs of cytotoxicity. Cells can be visualized in its normal shape and size.

Regarding $\beta$-TCP, cell adhesion seems to be faster in BM-MSCs (Fig. 5C) than in ASCs and DPSCs (Figs. 5A and 5E). After 7 days, cell overlays were observed in $\beta$-TCP discs independently of the MSC seeded (Figs. 5B-D-F). When culturing on HA, the adhesion process was similar for all MSCs (Figs. 6A-CE). On day 7, BM-MSCs and ASCs (Figs. 6B-D) exhibited similar appearance, and the number of cells increased without forming layers. In contrast, DPSCs (Fig. 6F) formed a multilayer covering the entire surface. Finally, all MSCs colonized the existing internal pores in both CaPs (Fig. 7). 


\section{Osteogenic Potential}

Figure 8 shows a significant differential ALP activity at both 24 hours and 7 days, being higher on HA ( $\mathrm{t}=$ 24 hours, $\beta-\mathrm{TCP}=0.4249, \mathrm{HA}=0.6213, p=0.0014 ; \mathrm{t}=7$ days, $\beta-\mathrm{TCP}=0.6201, \mathrm{HA}=0.9517, p=0.0002$ ).

According to cell localization (Fig. 9), each localization shows a significant increase in ALP activity

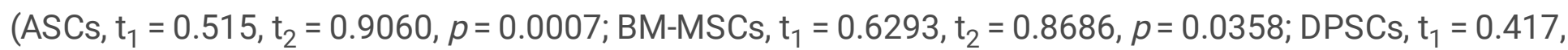
$\left.\mathrm{t}_{2}=0.7147, p=0.0002\right)$. The initial differences between locations disappeared at final time point $(\mathrm{t}=24$ hours, ASCs $=0.5150, \mathrm{BM}-\mathrm{MSC}=0.6293$, DPSCs $=0.4170, p=0.0306 ; \mathrm{t}=7$ days, $\mathrm{ASC}=0.9016, \mathrm{BM}-$ MSCs $=0.8636$, DPSCs $=0.7147, p=0.2394)$.

Finally, the increase in ALP activity, in percentage, was calculated. DPSCs presented a bigger although not significant increase in the ALP activity than the other sources (ASCs $=62.58 \%$, BM-MSCs $=40.15 \%$, DPSCs $=72.51 \%, p=0.4202$ ). Regarding biomaterial-cells combinations, DPSC + HA increased the most, although not significant different were obtained (ASCs + HA $=98.60 \%$, BM-MSCs $+\mathrm{HA}=43.46 \%$, DPSCs + $\mathrm{HA}=132.20 \%, \mathrm{ASC} s+\beta-\mathrm{TCP}=78.38 \%, \mathrm{BM}-\mathrm{MSC}+\beta-\mathrm{TCP}=112.20 \%, \mathrm{DPSC}+\beta-\mathrm{TCP}=56.44 \%, p=$ 0.1479 ) (Figs. 10 and 11).

\section{Discussion}

In bone regeneration context, therapies based on using osteoprogenitor cells are promising. However, the full therapeutic potential of these techniques has not been achieved. A full understanding of how different biological aspects influence the osteogenic potential is required. Anatomical localization of the cells used is among those characteristics. To our knowledge, this is the first comparative work that analyses a possible osteogenic commitment depending on the anatomic localization of non-commercial human MSCs from bone marrow, adipose tissue and dental pulp, seeded both on plastic surface and CaPs $(\beta-T C P$ and HA).

The starting point of this work was the analysis of the results obtained in a previous ITRAQ where MSCs from subchondral bone and cartilage were compared in an osteoarthritis (OA) study. $O A$ is a condition characterized by excessive bone growth, and the main affected tissues are subchondral bone and cartilage. Specifically, results obtained after comparing these locations in healthy individuals were analysed in a free-hypothesis context. Fifty proteins were identified (Table 2). Five out of those 50 proteins have been communicated as related to osteogenic process. FLNA, HSPA5/GRP78 and PALLD were up-regulated in subchondral bone and its expression correlated with osteoblast differentiation as they contribute to the stabilization of cytoskeleton, which is necessary for the osteogenesis, and regulate protein folding and calcium flux. [29-32] In contrast, DSTN and IBP3, inhibitors of the osteoblast differentiation, $[33,34]$ were down-regulated in MSCs isolated from subchondral bone. Considering this background, MScs from subchondral bone display a more established commitment to osteogenesis compared to MSCs from cartigale. This supports the hyptothesis that an anatomical proximity to bone has a direct effect on MSC phenotype in terms of increased osteogenic commitment. 
To confirm this hypothesis, we analysed the biological behiviour of MSCs isolated from locations with different proximity to bone (adipose tissue, bone marrow and dental pulp) on different surfaces. All cells used in this work met the minimal criteria to be defined as MSCs (see Additional file 1). [26]

When cultured on plastic surfaces, two biological characteristics of MSCs were evaluated: proliferative ability and osteogenic potential. Evaluating the cell proliferation is important for cell-based therapies since it has been communicated that failures on stem cell therapies is likely to be due to a massive cell death occurring after cell transplantation. [35] Our in vitro results established that DPSCs have the highest proliferation rate (Fig. 1), in line with previous studies. [36] Besides, it was observed that DPSCs present a smaller size. Since DPSCs have a higher proliferation rate, it is likely this smaller size is a consequence of this due to the indirect relationship between proliferation and cell size. $[37,38]$ Alizarin Red staining is commonly used as an osteogenic differentiation indicator as mineralized nodules are redcoloured. Microscopy images show that DPSCs exhibit the most intense staining, and its quantification evidence significant differences (Fig. 2). These results indicate that DPSCs present the most in vitro osteogenic capacity, followed by BM-MSCs and ASCs as the least osteogenic. This staining pattern confirms and extends results obtained by Tamaki et al. [16] Furthermore, it has been described that DPSCs likely have an advantage for osteogenic differentiation over other MSCs, [19] and DPSCs only differentiate into osteoblasts at high passages. [39]

Once MSCs were seeded on the scaffolds and constructs generated, it was studied their cell viability, colonization ability, and osteogenic capacity. Viability test showed that $\beta$-TCP is more cell-friendly than HA (Fig. 3). Both $\beta$-TCP and HA are biomaterials commonly used in bone tissue engineering and dentistry to treat bone defects. Implant surface quality is a major factor in biocompatibility. When the surface of the implanted biomaterial is exposed to tissue fluids, an initial interaction occurs between the living bone and tissue and the implant surface. In this sense, the use of materials filled with tricalcium phosphate appears promising following the observation that more living cells are in this material. [40] Regarding MSCs, viability test is favourable for DPSCs at $24 \mathrm{hs}$ and 4 days comparing to ASCs or BM-MSCs. These differences are not significant at 7 days (Fig. 4).

SEM images (Figs. 5 and 6) are coherent since only DPSCs developed cell layer on HA whereas on $\beta$-TCP the three source-derived MSCs did it. CaPs are porous, so it is required pore colonization by the cells for an optimal colonization of the CaP. Specific images of the pores existing in both CaPs proof a pore successfully colonization by all MSCs after 24 hours (Fig. 7). Besides, cytotoxicity was not appreciated in the studied samples. It is remarkable that DPSCs have shown to be the MSCs with the greatest proliferation ability on both plastic surface and bioceramics. This feature is an advantage for bone regeneration as a high MSCs density enhances the osteogenic differentiation. [41] These results indicate, together with other studies, that DPSCs could be the optimal stem cells for dental and bone regeneration. $[18,42]$

The interplay of the tissue engineering triad (cells, signaling molecules, and scaffolds) is essential for recapitulation of the biological events of tissue regeneration. These elements have been used either 
separately or in combination for the reconstitution of the pulp-dentin complex and bone defects. Recent data imply that $\beta$-TCP is a bioactive and biocompatible material capable of enhancing DPSCs proliferation, migration, and adhesion. Moreover, recent data are conclusive about DPSCs higher levels of osteogenic and odontogenic differentiation markers such as COLI, DSPP, OC, RUNX2, and DMP-1. Our results suggest, in accordance with the literature, that DPSCs may be a valuable tool in the context of dental and bone regeneration. [43]

Regarding osteogenic potential, ALP activity test results (Fig. 8) mismatch viability results (Fig. 3): while $\beta$-TCP appears to be the best in terms of viability, HA obtained the highest values in ALP activity. Theses results indicate that a combination of materials would be more effective. Referring to cell sources, ASCs and BM-MSCs present similar absolute values, that are slightly superior to DPSCs values but no significant. Interestingly, this pattern in ALP activity also appears in recent studies that compare multisources derived MSCs seeded on plastic surfaces, $[20,21]$ although these studies obtained significant differences. The absence of significance in our results could be due to the osteoinductive properties that both CaPs present, $[44,45]$ which the plastic surface lacks. Since DPSCs present the highest metabolic activity during osteogenesis on both CaPs (see Additional file 2), we consider conceivable that CaPs enhance the osteogenesis preferentially on DPSCs over other MSCs. In relation to biomaterial-cells combinations, the highest increase in ALP activity, although not significant, was obtained by DPSCs + HA combination.

\section{Conclusions}

In summary, our results point to DPSCs as ideal cell in bone regeneration scenario. Within bone regeneration, DPSCs might be especially beneficial in periodontal regeneration. Supporting this, a Phase 3 clinical study using DPSCs for alveolar cleft lip and palate repair has recently been initiated (ClinicalTrials.gov Identifier: NCT03766217), and promising results of the using DPSCs for periodontal regeneration has been published. [46] Moreover, a combination of the best viability of $\beta$-TCP and the enhanced osteogenic capacity of HA would be appropriate. Other studies will be necessaries to obtain the best combination of cells and biomaterials together with other signaling enhancers or inhibitors as different proteins have really demonstrated in the field of dentistry and bone regeneration. $[47,48]$

\section{Abbreviations}

MSC

Mesenchymal Stem Cell

$\mathrm{CaP}$

Calcium phosphate-based ceramic

BM-MSCS

Bone Marrow MSC

ASC

Adipose-derived MSC 
DPSC

Dental Pulp MSC

SEM

Scanning Electron Microscopy

ALP

Alakine Phosphatase

OA

Osteoarthritis

$\beta$-TCP

Beta-Tricalcium Phosphate

$\mathrm{HA}$

Hydroxyapatite

\section{Declarations}

\section{Ethics approval and consent to participate}

Written informed consent was obtained from all donors before sample collection. The study was approved following the guidelines of the institutional ethics committee (Comité Ético de Investigación Clínica Hospital Clínico San Carlos) and the principles expressed in the Declaration of Helsinki.

\section{Consent for publication}

Not applicable.

\section{Availability of data and materials}

The datasets used and/or analysed during the current study are available from the corresponding author on reasonable request.

\section{Competing interests}

The authors declare that they have no competing interests

\section{Funding}

This work was supported by grants RIER (Instituto de Salud Carlos III) and FIS PI13/01863 (Instituto de Salud Carlos III).

\section{Authors' contributions}

AM and EV performed the experiments and collected and assembled data. EM, AG-C, MJP-S, PP and CB provied study materials or patients. AM, LA and LR-R performed the data analysis and interpretated the 
results. AM writed the manuscript. JRL and BF-G planned the study and reviewed and edited the paper. All authors read and approved the final manuscript.

\section{Acknowledgements}

We thank the Hospital Clínico San Carlos surgeons for providing the samples used in the study.

\section{References}

1. Dimitriou R, Jones E, McGonagle D, Giannoudis P V. Bone regeneration: current concepts and future directions. BMC Med [Internet]. 2011;9:66. Available from:

http://bmcmedicine.biomedcentral.com/articles/10.1186/1741-7015-9-66

2. Einhorn TA. The Cell and Molecular Biology of Fracture Healing. Clin Orthop Relat Res [Internet]. 1998;355S:S7-21. Available from: http://journals.Iww.com/00003086-199810001-00003

3. Giannoudis P V., Calori GM, Begue T, Schmidmaier G. Bone regeneration strategies: Current trends but what the future holds? Injury [Internet]. 2013;44:S1-2. Available from:

https://linkinghub.elsevier.com/retrieve/pii/S0020138313700020

4. Wang P, Zhao L, Chen W, Liu X, Weir M, Xu H. Stem Cells and Calcium Phosphate Cement Scaffolds for Bone Regeneration. J Dent Res [Internet]. 2014;93:618-25. Available from:

http://journals.sagepub.com/doi/10.1177/0022034514534689

5. Wagoner Johnson AJ, Herschler BA. A review of the mechanical behavior of $\mathrm{CaP}$ and $\mathrm{CaP} /$ polymer composites for applications in bone replacement and repair. Acta Biomater [Internet]. 2011;7:16-30. Available from: https://linkinghub.elsevier.com/retrieve/pii/S1742706110003296

6. Descamps M, Boilet L, Moreau G, Tricoteaux A, Lu J, Leriche A, et al. Processing and properties of biphasic calcium phosphates bioceramics obtained by pressureless sintering and hot isostatic pressing. J Eur Ceram Soc [Internet]. 2013;33:1263-70. Available from: https://linkinghub.elsevier.com/retrieve/pii/S0955221913000265

7. da Silva Meirelles L, Chagastelles PC, Nardi NB. Mesenchymal stem cells reside in virtually all postnatal organs and tissues. J Cell Sci [Internet]. 2006;119:2204-13. Available from: http://www.ncbi.nlm.nih.gov/pubmed/16684817

8. Pittenger MF, Mackay AM, Beck SC, Jaiswal RK, Douglas R, Mosca JD, et al. Multilineage potential of adult human mesenchymal stem cells. Science [Internet]. 1999;284:143-7. Available from: http://www.ncbi.nlm.nih.gov/pubmed/10102814

9. Castro-Manrreza ME, Montesinos JJ. Immunoregulation by mesenchymal stem cells: biological aspects and clinical applications. J Immunol Res [Internet]. 2015;2015:394917. Available from: http://www.ncbi.nlm.nih.gov/pubmed/25961059 
10. Escacena N, Quesada-Hernández E, Capilla-Gonzalez V, Soria B, Hmadcha A. Bottlenecks in the Efficient Use of Advanced Therapy Medicinal Products Based on Mesenchymal Stromal Cells. Stem Cells Int [Internet]. 2015;2015:1-12. Available from: http://www.hindawi.com/journals/sci/2015/895714/

11. Hass R, Kasper C, Böhm S, Jacobs R. Different populations and sources of human mesenchymal stem cells (MSC): A comparison of adult and neonatal tissue-derived MSC. Cell Commun Signal [Internet]. 2011;9:12. Available from: https://biosignaling.biomedcentral.com/articles/10.1186/1478-811X-9-12

12. Baer PC, Geiger H. Adipose-Derived Mesenchymal Stromal/Stem Cells: Tissue Localization, Characterization, and Heterogeneity. Stem Cells Int. 2012;

13. Xia L, Lin K, Jiang X, Fang B, Xu Y, Liu J, et al. Effect of nano-structured bioceramic surface on osteogenic differentiation of adipose derived stem cells. Biomaterials. 2014;

14. Potdar PD, Jethmalani YD. Human dental pulp stem cells: Applications in future regenerative medicine. World J Stem Cells [Internet]. 2015;7:839-51. Available from: http://www.wjgnet.com/19480210/full/v7/i5/839.htm

15. Kichenbrand C, Velot E, Menu P, Moby V. Dental Pulp Stem Cell-Derived Conditioned Medium: An Attractive Alternative for Regenerative Therapy. Tissue Eng Part B Rev [Internet]. 2019;25:78-88. Available from: http://www.ncbi.nlm.nih.gov/pubmed/30156475

16. Tamaki Y, Nakahara T, Ishikawa H, Sato S. In vitro analysis of mesenchymal stem cells derived from human teeth and bone marrow. Odontology. 2013;

17. Li C, Wu X, Tong J, Yang X, Zhao J, Zheng Q, et al. Comparative analysis of human mesenchymal stem cells from bone marrow and adipose tissue under xeno-free conditions for cell therapy. Stem Cell Res Ther [Internet]. 2015;6:55. Available from: http://www.ncbi.nlm.nih.gov/pubmed/25884704

18. Lobo SE, Glickman R, da Silva WN, Arinzeh TL, Kerkis I. Response of stem cells from different origins to biphasic calcium phosphate bioceramics. Cell Tissue Res. 2015;

19. Ren H, Sang Y, Zhang F, Liu Z, Qi N, Chen Y. Comparative Analysis of Human Mesenchymal Stem Cells from Umbilical Cord, Dental Pulp, and Menstrual Blood as Sources for Cell Therapy. Stem Cells Int [Internet]. 2016;2016:1-13. Available from: http://www.hindawi.com/journals/sci/2016/3516574/

20. D’Alimonte I, Mastrangelo F, Giuliani P, Pierdomenico L, Marchisio M, Zuccarini M, et al. Osteogenic Differentiation of Mesenchymal Stromal Cells: A Comparative Analysis Between Human Subcutaneous Adipose Tissue and Dental Pulp. Stem Cells Dev [Internet]. 2017;26:843-55. Available from: https://www.liebertpub.com/doi/10.1089/scd.2016.0190

21. Zhang Y, Xing Y, Jia L, Ji Y, Zhao B, Wen Y, et al. An In Vitro Comparative Study of Multisource Derived Human Mesenchymal Stem Cells for Bone Tissue Engineering. Stem Cells Dev [Internet]. 2018 [cited 2019 Jun 11];27:1634-45. Available from: https://www.liebertpub.com/doi/10.1089/scd.2018.0119 
22. Yang X-F, He X, He J, Zhang L-H, Su X-J, Dong Z-Y, et al. High efficient isolation and systematic identification of human adipose-derived mesenchymal stem cells. J Biomed Sci [Internet]. 2011;18:59. Available from: http://www.ncbi.nlm.nih.gov/pubmed/21854621

23. Huang GTJ, Sonoyama W, Chen J, Park SH. In vitro characterization of human dental pulp cells: various isolation methods and culturing environments. Cell Tissue Res [Internet]. 2006;324:225-36. Available from: http://www.ncbi.nlm.nih.gov/pubmed/16440193

24. Gudleviciene Z, Kundrotas G, Liudkeviciene R, Rascon J, Jurga M. Quick and effective method of bone marrow mesenchymal stem cell extraction. Open Med (Warsaw, Poland) [Internet]. 2015;10:44-9. Available from: http://www.ncbi.nlm.nih.gov/pubmed/28352676

25. Alkhalil M, Smajilagić A, Redžić A. Human dental pulp mesenchymal stem cells isolation and osteoblast differentiation. Med Glas. 2015;12:27-32.

26. Dominici M, Le Blanc K, Mueller I, Slaper-Cortenbach I, Marini F., Krause DS, et al. Minimal criteria for defining multipotent mesenchymal stromal cells. The International Society for Cellular Therapy position statement. Cytotherapy [Internet]. 2006 [cited 2019 Jun 11];8:315-7. Available from:

http://www.ncbi.nlm.nih.gov/pubmed/16923606

27. Tornero-Esteban P, Peralta-Sastre A, Herranz E, Rodríguez-Rodríguez L, Mucientes A, Abásolo L, et al. Altered Expression of Wnt Signaling Pathway Components in Osteogenesis of Mesenchymal Stem Cells in Osteoarthritis Patients. PLoS One [Internet]. 2015;10:e0137170. Available from:

http://www.ncbi.nlm.nih.gov/pubmed/26352263

28. Golub EE, Boesze-Battaglia K. The role of alkaline phosphatase in mineralization. Curr Opin Orthop [Internet]. 2007;18:444-8. Available from: https://rupress.org/jem/article/93/5/415/10511/THE-ROLEOF-ALKALINE-PHOSPHATASE-IN-OSTEOGENESIS

29. Wall ME, Rachlin A, Otey CA, Loboa EG. Human adipose-derived adult stem cells upregulate palladin during osteogenesis and in response to cyclic tensile strain. Am J Physiol Cell Physiol [Internet]. 2007 [cited 2019 Jun 11];293:C1532-8. Available from: http://www.physiology.org/doi/10.1152/ajpcell.00065.2007

30. Yu H, Tay CY, Leong WS, Tan SCW, Liao K, Tan LP. Mechanical behavior of human mesenchymal stem cells during adipogenic and osteogenic differentiation. Biochem Biophys Res Commun [Internet]. 2010 [cited 2019 Jun 11];393:150-5. Available from:

https://linkinghub.elsevier.com/retrieve/pii/S0006291X10001701

31. Tan J, Zhou L, Xue P, An Y, Luo L, Zhang R, et al. Tumor Necrosis Factor-a Attenuates the Osteogenic Differentiation Capacity of Periodontal Ligament Stem Cells by Activating PERK Signaling. J Periodontol [Internet]. 2016 [cited 2019 Jun 11];87:e159-71. Available from:

http://doi.wiley.com/10.1902/jop.2016.150718

Page 18/65 
32. Corsetti G, Romano C, Stacchiotti A, Pasini E, Dioguardi FS. Endoplasmic Reticulum Stress and Apoptosis Triggered by Sub-Chronic Lead Exposure in Mice Spleen: a Histopathological Study. Biol Trace Elem Res [Internet]. 2017;178:86-97. Available from: http://link.springer.com/10.1007/s12011-016-0912Z

33. Chen L, Shi K, Frary CE, Ditzel N, Hu H, Qiu W, et al. Inhibiting actin depolymerization enhances osteoblast differentiation and bone formation in human stromal stem cells. Stem Cell Res [Internet]. 2015 [cited 2019 Jun 11];15:281-9. Available from:

https://linkinghub.elsevier.com/retrieve/pii/S1873506115000823

34. Eguchi K, Akiba Y, Akiba N, Nagasawa M, Cooper LF, Uoshima K. Insulin-like growth factor binding Protein-3 suppresses osteoblast differentiation via bone morphogenetic protein-2. Biochem Biophys Res Commun [Internet]. 2018 [cited 2019 Jun 11];507:465-70. Available from: https://linkinghub.elsevier.com/retrieve/pii/S0006291X18324793

35. Chacko SM, Ahmed S, Selvendiran K, Kuppusamy ML, Khan M, Kuppusamy P. Hypoxic preconditioning induces the expression of prosurvival and proangiogenic markers in mesenchymal stem cells. Am J Physiol Physiol [Internet]. 2010;299:C1562-70. Available from: https://www.physiology.org/doi/10.1152/ajpcell.00221.2010

36. Tsutsui T. Dental Pulp Stem Cells: Advances to Applications. Stem Cells Cloning Adv Appl [Internet]. 2020;Volume 13:33-42. Available from: https://www.dovepress.com/dental-pulp-stem-cells-advances-toapplications-peer-reviewed-article-SCCAA

37. Björklund M. Cell size homeostasis: Metabolic control of growth and cell division. Biochim Biophys Acta - Mol Cell Res [Internet]. 2019;1866:409-17. Available from:

https://linkinghub.elsevier.com/retrieve/pii/S0167488918302544

38. Lloyd AC. The Regulation of Cell Size. Cell [Internet]. 2013;154:1194-205. Available from: https://linkinghub.elsevier.com/retrieve/pii/S0092867413010842

39. Yu J, He H, Tang C, Zhang G, Li Y, Wang R, et al. Differentiation potential of STRO-1 + dental pulp stem cells changes during cell passaging. BMC Cell Biol [Internet]. 2010;11:32. Available from: http://www.ncbi.nlm.nih.gov/pubmed/20459680

40. Kozakiewicz M, Wach T. New Oral Surgery Materials for Bone Reconstruction-A Comparison of Five Bone Substitute Materials for Dentoalveolar Augmentation. Materials (Basel) [Internet]. 2020;13:2935. Available from: https://www.mdpi.com/1996-1944/13/13/2935

41. Wang X, Song W, Kawazoe N, Chen G. The osteogenic differentiation of mesenchymal stem cells by controlled cell-cell interaction on micropatterned surfaces. J Biomed Mater Res Part A [Internet]. 2013;101:3388-95. Available from: http://doi.wiley.com/10.1002/jbm.a.34645 
42. Wongsupa N, Nuntanaranont T, Kamolmattayakul S, Thuaksuban N. Biological characteristic effects of human dental pulp stem cells on poly-e-caprolactone-biphasic calcium phosphate fabricated scaffolds using modified melt stretching and multilayer deposition. J Mater Sci Mater Med [Internet]. 2017;28:25. Available from: http://link.springer.com/10.1007/s10856-016-5833-z

43. Sabbagh J, Ghassibe-Sabbagh M, Fayyad-Kazan M, Al-Nemer F, Fahed JC, Berberi A, et al. Differences in osteogenic and odontogenic differentiation potential of DPSCs and SHED. J Dent. 2020;101:103413.

44. Thorpe AA, Creasey S, Sammon C, Le Maitre CL. Hydroxyapatite nanoparticle injectable hydrogel scaffold to support osteogenic differentiation of human mesenchymal stem cells. Eur Cell Mater [Internet]. 2016;32:1-23. Available from: http://www.ncbi.nlm.nih.gov/pubmed/27377664

45. Tsukanaka M, Fujibayashi S, Otsuki B, Takemoto M, Matsuda S. Osteoinductive potential of highly purified porous $\beta$-TCP in mice. J Mater Sci Mater Med [Internet]. 2015;26:132. Available from: http://www.ncbi.nlm.nih.gov/pubmed/25698341

46. Ferrarotti F, Romano F, Gamba MN, Quirico A, Giraudi M, Audagna M, et al. Human intrabony defect regeneration with micrografts containing dental pulp stem cells: A randomized controlled clinical trial. J Clin Periodontol [Internet]. 2018;45:841-50. Available from:

http://www.ncbi.nlm.nih.gov/pubmed/29779220

47. Fischer NG, Münchow EA, Tamerler C, Bottino MC, Aparicio C. Harnessing biomolecules for bioinspired dental biomaterials. J Mater Chem B. 2020;8:8713-47.

48. Deb S, Chana S. Biomaterials in Relation to Dentistry. Front Oral Biol [Internet]. 2015;17:1-12. Available from: https://www.karger.com/Article/FullText/381686

\section{Figures}




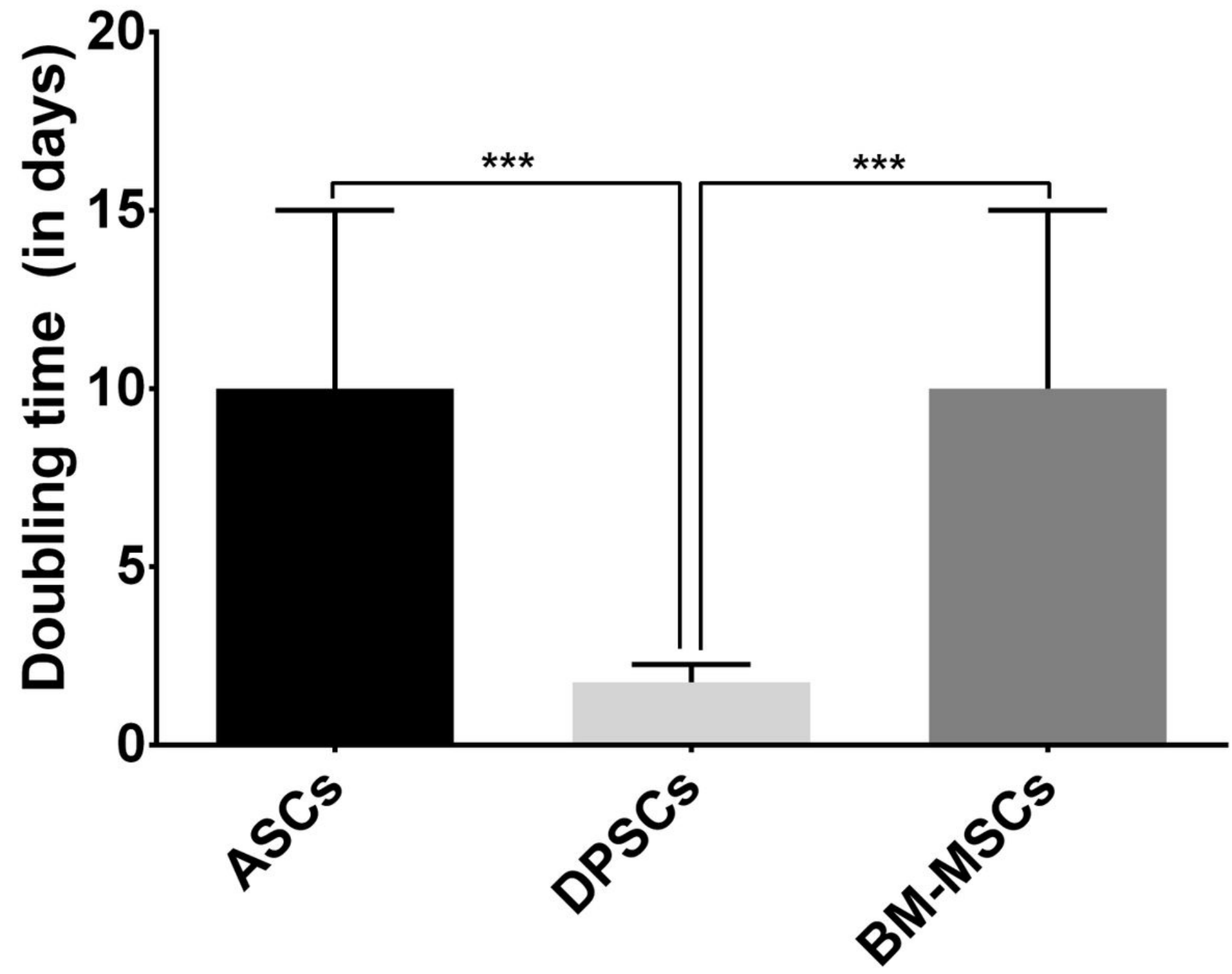

Figure 1

MSCs proliferation. Doubling time (in days) when cultured in plastic presented by MSC isolated from adipose tissue (ASCs), dental pulp (DPSCs) and bone marrow (BM-MSCs). 


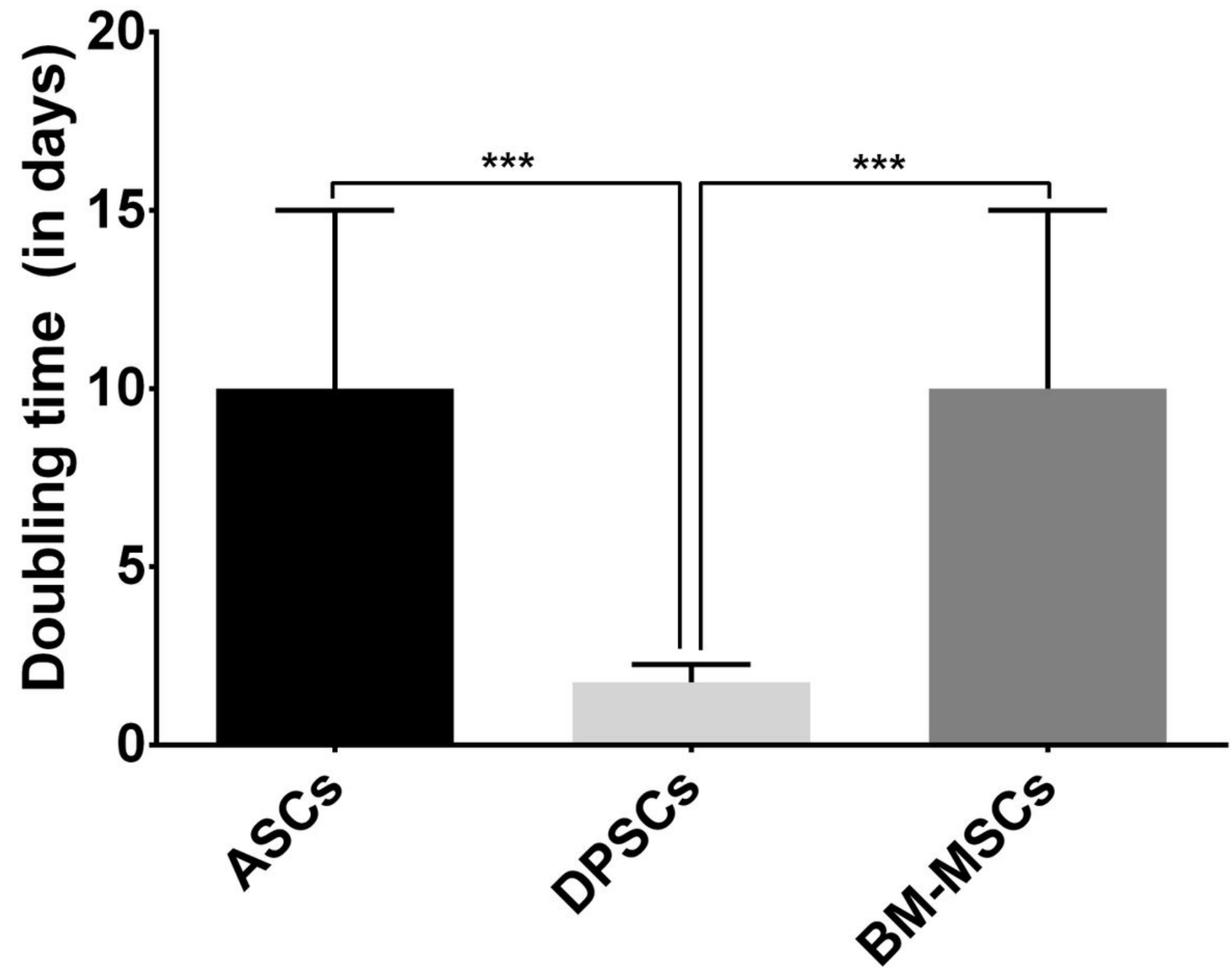

Figure 1

MSCs proliferation. Doubling time (in days) when cultured in plastic presented by MSC isolated from adipose tissue (ASCs), dental pulp (DPSCs) and bone marrow (BM-MSCs). 


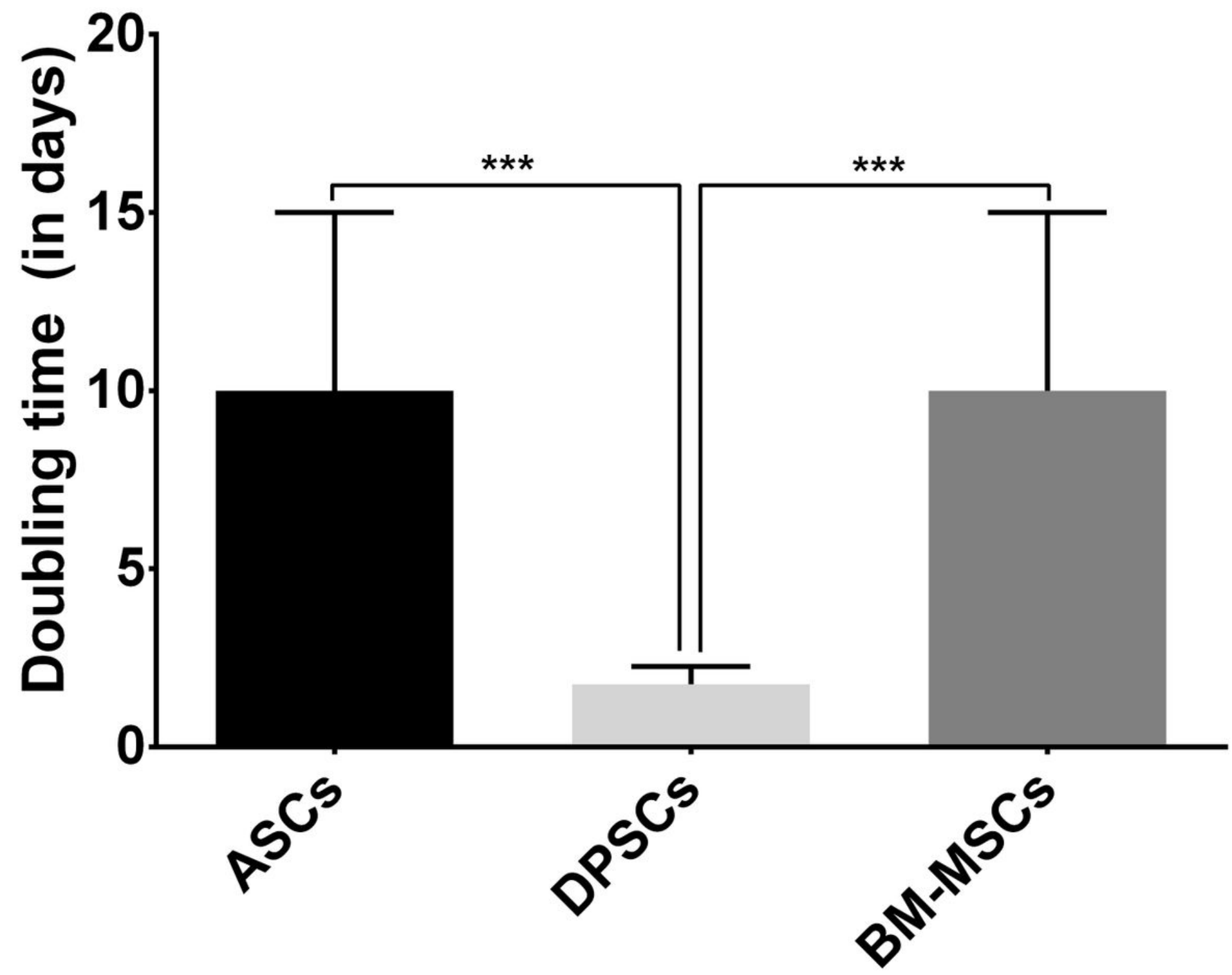

Figure 1

MSCs proliferation. Doubling time (in days) when cultured in plastic presented by MSC isolated from adipose tissue (ASCs), dental pulp (DPSCs) and bone marrow (BM-MSCs). 


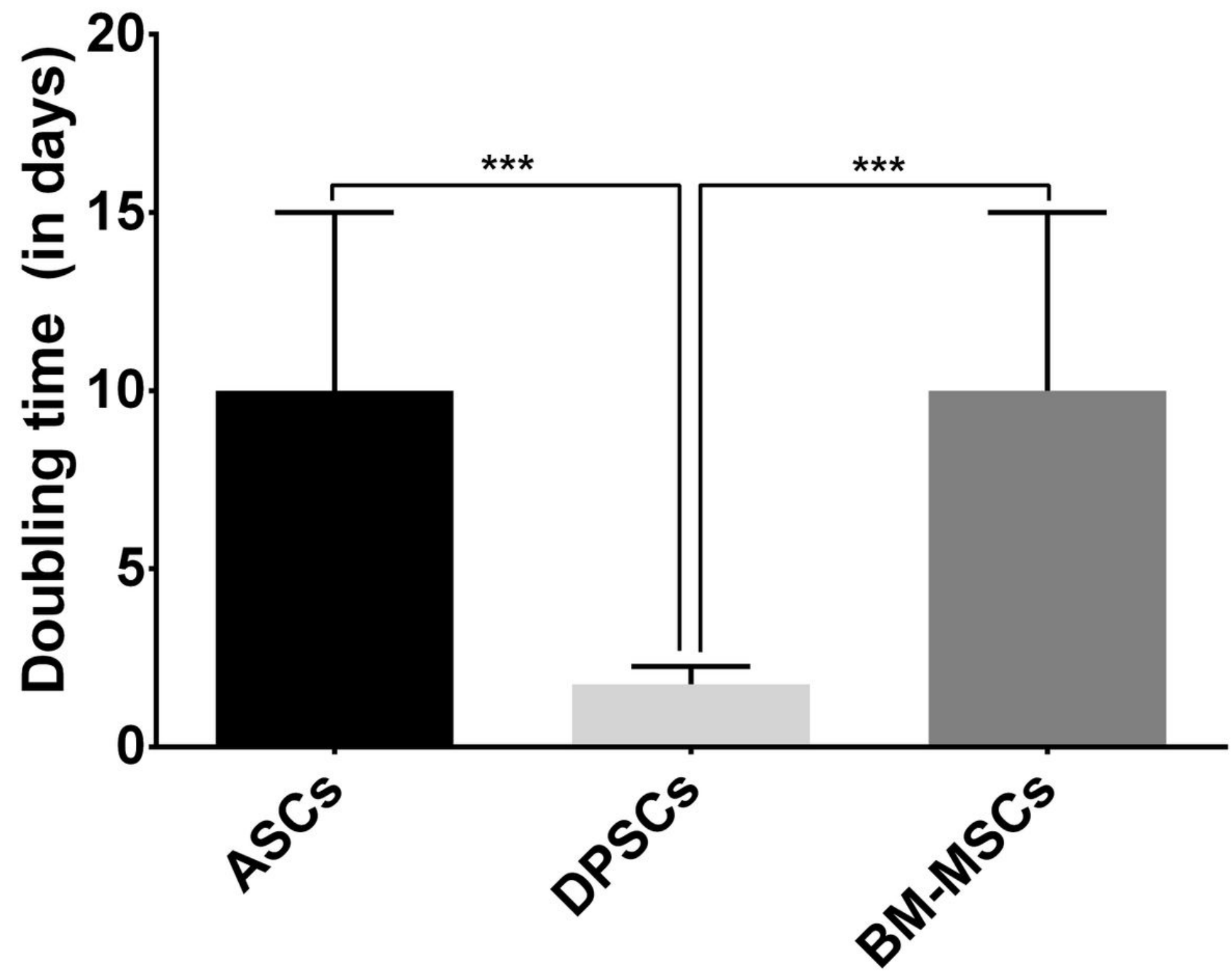

Figure 1

MSCs proliferation. Doubling time (in days) when cultured in plastic presented by MSC isolated from adipose tissue (ASCs), dental pulp (DPSCs) and bone marrow (BM-MSCs). 


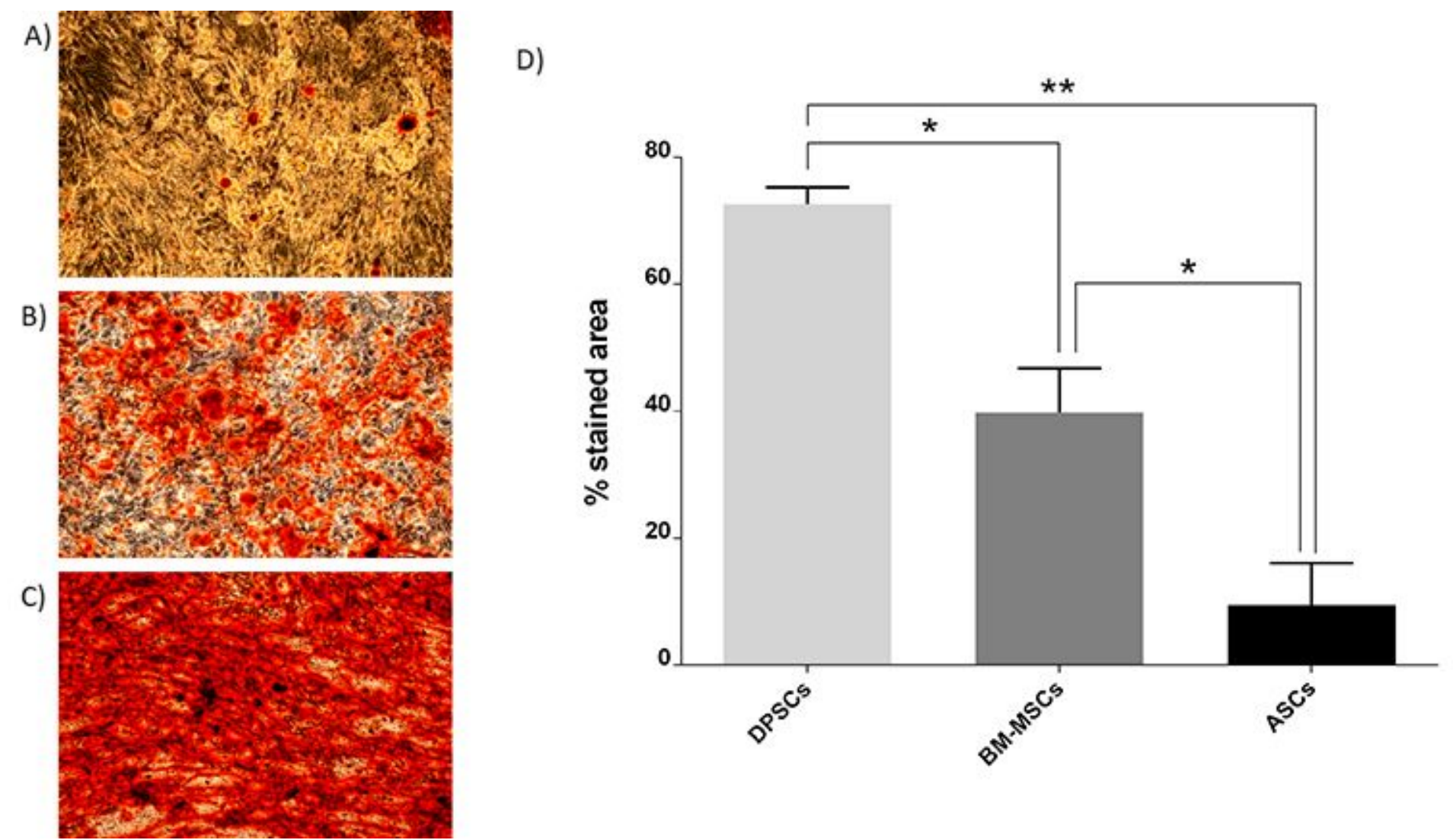

\section{Figure 2}

Alizarin Red staining and its quantification of different source-derived mesAlizarin Red staining and its quantification of different source-derived mesenchymal stem cells. A) Alizarin Red staining of ASCs after 21 days of culture in osteogenic medium (x10). B) Alizarin Red staining of BM-MSCs after 21 days of culture in osteogenic medium (x10). C) Alizarin Red staining of DPSCs after 21 days of culture in osteogenic medium (x10). D) Alizarin Red staining quantification of MSC according to the cell source: adipose tissue (ASCs), dental pulp (DPSCs) and bone marrow (BM-MSCs).enchymal stem cells. A) Alizarin Red staining of ASCs after 21 days of culture in osteogenic medium (x10). B) Alizarin Red staining of BM-MSCs after 21 days of culture in osteogenic medium (x10). C) Alizarin Red staining of DPSCs after 21 days of culture in osteogenic medium (x10). D) Alizarin Red staining quantification of MSC according to the cell source: adipose tissue (ASCs), dental pulp (DPSCs) and bone marrow (BMMSCs). 


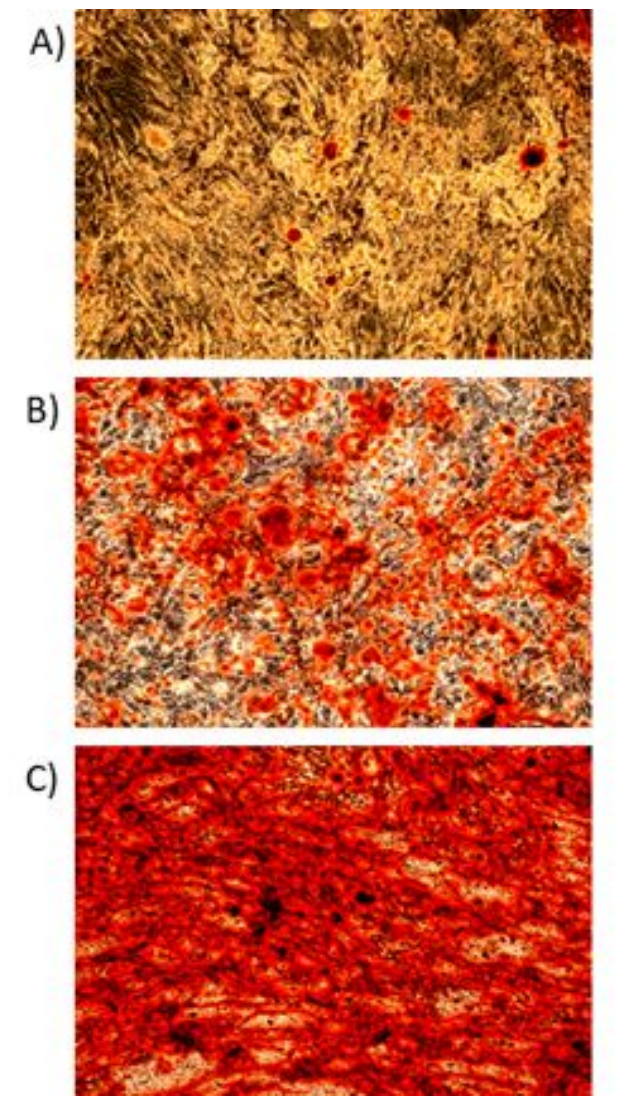

D)

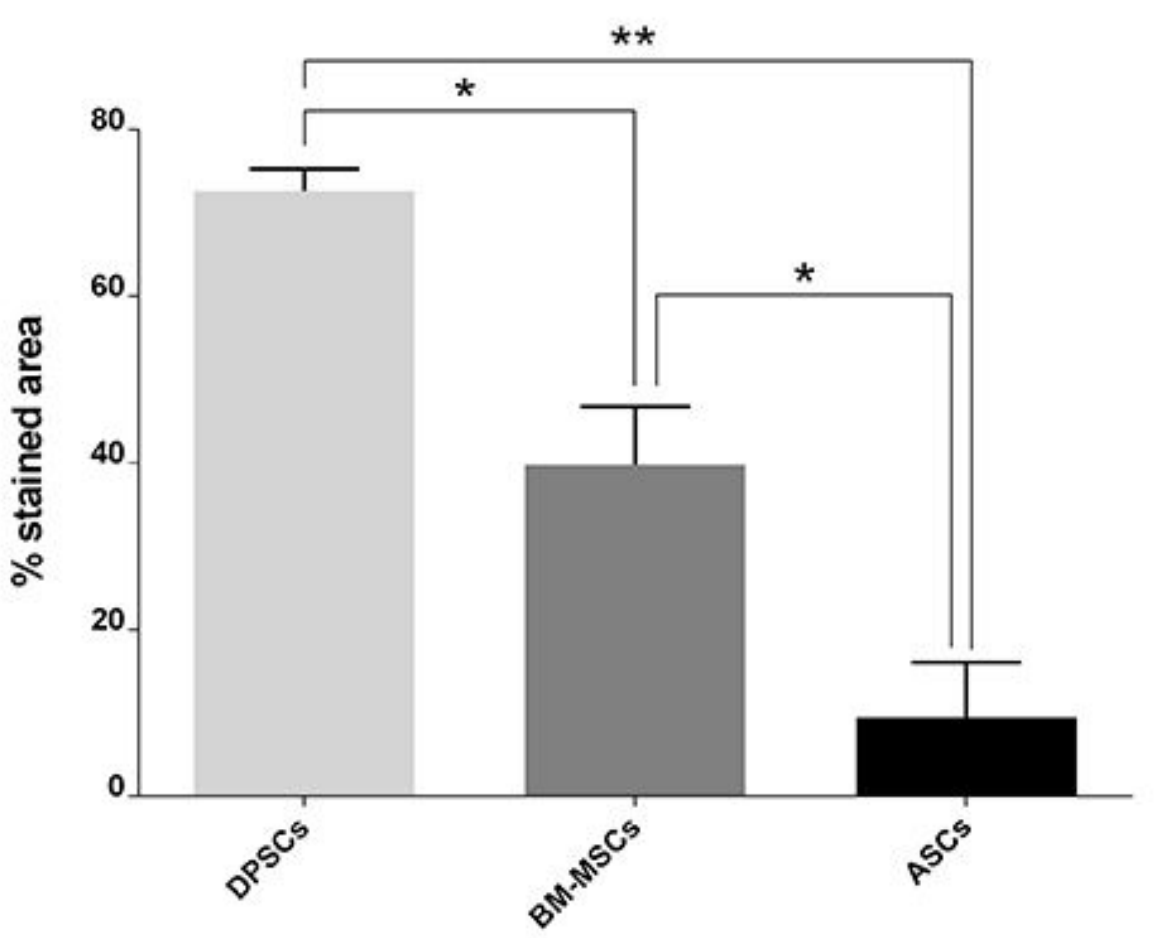

Figure 2

Alizarin Red staining and its quantification of different source-derived mesAlizarin Red staining and its quantification of different source-derived mesenchymal stem cells. A) Alizarin Red staining of ASCs after 21 days of culture in osteogenic medium (x10). B) Alizarin Red staining of BM-MSCs after 21 days of culture in osteogenic medium (x10). C) Alizarin Red staining of DPSCs after 21 days of culture in osteogenic medium (x10). D) Alizarin Red staining quantification of MSC according to the cell source: adipose tissue (ASCs), dental pulp (DPSCs) and bone marrow (BM-MSCs).enchymal stem cells. A) Alizarin Red staining of ASCs after 21 days of culture in osteogenic medium (x10). B) Alizarin Red staining of BM-MSCs after 21 days of culture in osteogenic medium (x10). C) Alizarin Red staining of DPSCs after 21 days of culture in osteogenic medium (x10). D) Alizarin Red staining quantification of MSC according to the cell source: adipose tissue (ASCs), dental pulp (DPSCs) and bone marrow (BMMSCs). 


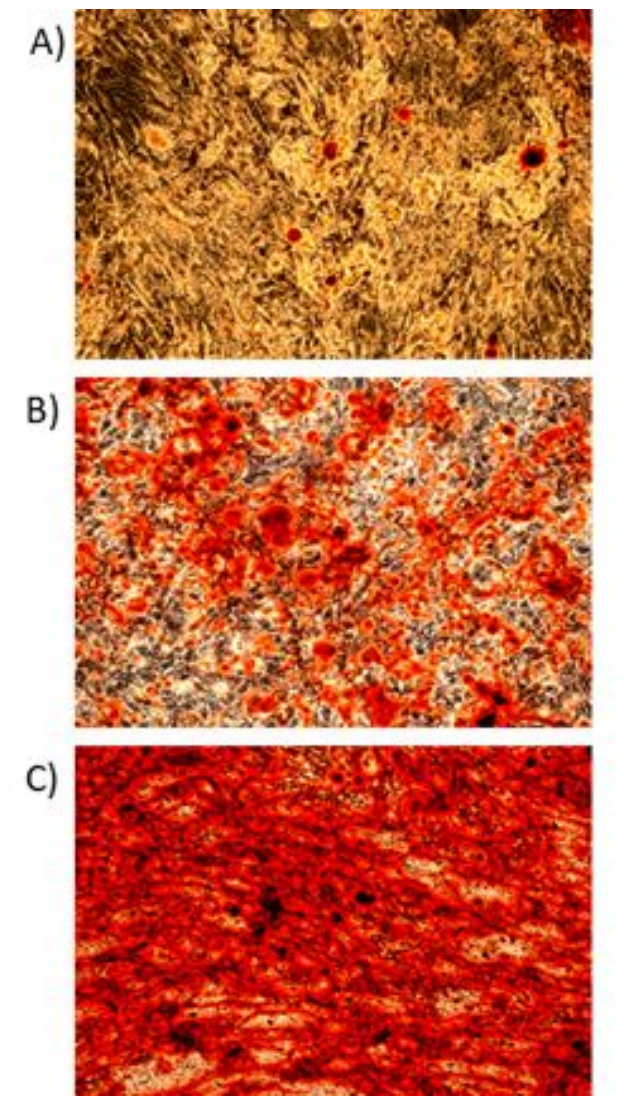

D)

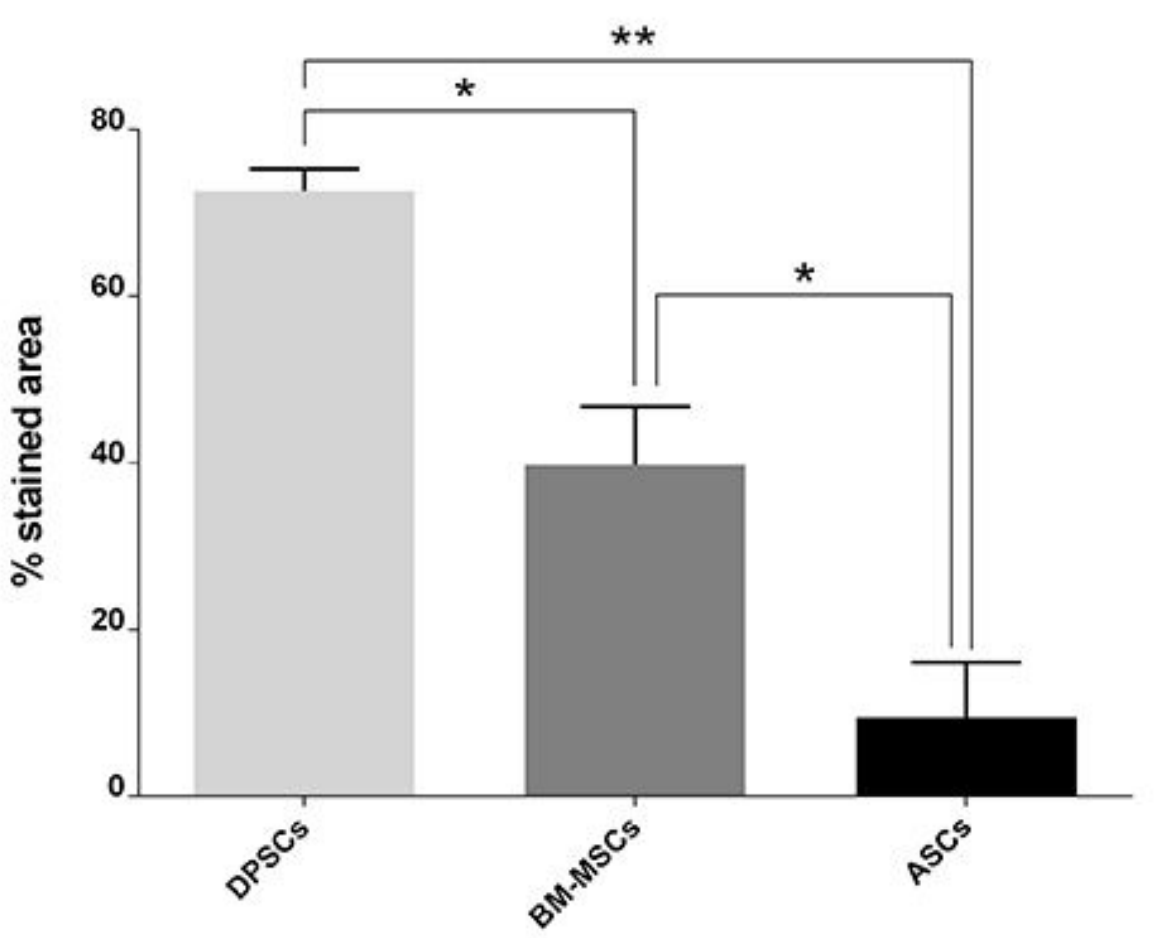

Figure 2

Alizarin Red staining and its quantification of different source-derived mesAlizarin Red staining and its quantification of different source-derived mesenchymal stem cells. A) Alizarin Red staining of ASCs after 21 days of culture in osteogenic medium (x10). B) Alizarin Red staining of BM-MSCs after 21 days of culture in osteogenic medium (x10). C) Alizarin Red staining of DPSCs after 21 days of culture in osteogenic medium (x10). D) Alizarin Red staining quantification of MSC according to the cell source: adipose tissue (ASCs), dental pulp (DPSCs) and bone marrow (BM-MSCs).enchymal stem cells. A) Alizarin Red staining of ASCs after 21 days of culture in osteogenic medium (x10). B) Alizarin Red staining of BM-MSCs after 21 days of culture in osteogenic medium (x10). C) Alizarin Red staining of DPSCs after 21 days of culture in osteogenic medium (x10). D) Alizarin Red staining quantification of MSC according to the cell source: adipose tissue (ASCs), dental pulp (DPSCs) and bone marrow (BMMSCs). 


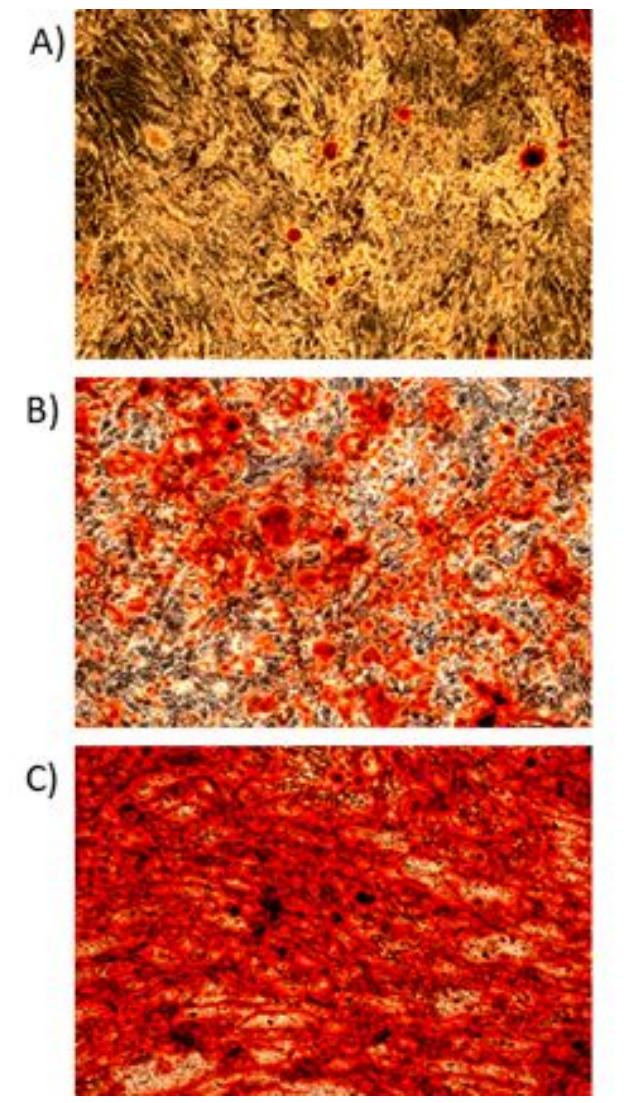

D)

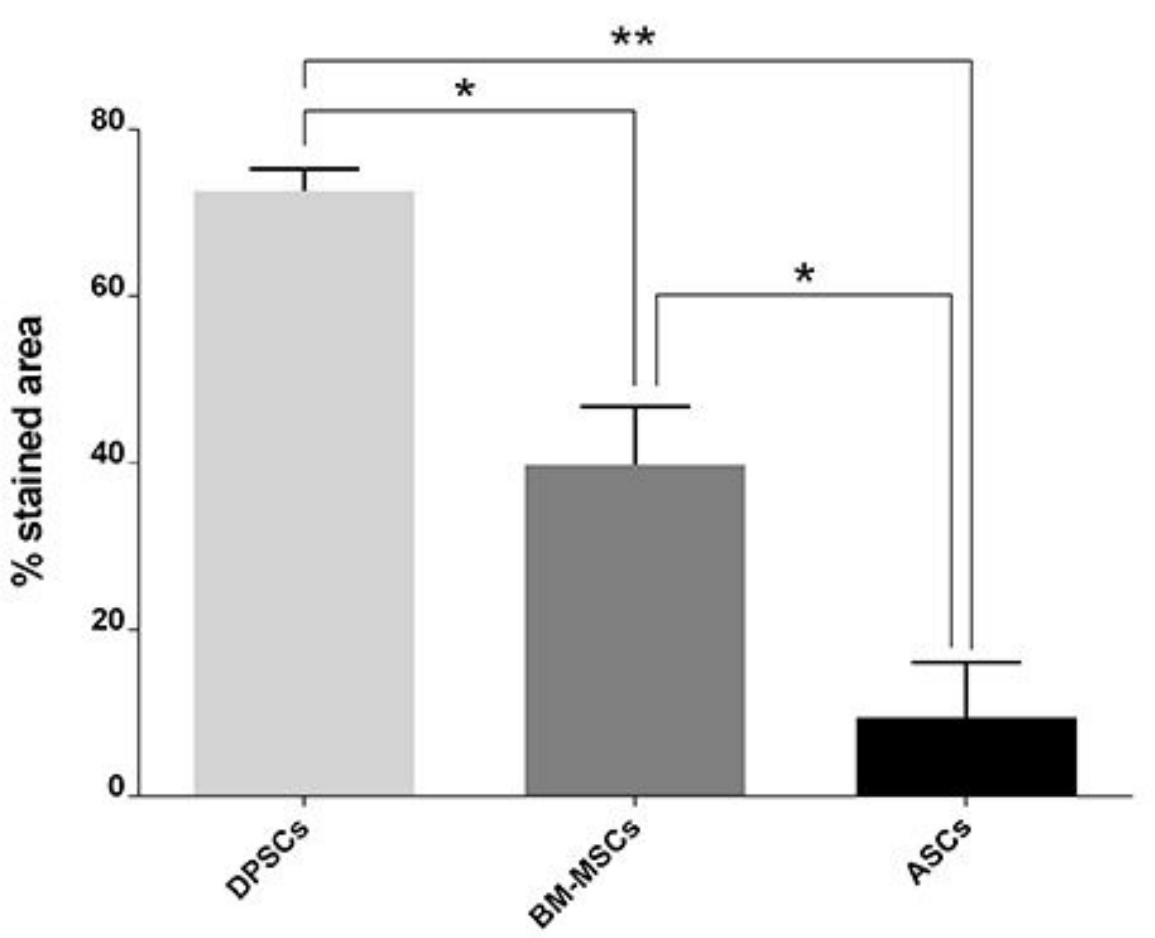

Figure 2

Alizarin Red staining and its quantification of different source-derived mesAlizarin Red staining and its quantification of different source-derived mesenchymal stem cells. A) Alizarin Red staining of ASCs after 21 days of culture in osteogenic medium (x10). B) Alizarin Red staining of BM-MSCs after 21 days of culture in osteogenic medium (x10). C) Alizarin Red staining of DPSCs after 21 days of culture in osteogenic medium (x10). D) Alizarin Red staining quantification of MSC according to the cell source: adipose tissue (ASCs), dental pulp (DPSCs) and bone marrow (BM-MSCs).enchymal stem cells. A) Alizarin Red staining of ASCs after 21 days of culture in osteogenic medium (x10). B) Alizarin Red staining of BM-MSCs after 21 days of culture in osteogenic medium (x10). C) Alizarin Red staining of DPSCs after 21 days of culture in osteogenic medium (x10). D) Alizarin Red staining quantification of MSC according to the cell source: adipose tissue (ASCs), dental pulp (DPSCs) and bone marrow (BMMSCs). 


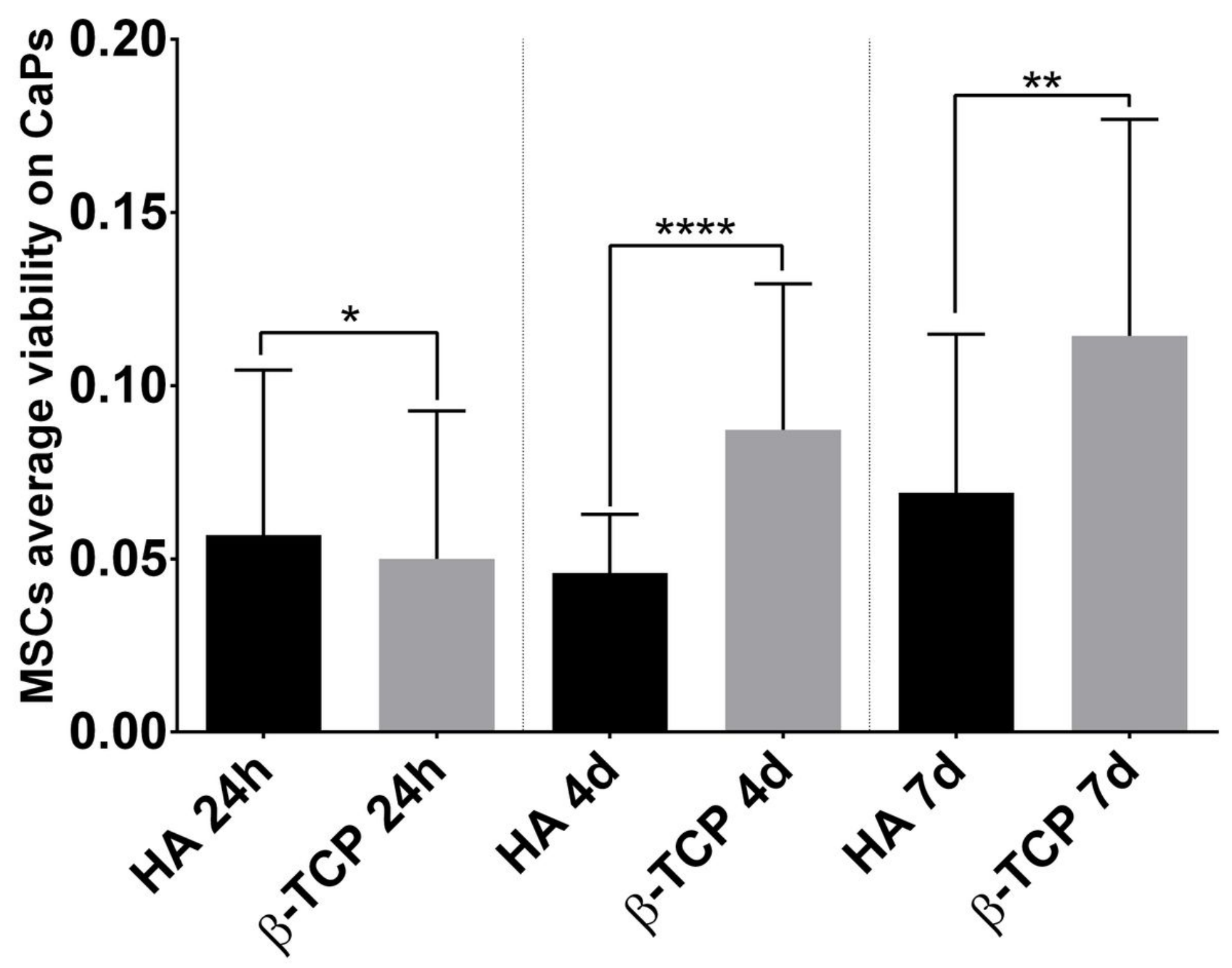

Figure 3

Average viability showed by all MSCs on each CaP. Hydroxyapatite (HA) and $ß$-tricalcium phosphate ( $\beta$ TCP). All data are shown as mean \pm standard deviation. Significance level: ${ }^{*} \leq 0.05 * \star \leq 0.01 * \star \star \leq 0.001$ $\star \star \star \star ~ \leq 0.0001$. 


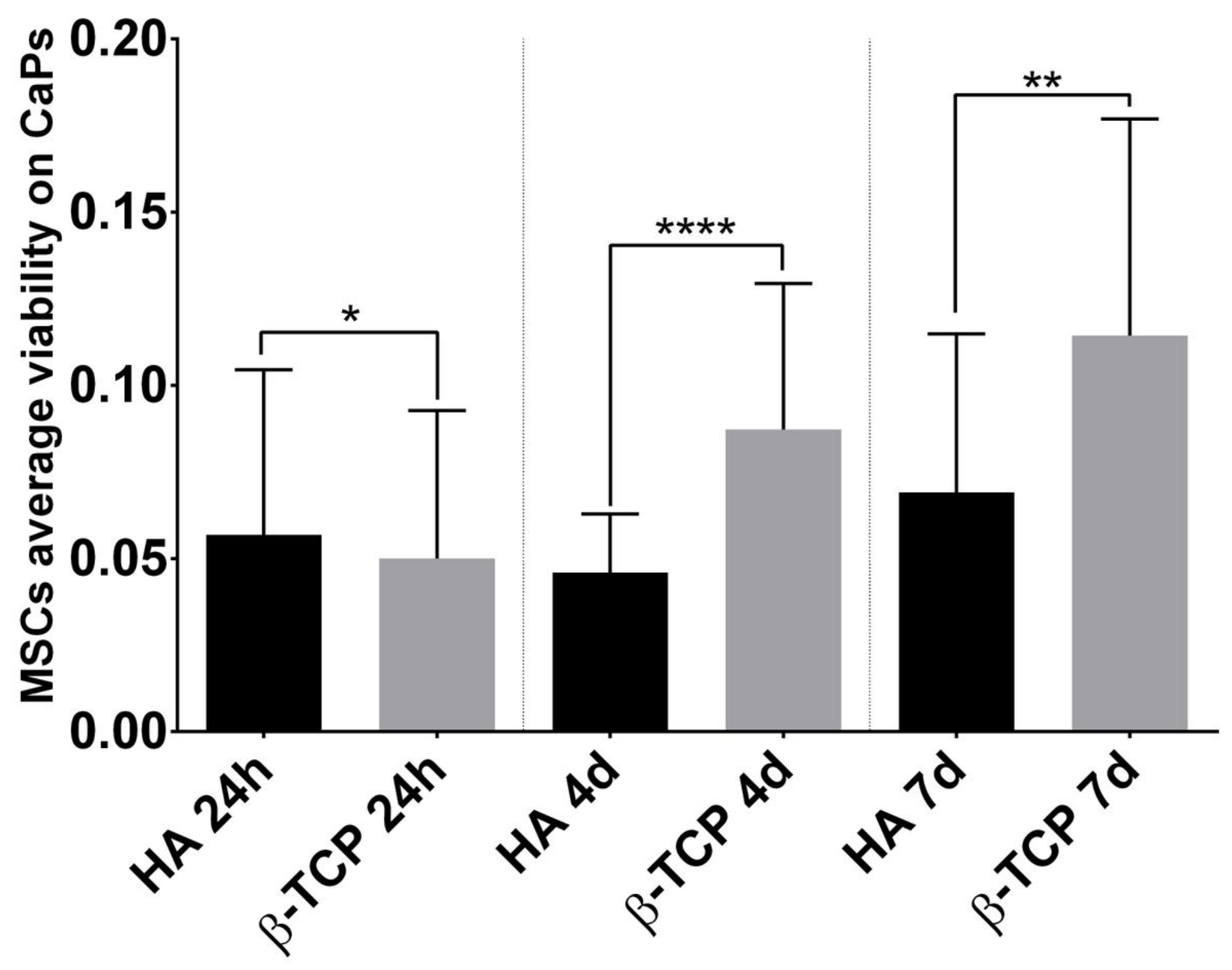

Figure 3

Average viability showed by all MSCs on each CaP. Hydroxyapatite (HA) and $ß$-tricalcium phosphate ( $\beta$ TCP). All data are shown as mean \pm standard deviation. Significance level: ${ }^{*} \leq 0.05 * \star \leq 0.01 * \star \star \leq 0.001$ $\star \star \star \star ~ \leq 0.0001$. 


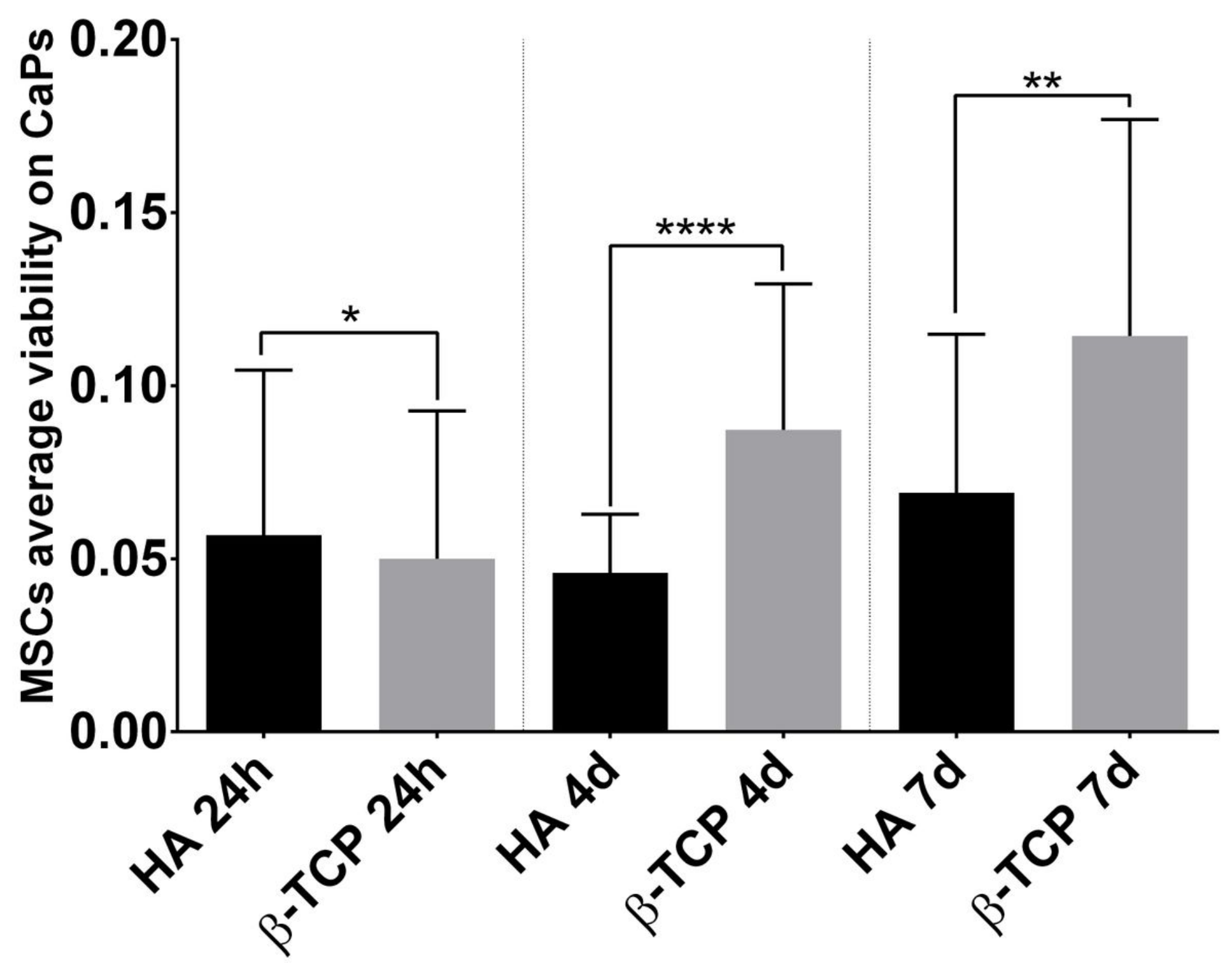

Figure 3

Average viability showed by all MSCs on each CaP. Hydroxyapatite (HA) and $ß$-tricalcium phosphate ( $\beta$ TCP). All data are shown as mean \pm standard deviation. Significance level: ${ }^{*} \leq 0.05 * \star \leq 0.01 * \star \star \leq 0.001$ $\star \star \star \star ~ \leq 0.0001$. 


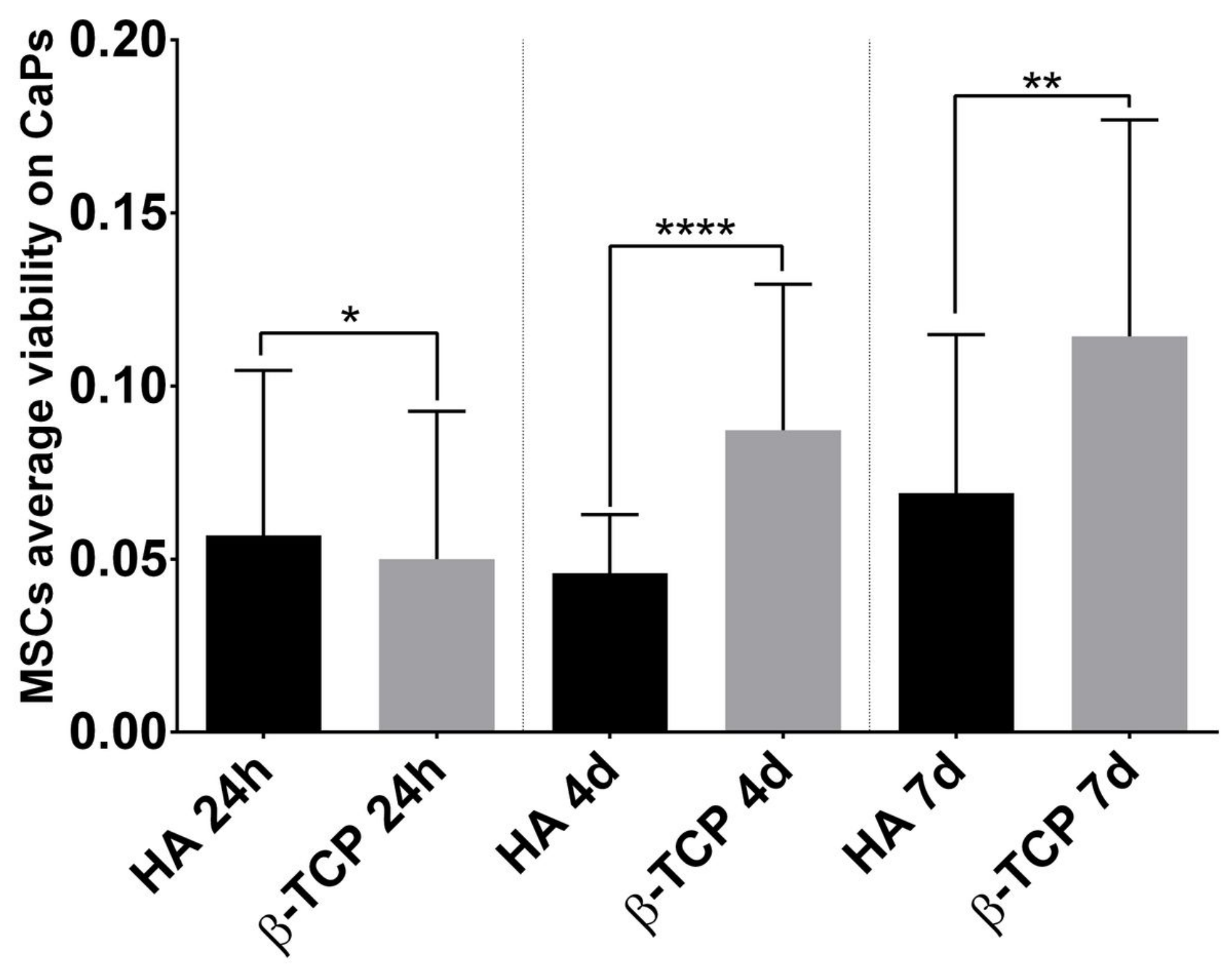

Figure 3

Average viability showed by all MSCs on each CaP. Hydroxyapatite (HA) and ß-tricalcium phosphate ( $\beta$ TCP). All data are shown as mean \pm standard deviation. Significance level: * $\leq 0.05^{\star \star} \leq 0.01 * \star \star \leq 0.001$ $\star \star \star \star \leq 0.0001$. 


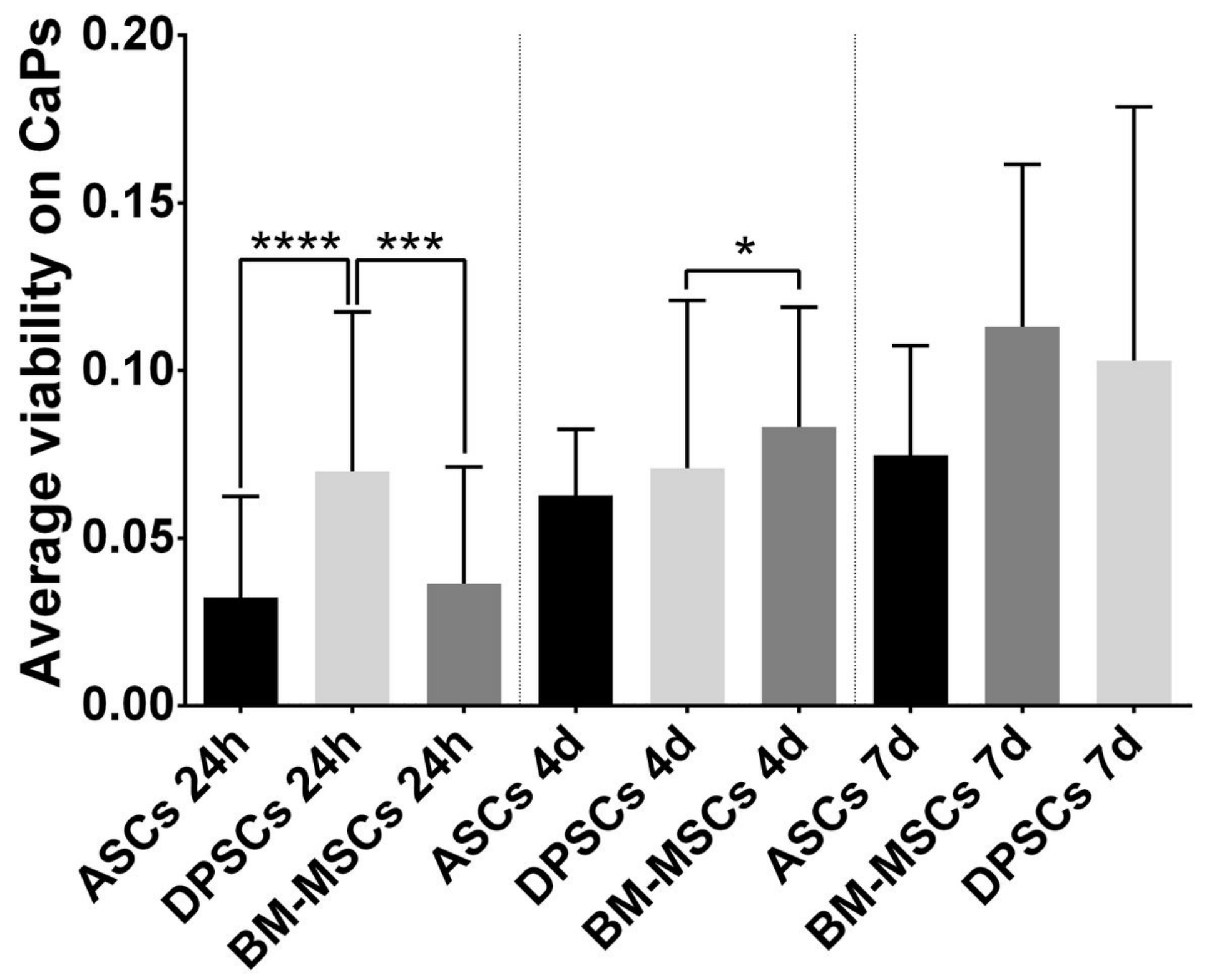

Figure 4

Average viability showed by each MSC on both CaPs. Adipose tissue (ASCs), dental pulp (DPSCs) and bone marrow (BM-MSCs). All data are shown as mean \pm standard deviation. Significance level: * $\leq 0.05$ $\star * \leq 0.01^{* * *} \leq 0.001^{* * * *} \leq 0.0001$. 


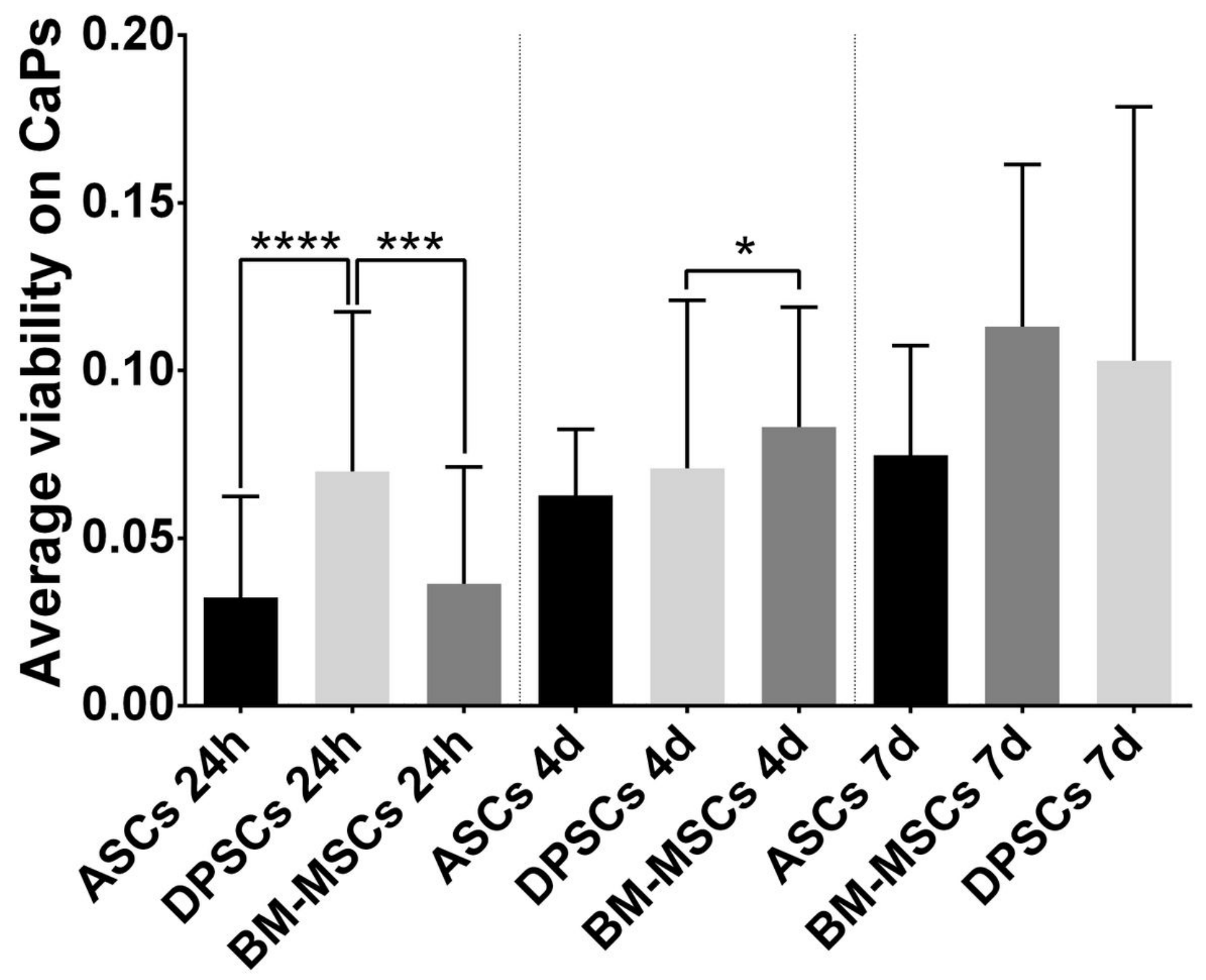

Figure 4

Average viability showed by each MSC on both CaPs. Adipose tissue (ASCs), dental pulp (DPSCs) and bone marrow (BM-MSCs). All data are shown as mean \pm standard deviation. Significance level: * $\leq 0.05$ $\star * \leq 0.01^{* * *} \leq 0.001^{* * * *} \leq 0.0001$. 


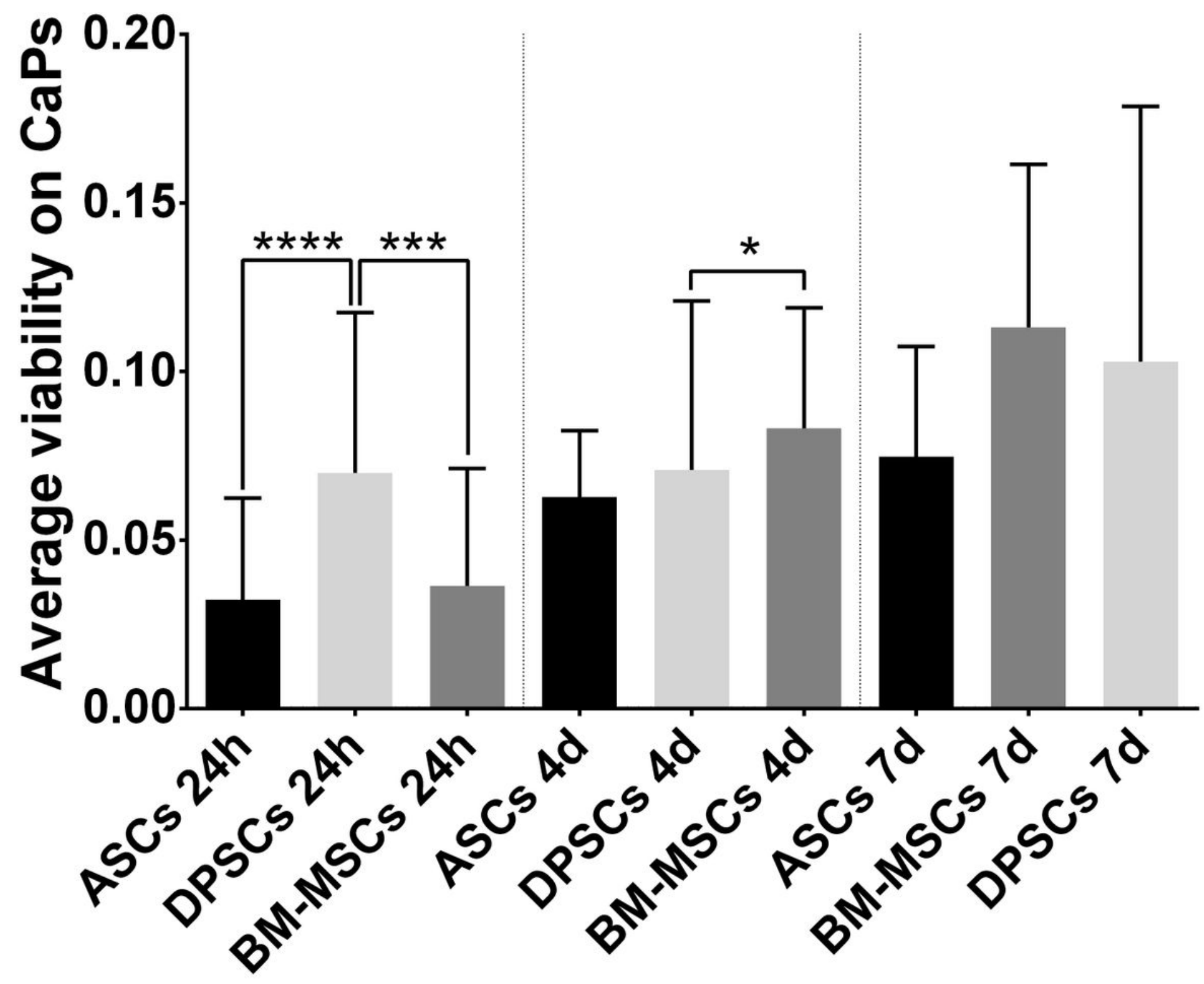

Figure 4

Average viability showed by each MSC on both CaPs. Adipose tissue (ASCs), dental pulp (DPSCs) and bone marrow (BM-MSCs). All data are shown as mean \pm standard deviation. Significance level: * $\leq 0.05$ $\star * \leq 0.01^{* * *} \leq 0.001^{* * * *} \leq 0.0001$. 


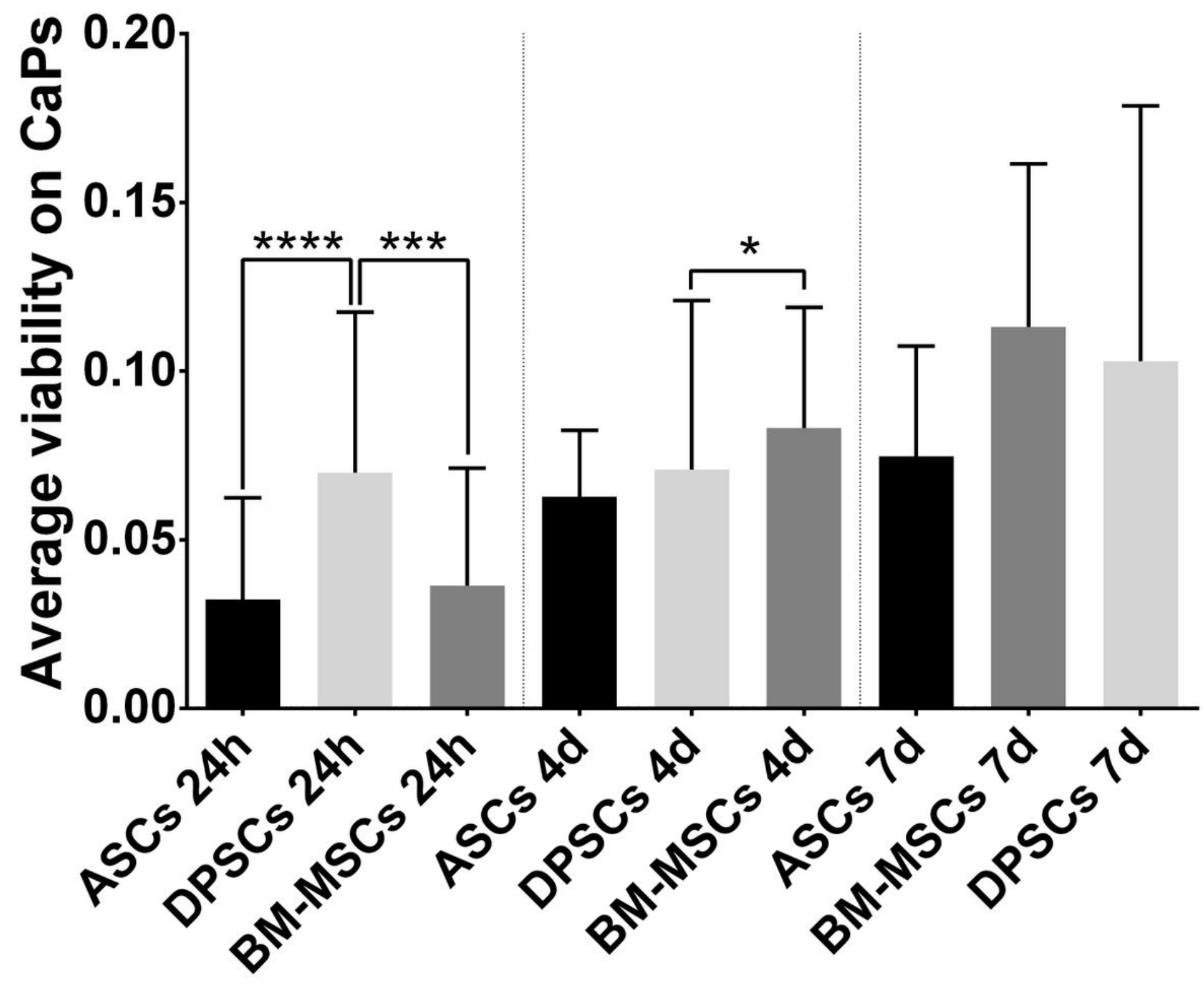

Figure 4

Average viability showed by each MSC on both CaPs. Adipose tissue (ASCs), dental pulp (DPSCs) and bone marrow (BM-MSCs). All data are shown as mean \pm standard deviation. Significance level: * $\leq 0.05$ $\star * \leq 0.01^{* * *} \leq 0.001^{* * * *} \leq 0.0001$. 


\section{4 hours}
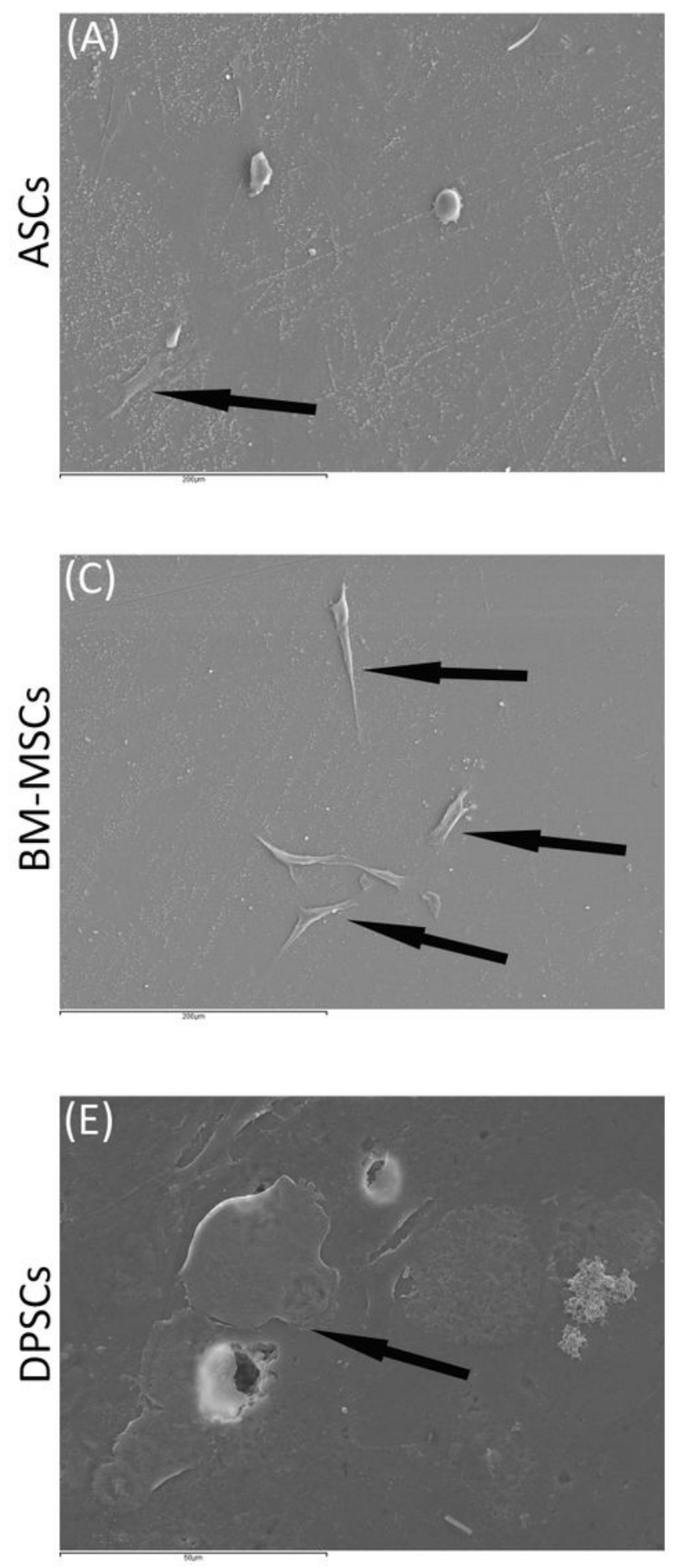

\section{7 days}
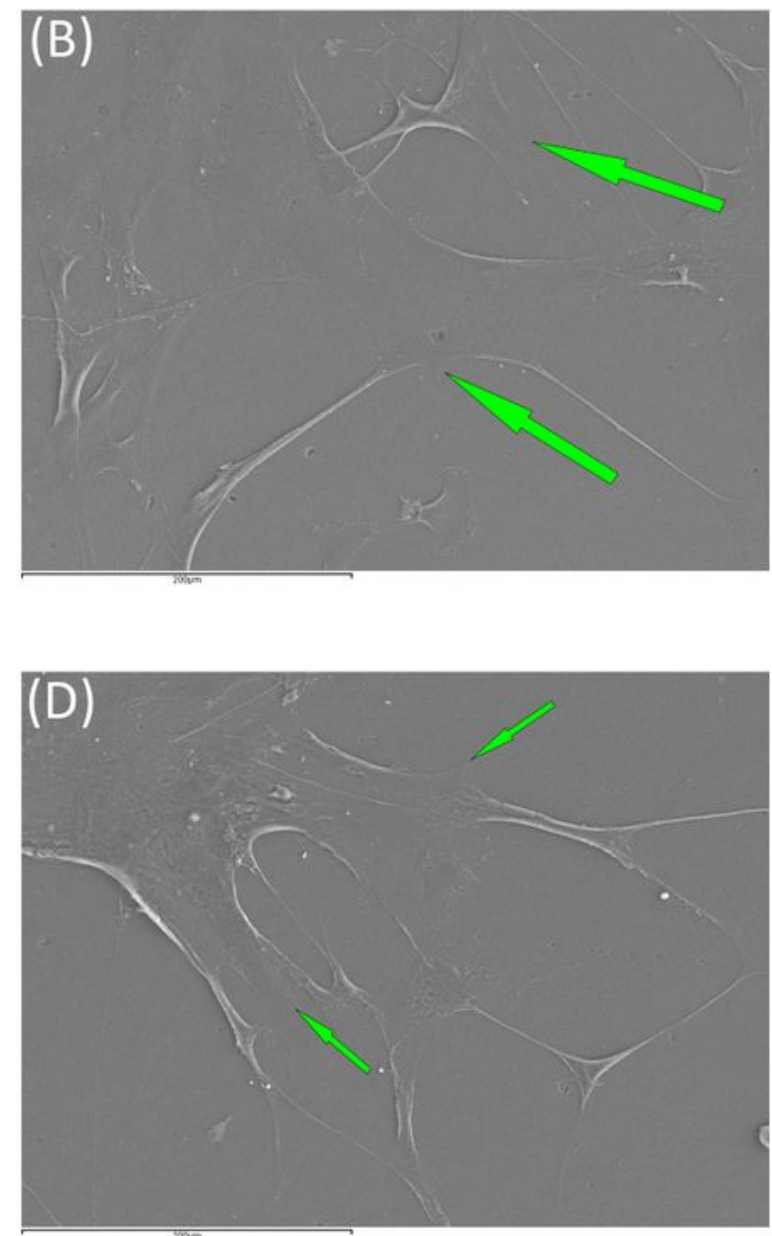

( $\mathrm{F})$

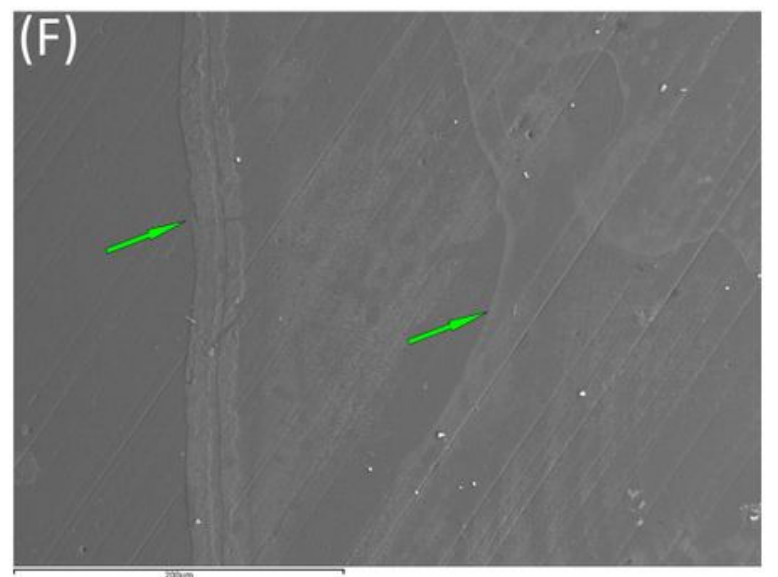

\section{Figure 5}

Behaviour of MSC seeded on B-TCP scaffold at different time points. A) ASCs on B-TCP scaffold after 24

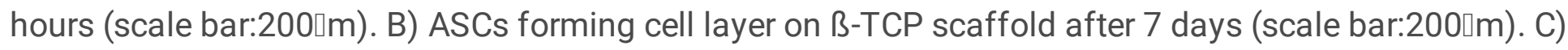
BM-MSCs on B-TCP scaffold after 24 hours (scale bar:200』m). D) BM-MSCs forming cell layer on B-TCP scaffold after 7 days scale bar:200』m). E) DPSCs on B-TCP scaffold at 24 hours (scale bar:50ロm). F) 
DPSCs forming cell layer on ß-TCP scaffold after 7 days (scale bar:200』m). Black arrows point to unique cells. Green arrows point to cell layers.

\section{4 hours}
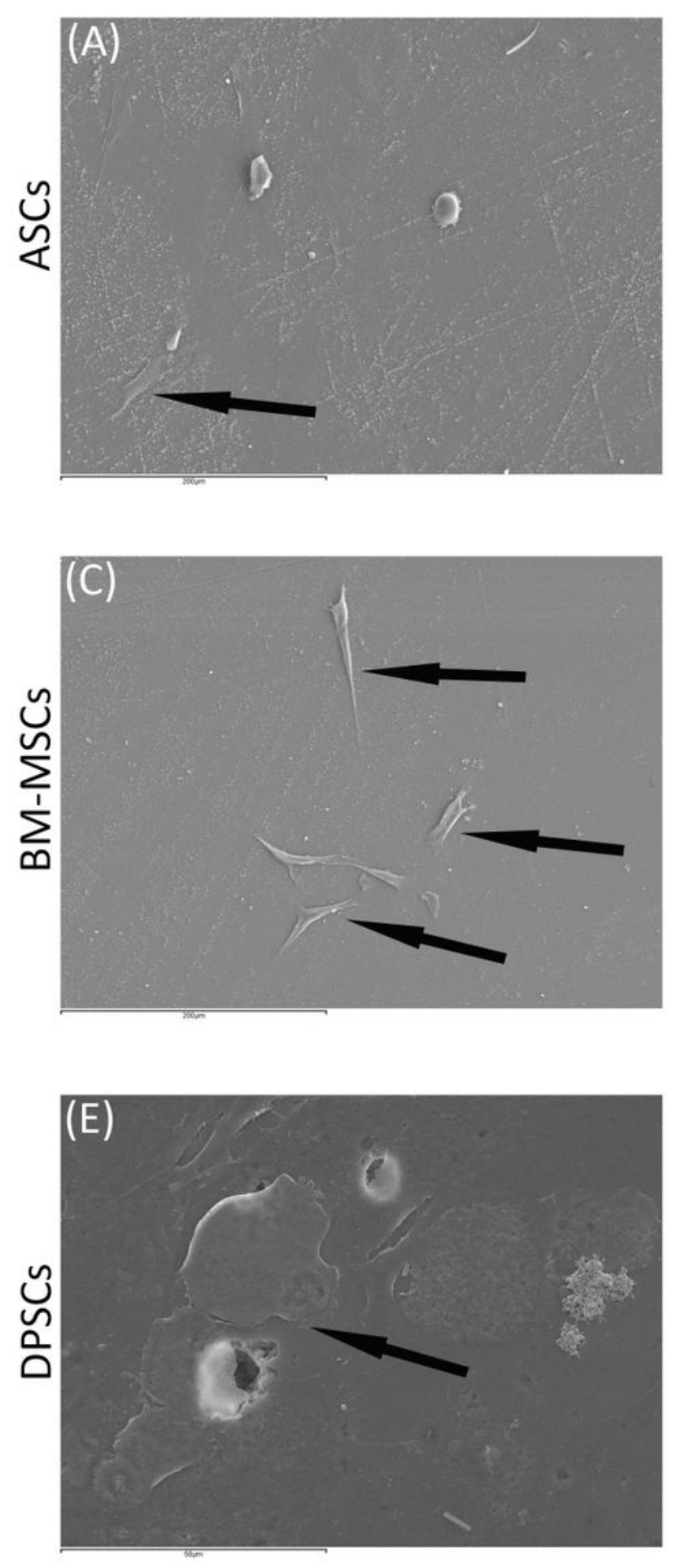

\section{7 days}
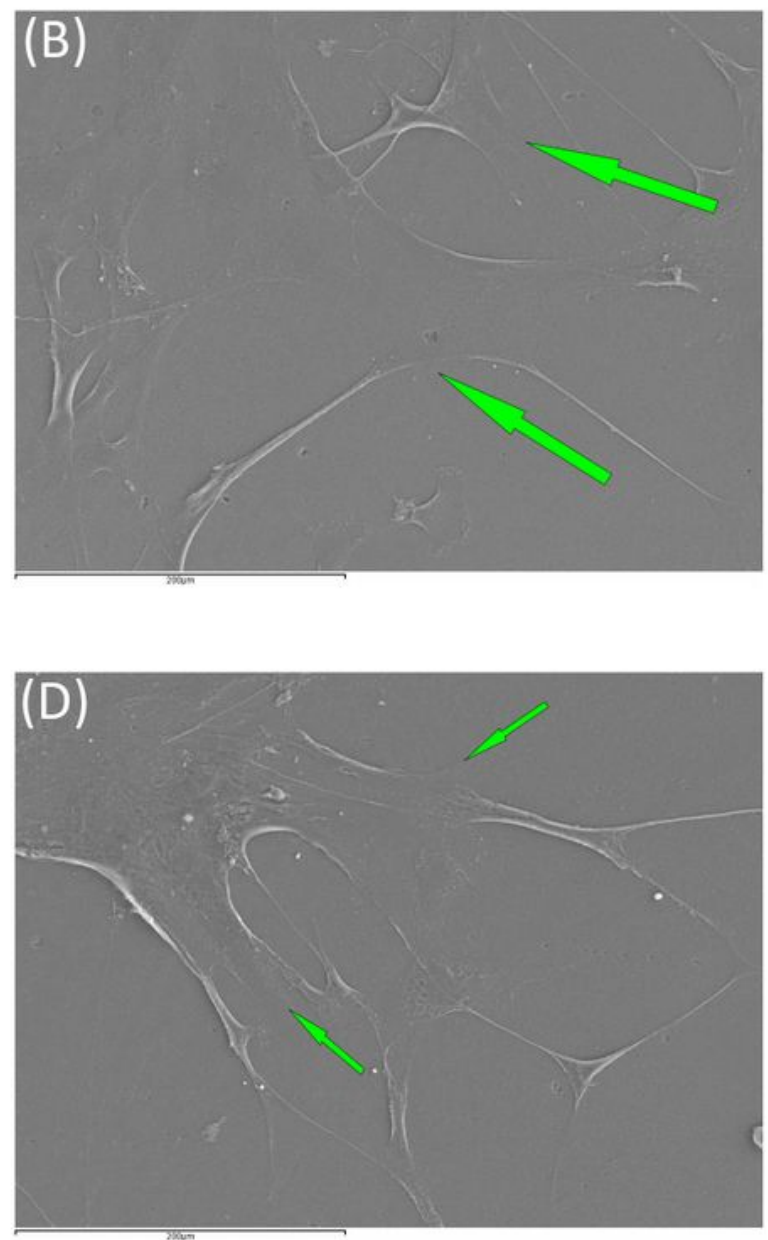

(F)

\section{Figure 5}

Behaviour of MSC seeded on B-TCP scaffold at different time points. A) ASCs on B-TCP scaffold after 24

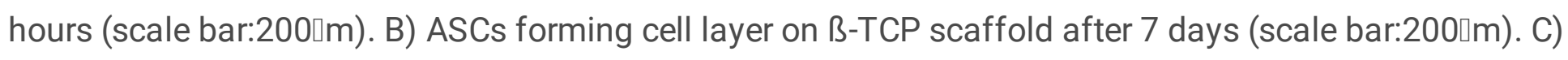
BM-MSCs on B-TCP scaffold after 24 hours (scale bar:200』m). D) BM-MSCs forming cell layer on ß-TCP 
scaffold after 7 days scale bar:200』m). E) DPSCs on B-TCP scaffold at 24 hours (scale bar:50』m). F) DPSCs forming cell layer on ß-TCP scaffold after 7 days (scale bar:200』m). Black arrows point to unique cells. Green arrows point to cell layers.

\section{4 hours}
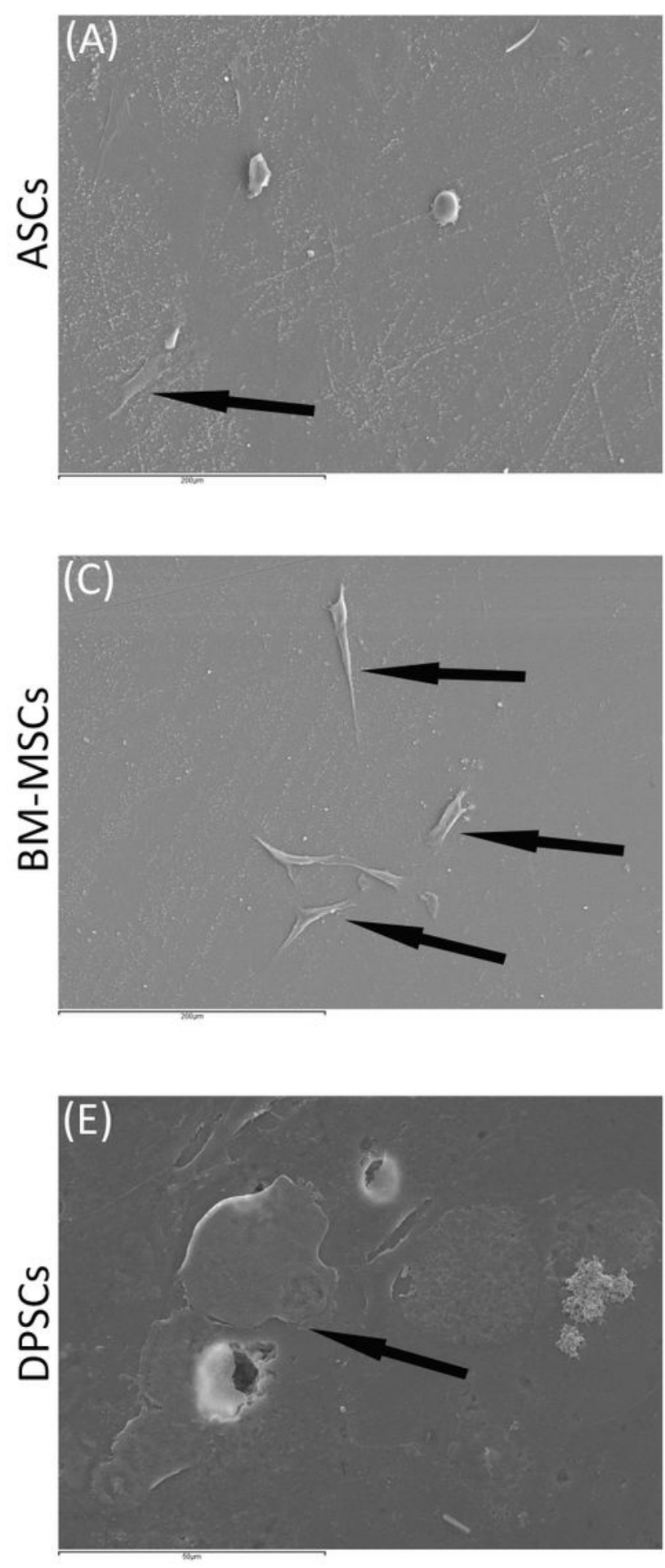

\section{7 days}
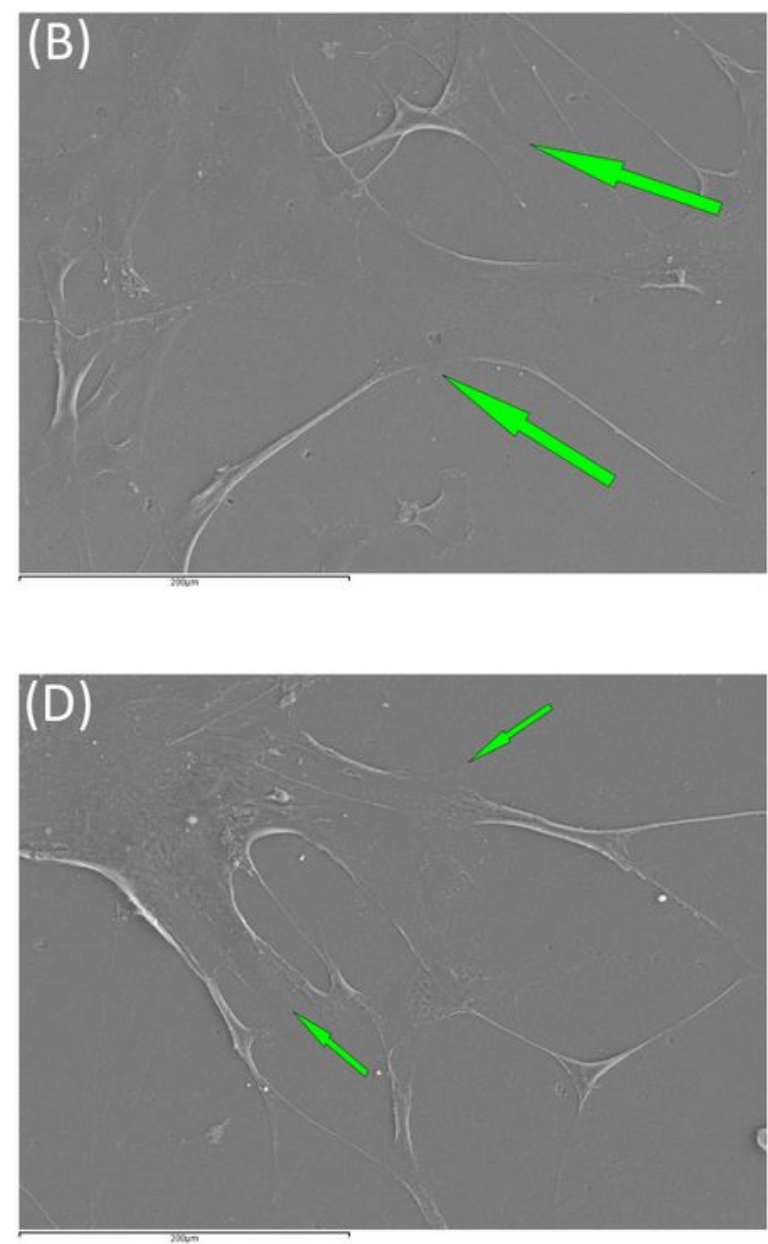

(F)

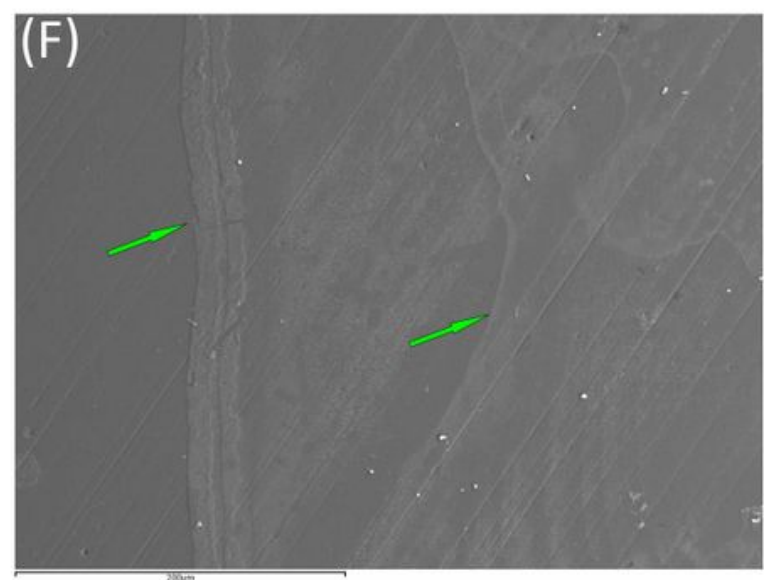

\section{Figure 5}

Behaviour of MSC seeded on B-TCP scaffold at different time points. A) ASCs on B-TCP scaffold after 24 hours (scale bar:200』m). B) ASCs forming cell layer on ß-TCP scaffold after 7 days (scale bar:200ロm). C) 
BM-MSCs on ß-TCP scaffold after 24 hours (scale bar:200』m). D) BM-MSCs forming cell layer on ß-TCP scaffold after 7 days scale bar:200』m). E) DPSCs on B-TCP scaffold at 24 hours (scale bar:50ロm). F) DPSCs forming cell layer on ß-TCP scaffold after 7 days (scale bar:200ロm). Black arrows point to unique cells. Green arrows point to cell layers.

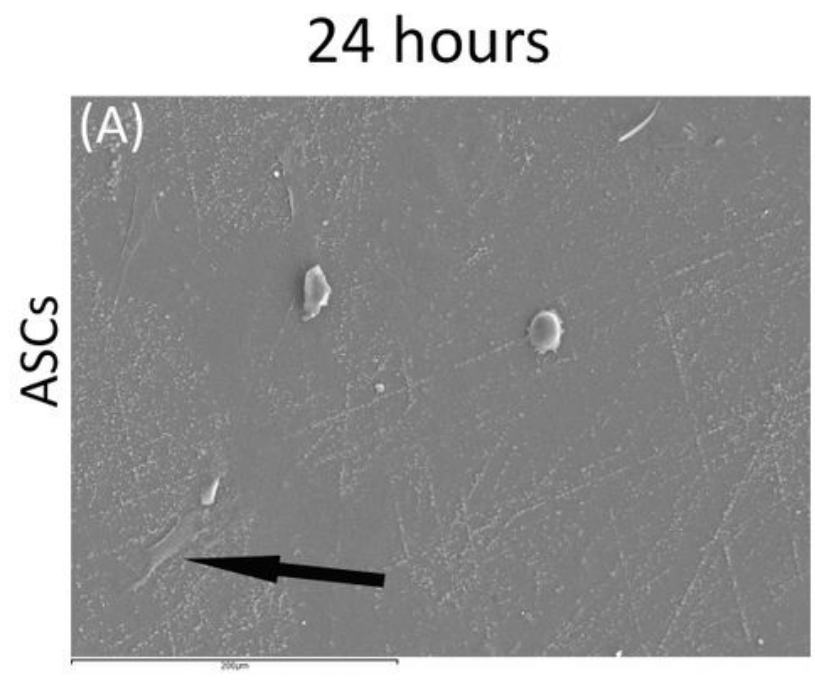

\section{7 days}
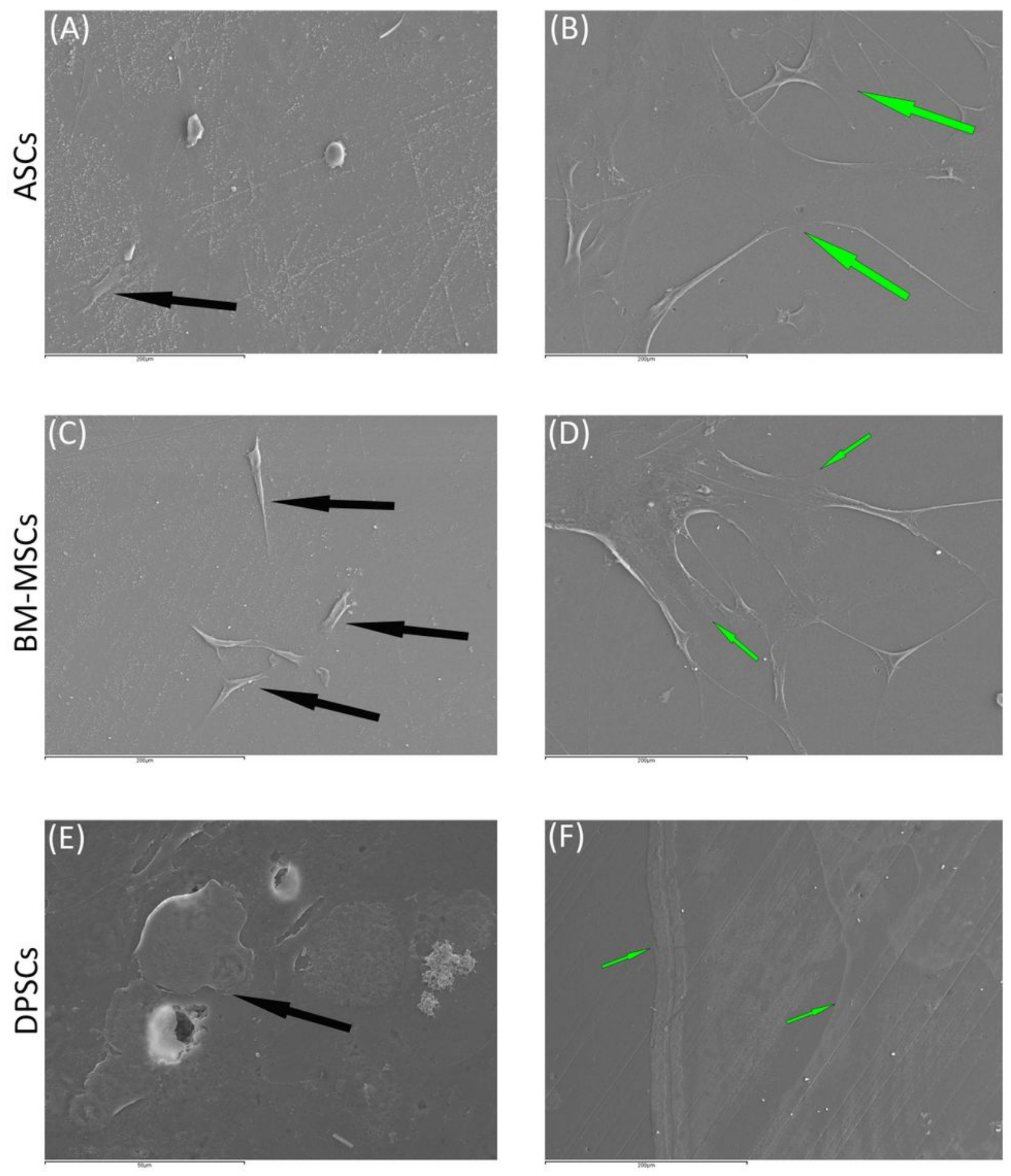

Figure 5 
Behaviour of MSC seeded on B-TCP scaffold at different time points. A) ASCs on B-TCP scaffold after 24

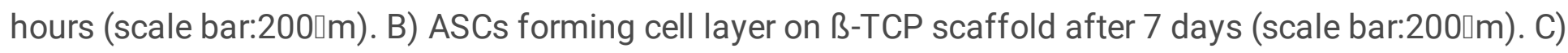
BM-MSCs on B-TCP scaffold after 24 hours (scale bar:200』m). D) BM-MSCs forming cell layer on ß-TCP scaffold after 7 days scale bar:200』m). E) DPSCs on B-TCP scaffold at 24 hours (scale bar:50ロm). F) DPSCs forming cell layer on B-TCP scaffold after 7 days (scale bar:200』m). Black arrows point to unique cells. Green arrows point to cell layers.

\section{4 hours}
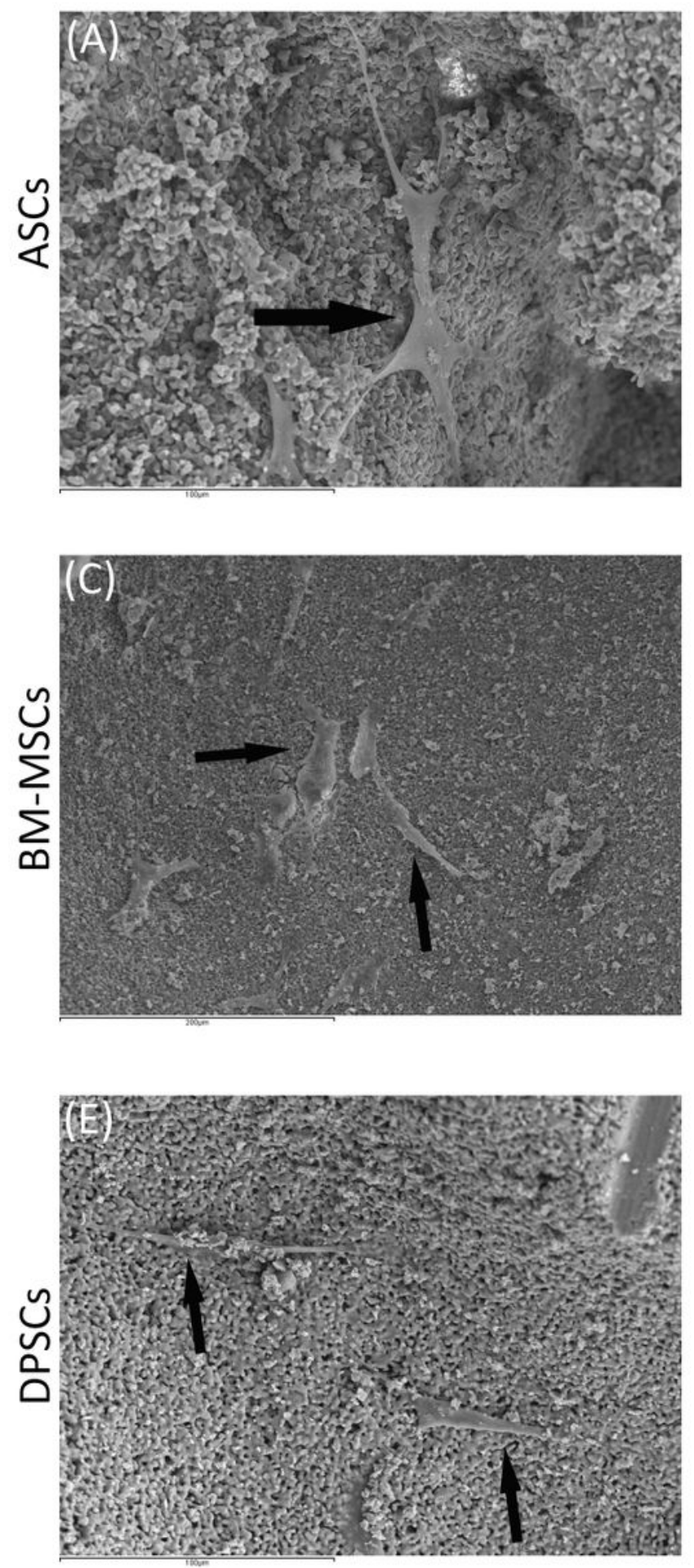

7 days
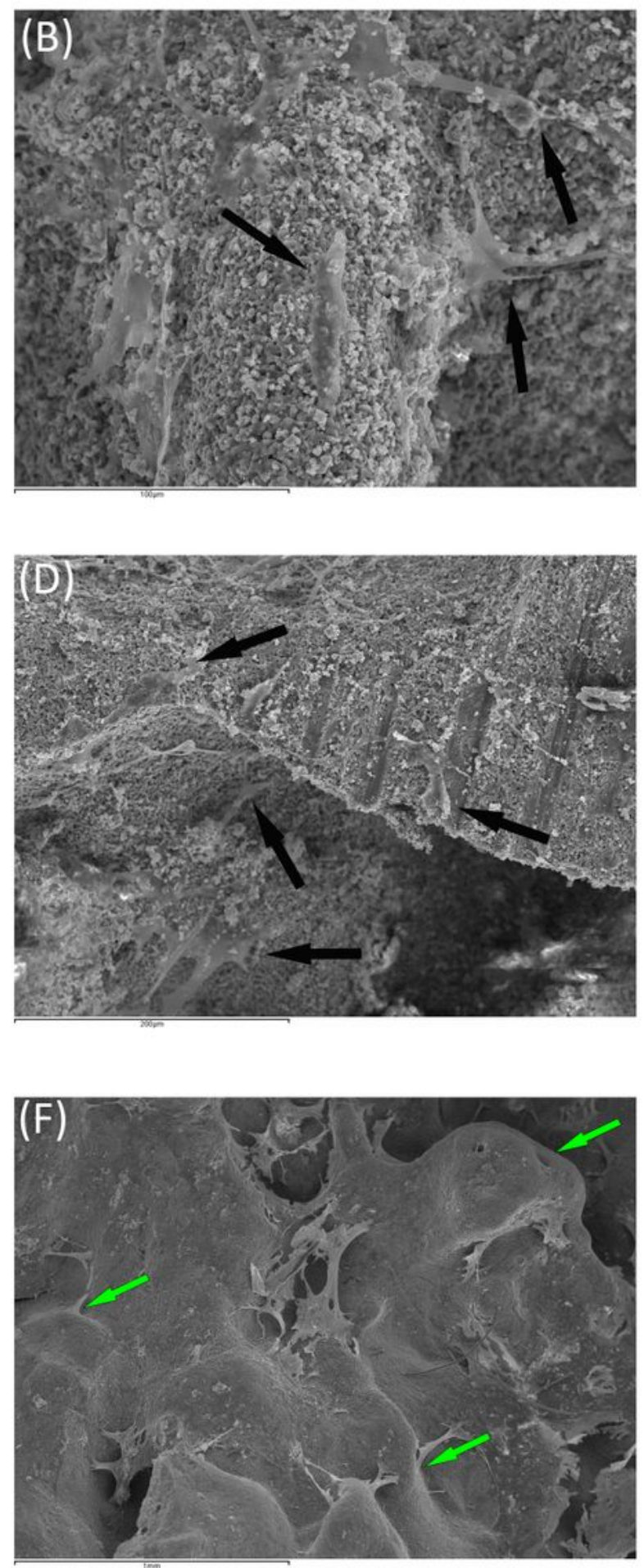

Figure 6 
Behaviour of MSC seeded on HA scaffold at different time points. A) ASCs on HA scaffold after 24 hours (scale bar:100』m). B) ASCs forming cell layer on HA scaffold after 7 days (scale bar:100ロm). C) BMMSCs on HA scaffold after 24 hours (scale bar:200Пm). D) BM-MSCs forming cell layer on HA scaffold after 7 days scale bar:200』m). E) DPSCs on HA scaffold at 24 hours (scale bar:100Пm). F) DPSCs forming cell layer on HA scaffold after 7 days (scale bar: $1 \mathrm{~mm}$ ). Black arrows point to unique cells. Green arrows point to cell layers.

\section{4 hours}
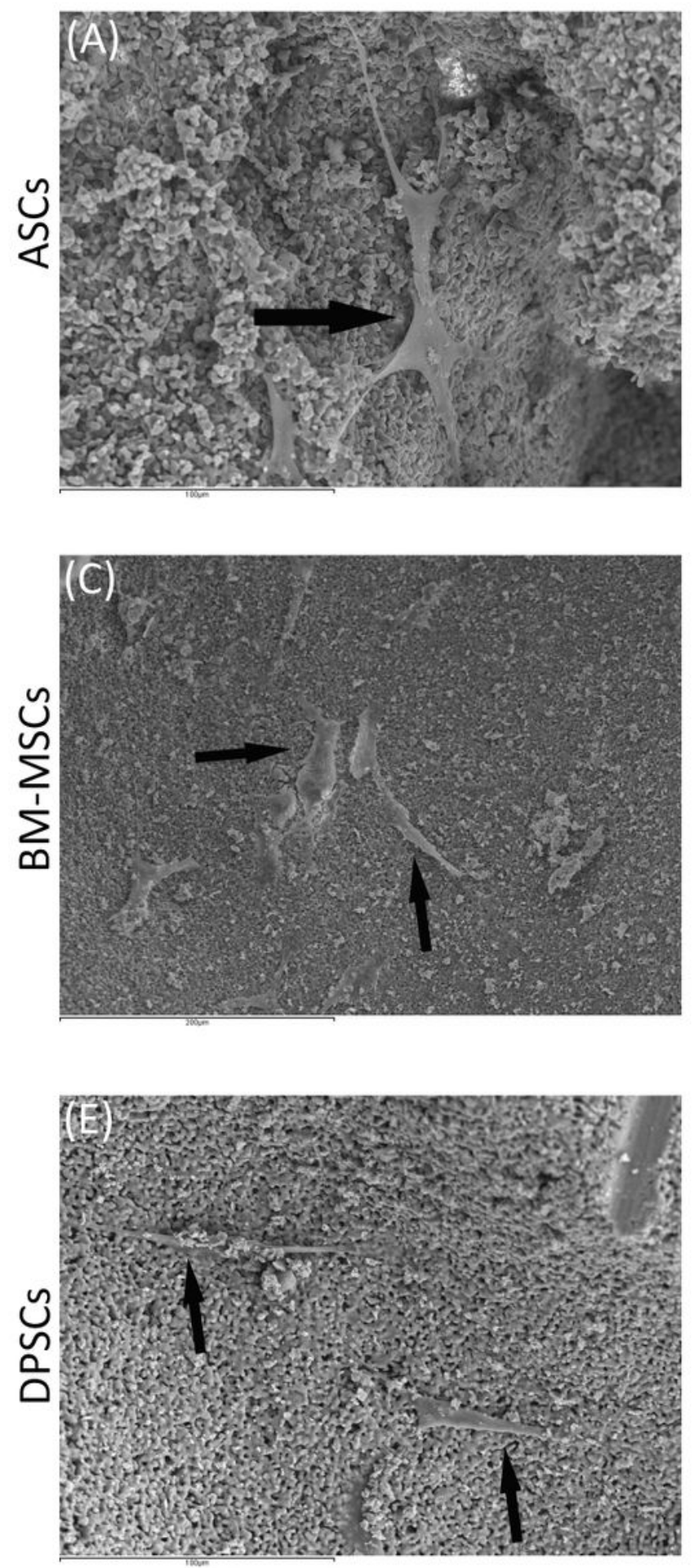

7 days
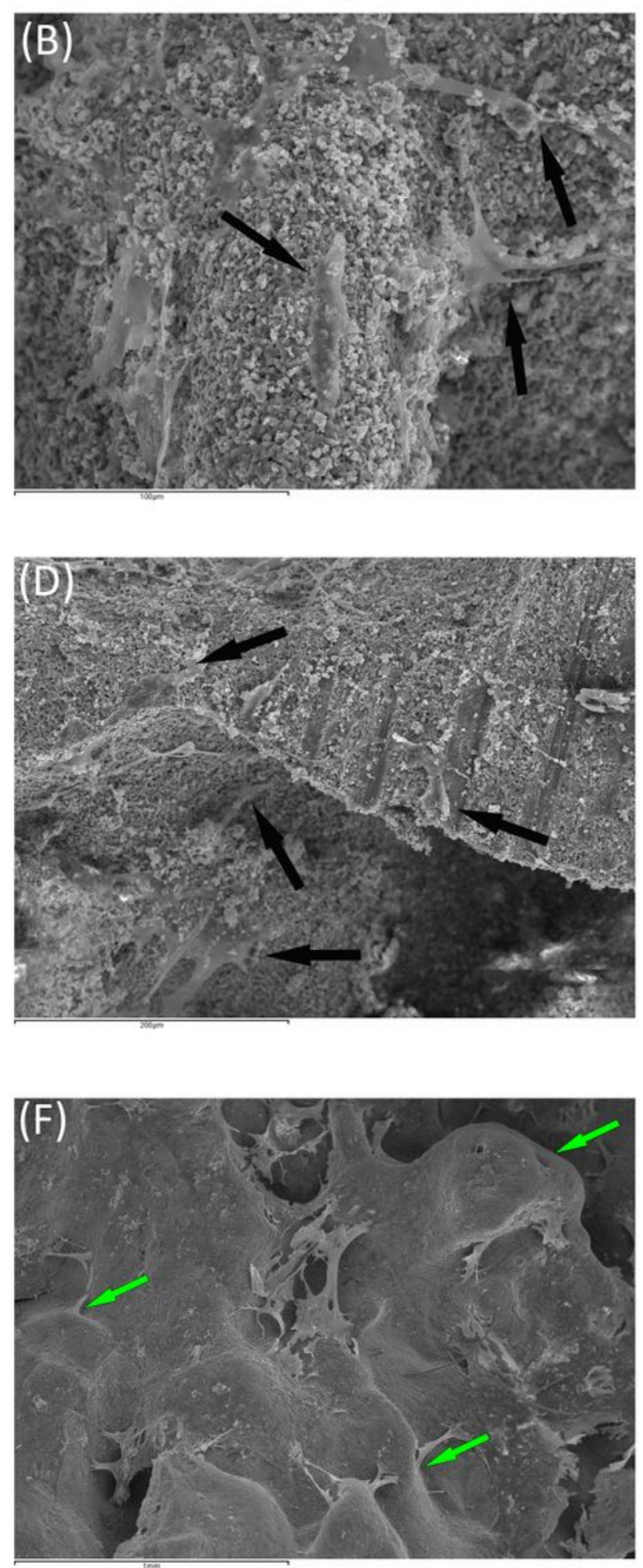

Figure 6 
Behaviour of MSC seeded on HA scaffold at different time points. A) ASCs on HA scaffold after 24 hours (scale bar:100』m). B) ASCs forming cell layer on HA scaffold after 7 days (scale bar:100ロm). C) BMMSCs on HA scaffold after 24 hours (scale bar:200Пm). D) BM-MSCs forming cell layer on HA scaffold after 7 days scale bar:200』m). E) DPSCs on HA scaffold at 24 hours (scale bar:100Пm). F) DPSCs forming cell layer on HA scaffold after 7 days (scale bar: $1 \mathrm{~mm}$ ). Black arrows point to unique cells. Green arrows point to cell layers.

\section{4 hours}
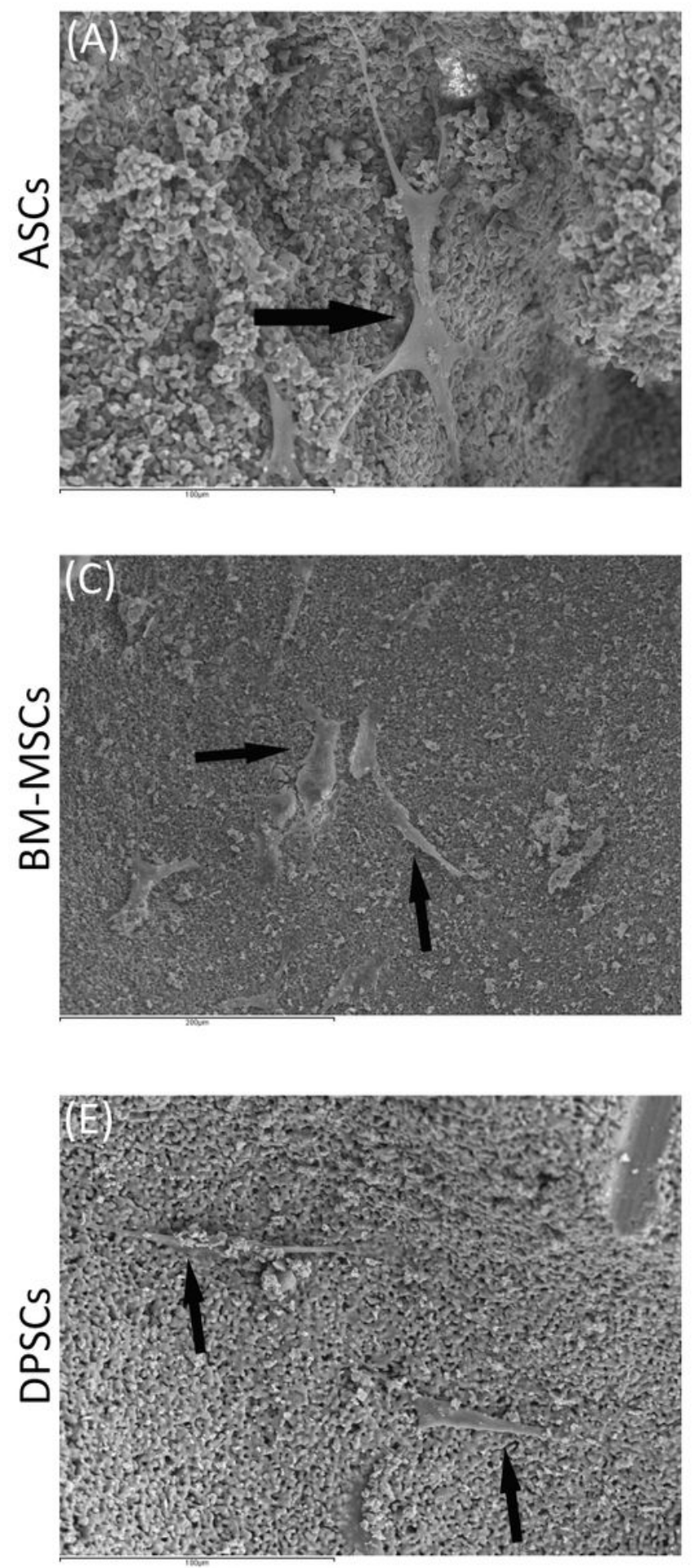

7 days
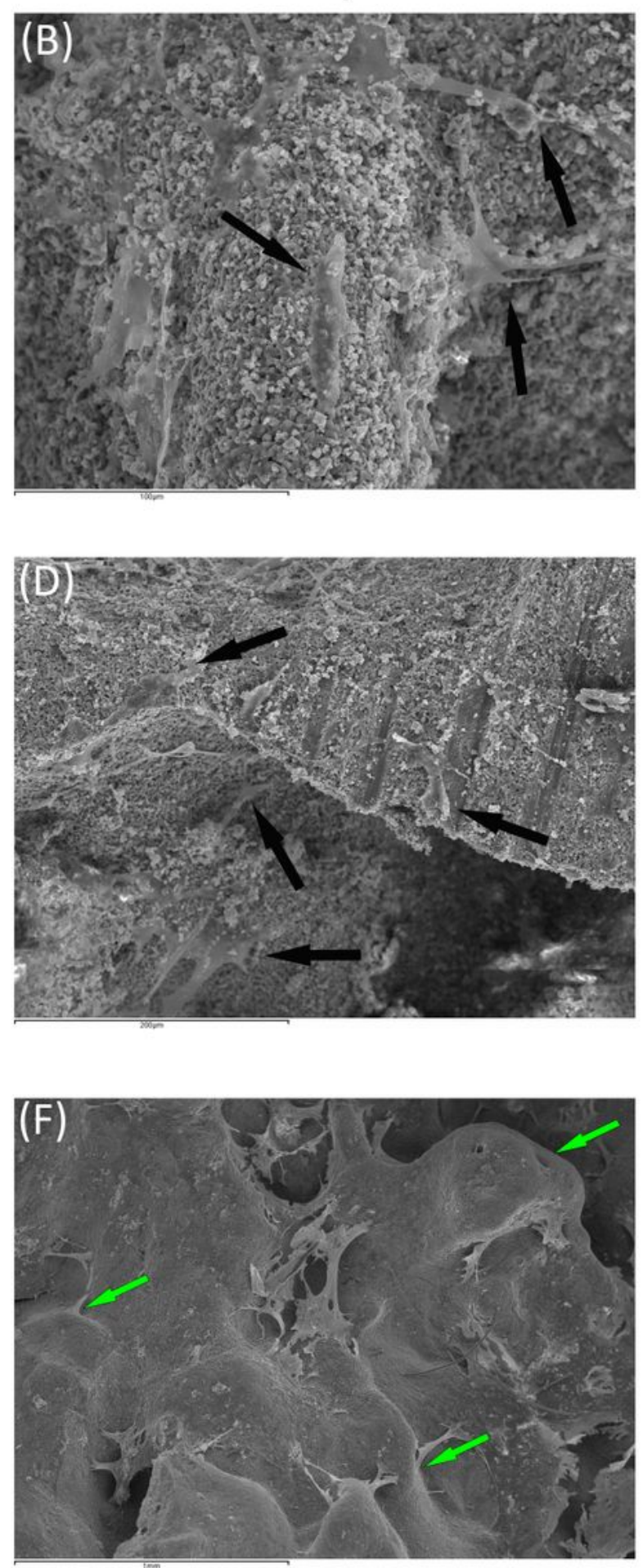

Figure 6 
Behaviour of MSC seeded on HA scaffold at different time points. A) ASCs on HA scaffold after 24 hours (scale bar:100』m). B) ASCs forming cell layer on HA scaffold after 7 days (scale bar:100ロm). C) BMMSCs on HA scaffold after 24 hours (scale bar:200Пm). D) BM-MSCs forming cell layer on HA scaffold after 7 days scale bar:200』m). E) DPSCs on HA scaffold at 24 hours (scale bar:100Пm). F) DPSCs forming cell layer on HA scaffold after 7 days (scale bar: $1 \mathrm{~mm}$ ). Black arrows point to unique cells. Green arrows point to cell layers.

\section{4 hours}
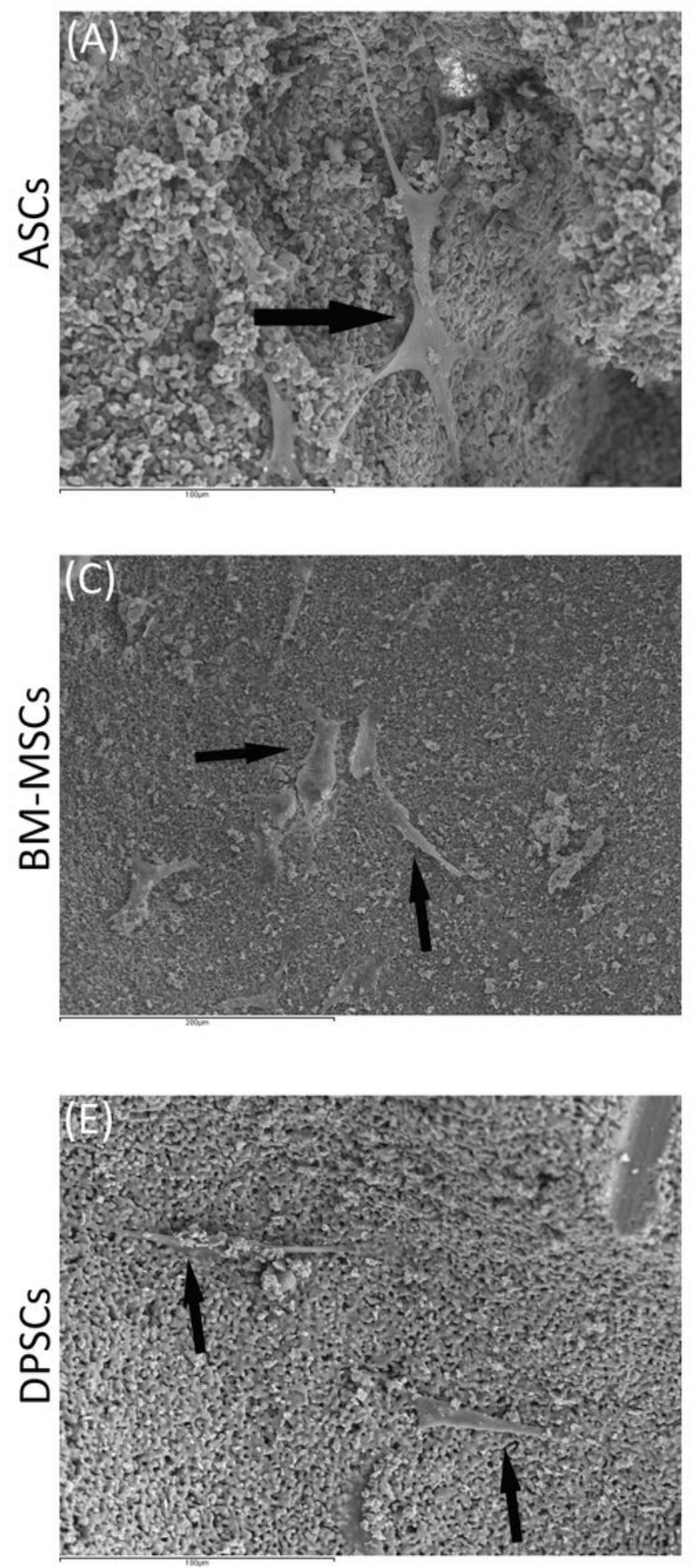

7 days
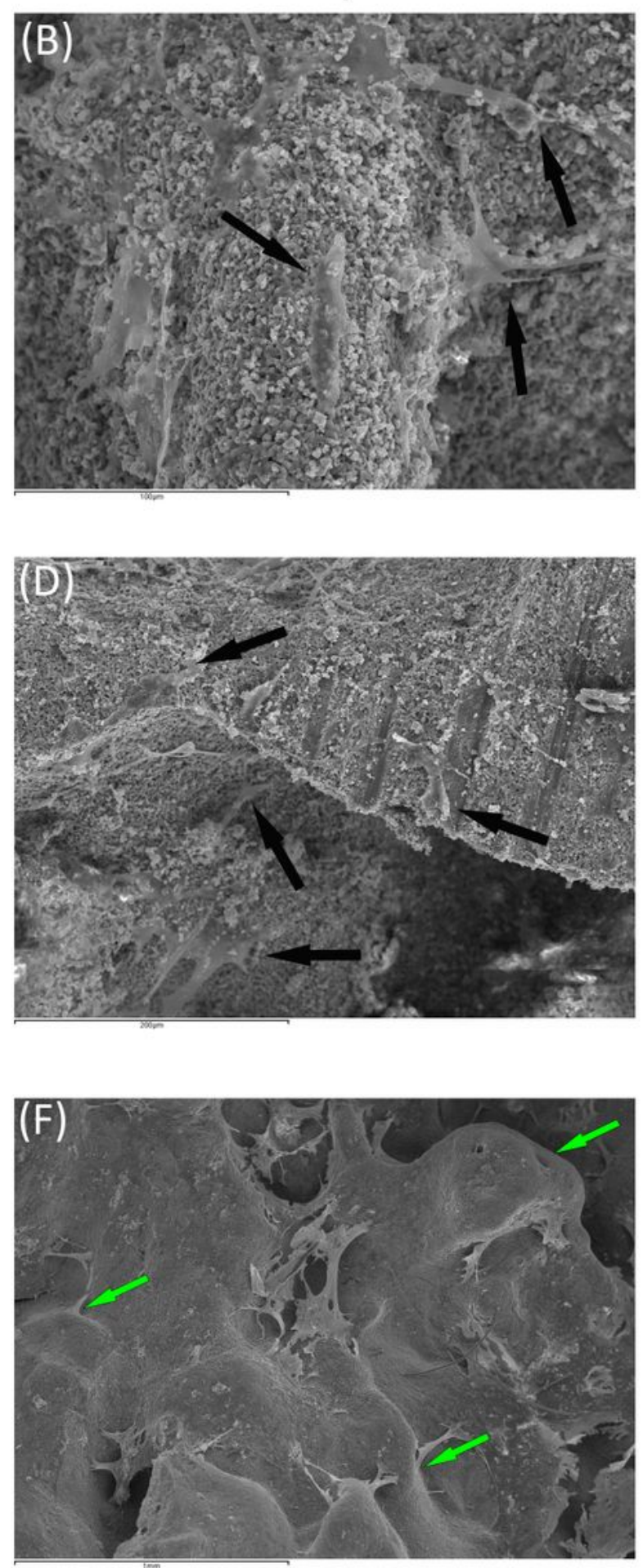

Figure 6 
Behaviour of MSC seeded on HA scaffold at different time points. A) ASCs on HA scaffold after 24 hours (scale bar:100』m). B) ASCs forming cell layer on HA scaffold after 7 days (scale bar:100ロm). C) BMMSCs on HA scaffold after 24 hours (scale bar:200ロm). D) BM-MSCs forming cell layer on HA scaffold after 7 days scale bar:200』m). E) DPSCs on HA scaffold at 24 hours (scale bar:100Пm). F) DPSCs forming cell layer on HA scaffold after 7 days (scale bar: $1 \mathrm{~mm}$ ). Black arrows point to unique cells. Green arrows point to cell layers.

$\beta-\mathrm{TCP}$
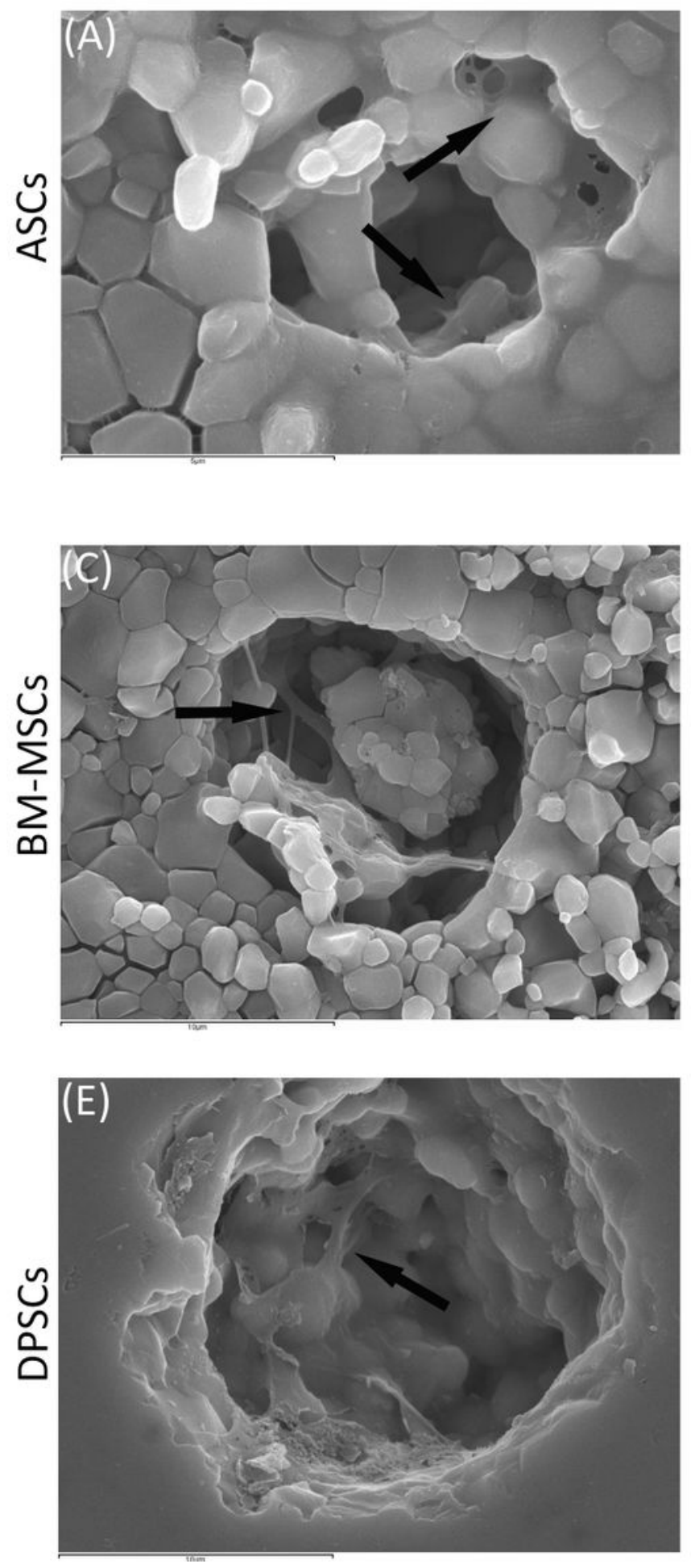

$\mathrm{HA}$
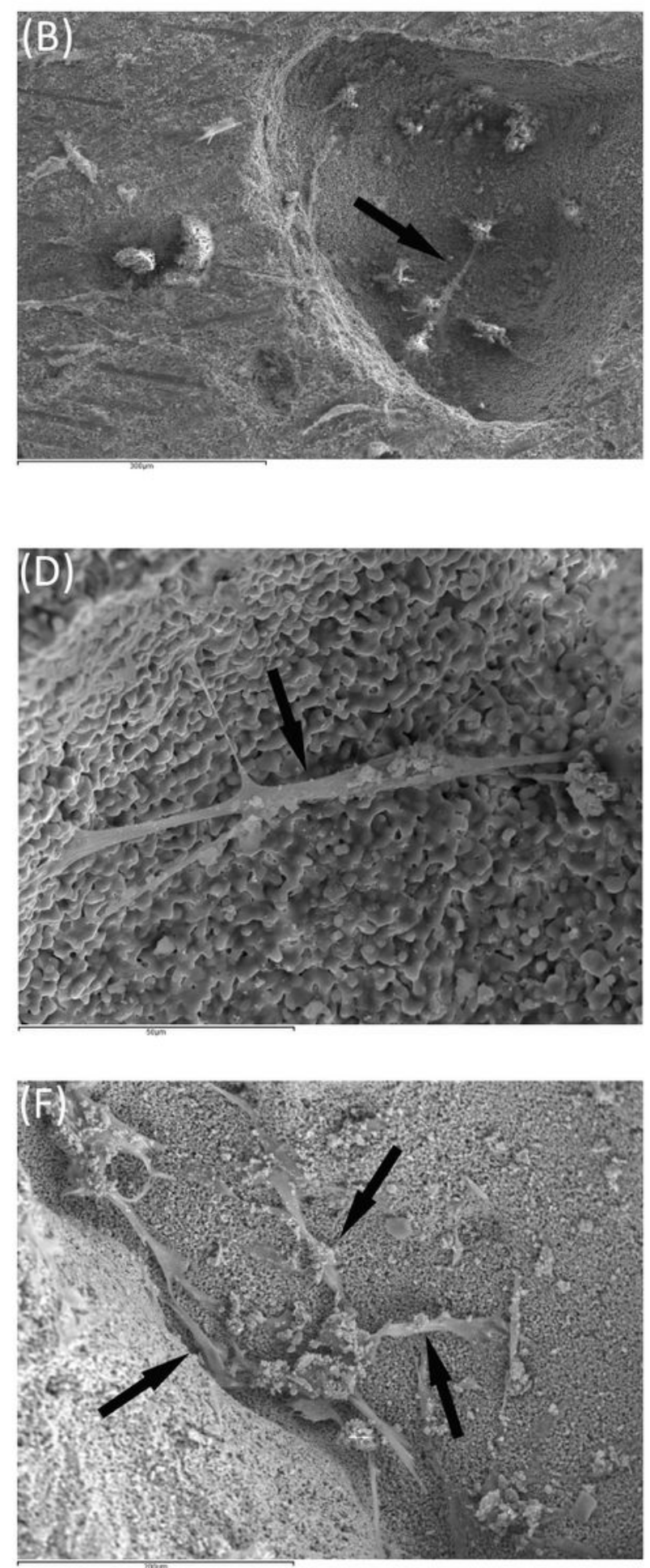

Figure 7 
MSCs colonizing pores of both HA and B-TCP scaffolds after 24 hours. A) Existing pores in HA colonized

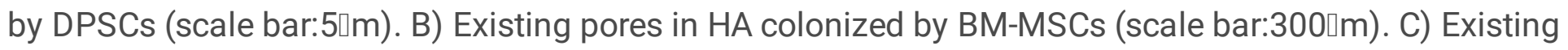
pores in HA colonized by ASCs (scale bar:10 $1 \mathrm{~m}$ ). D) Existing pores in ß-TCP colonized by DPSCs (scale

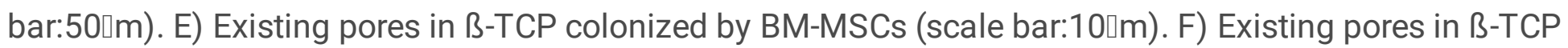
colonized by ASCs (scale bar:200ロm).

$\beta-\mathrm{TCP}$
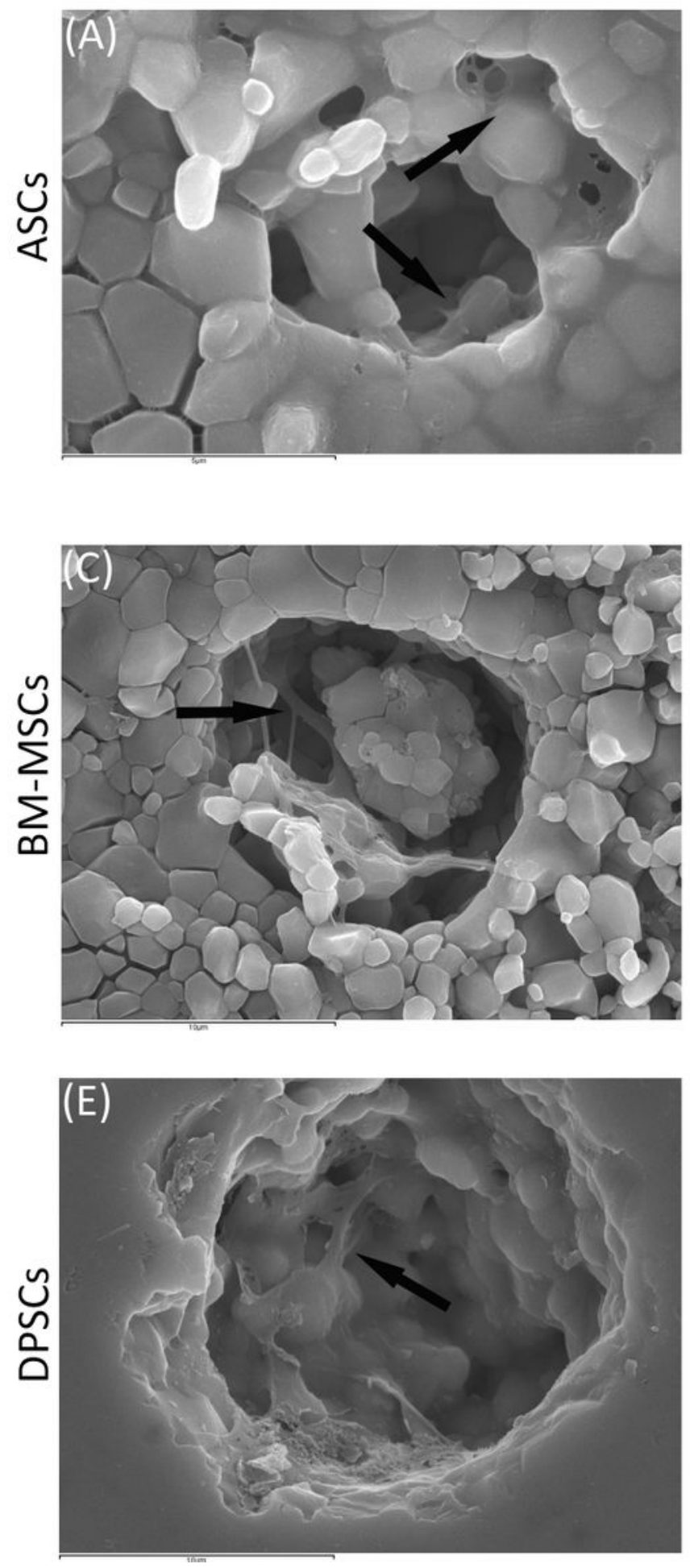

\section{$\mathrm{HA}$}
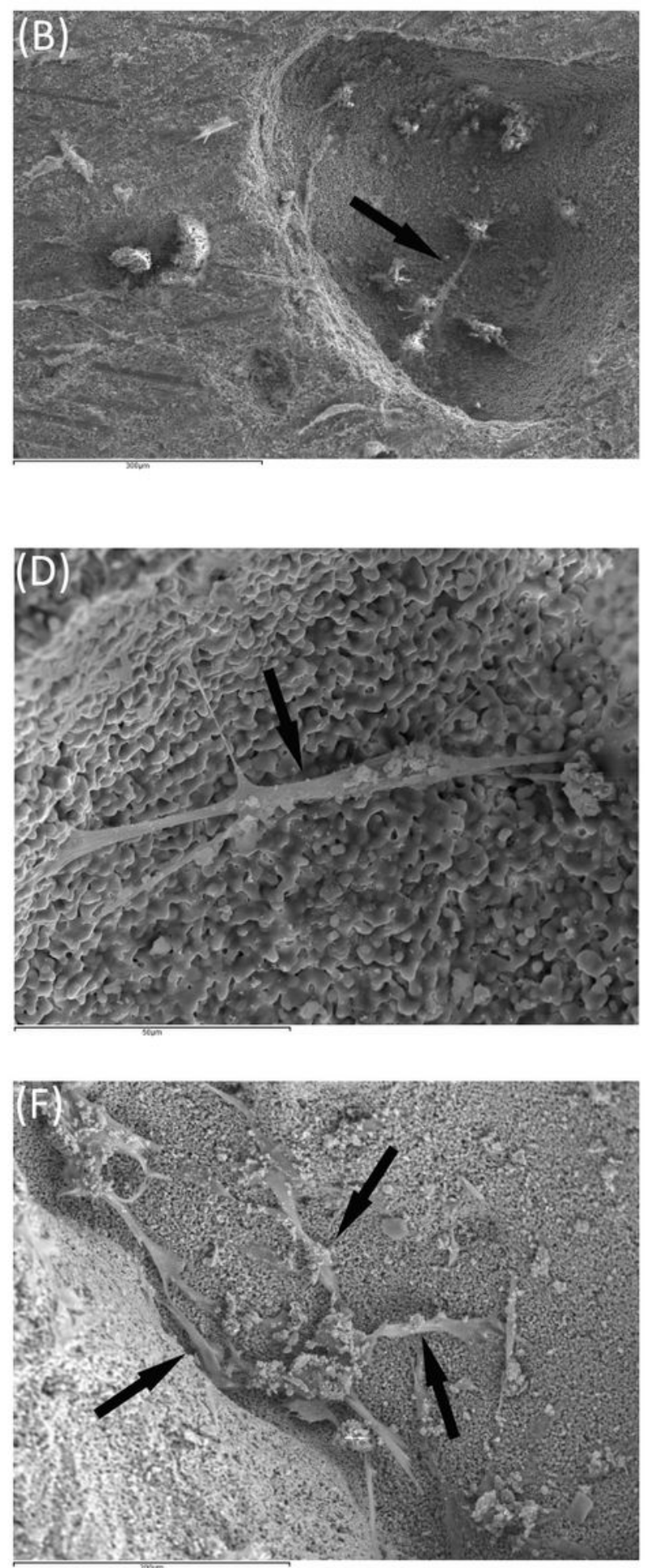

Figure 7 
MSCs colonizing pores of both HA and B-TCP scaffolds after 24 hours. A) Existing pores in HA colonized

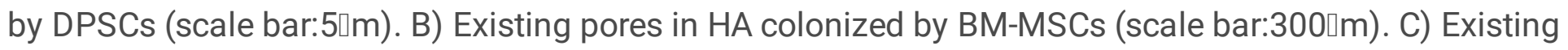
pores in HA colonized by ASCs (scale bar:10 $1 \mathrm{~m}$ ). D) Existing pores in ß-TCP colonized by DPSCs (scale

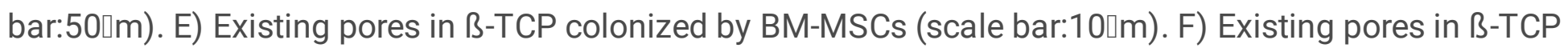
colonized by ASCs (scale bar:200ロm).

$\beta-\mathrm{TCP}$
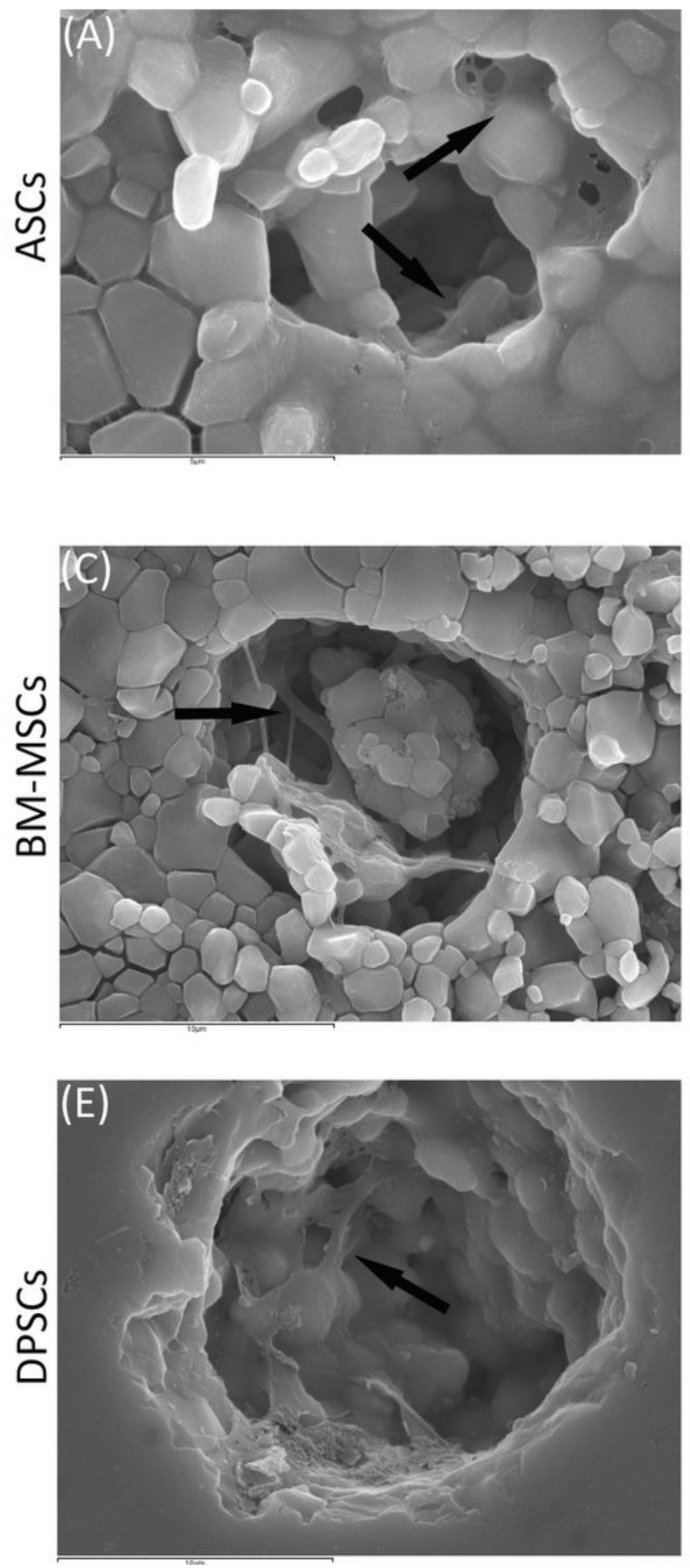

\section{HA}
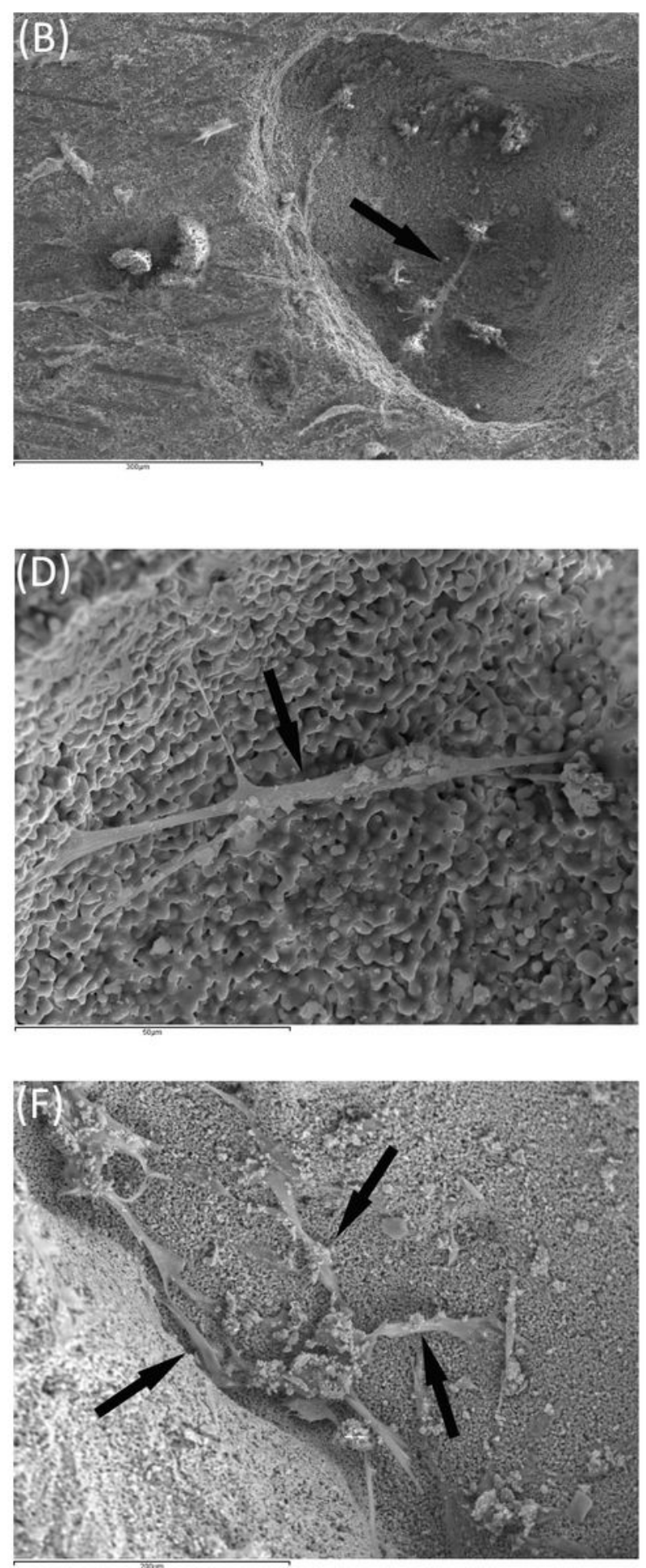

Figure 7 
MSCs colonizing pores of both HA and B-TCP scaffolds after 24 hours. A) Existing pores in HA colonized

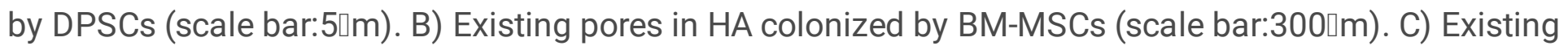
pores in HA colonized by ASCs (scale bar:10 $1 \mathrm{~m}$ ). D) Existing pores in ß-TCP colonized by DPSCs (scale

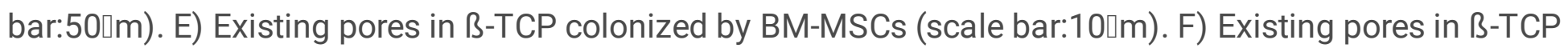
colonized by ASCs (scale bar:200ロm).

$\beta-\mathrm{TCP}$
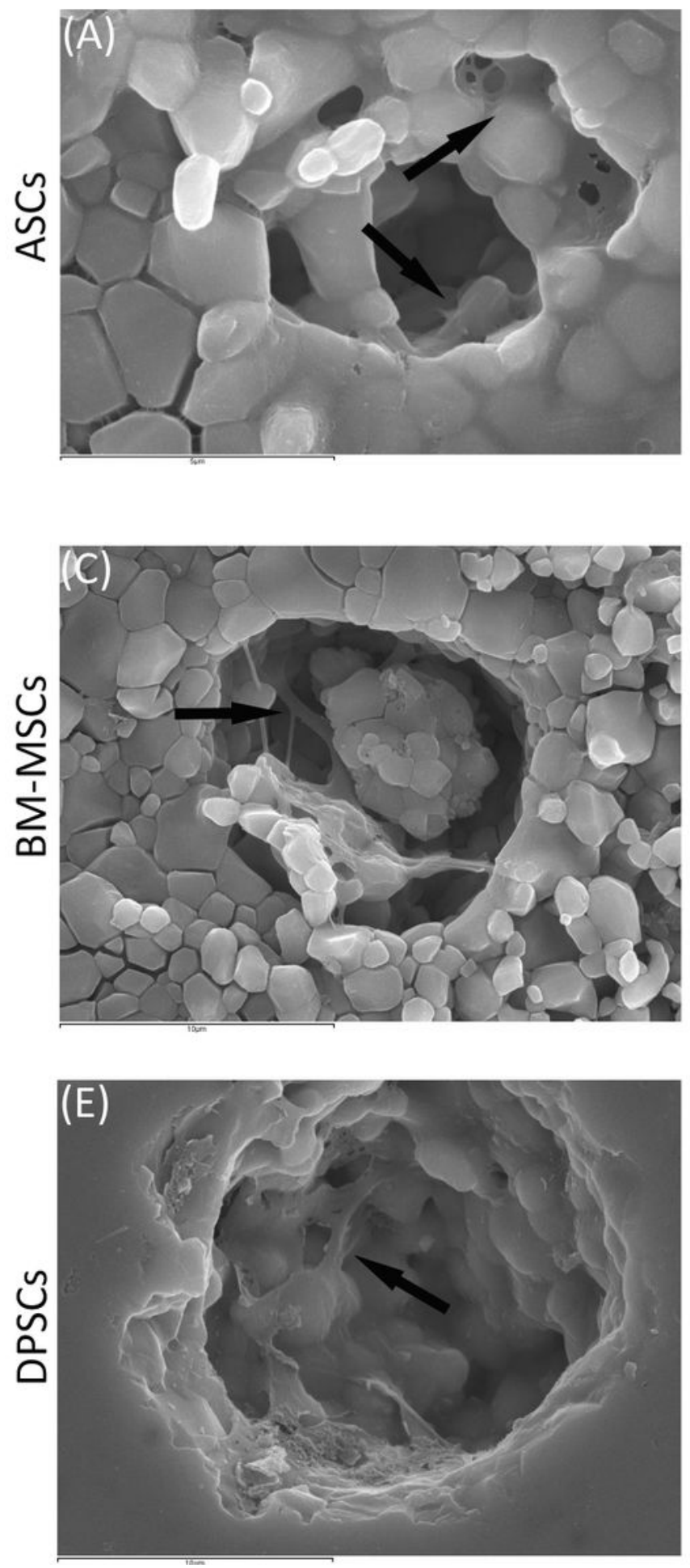

\section{HA}
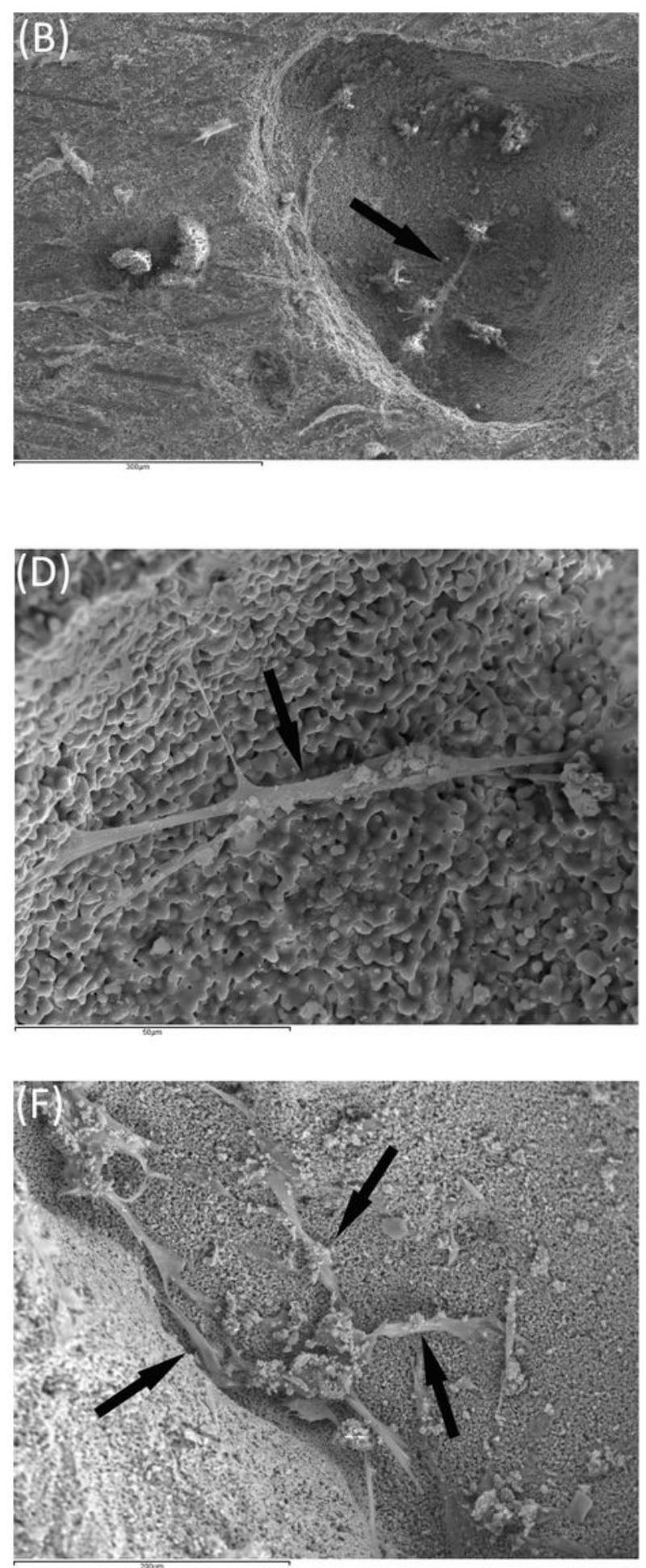

Figure 7 
MSCs colonizing pores of both HA and B-TCP scaffolds after 24 hours. A) Existing pores in HA colonized

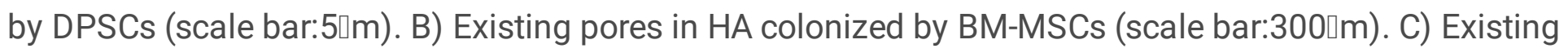
pores in HA colonized by ASCs (scale bar:10 $1 \mathrm{~m}$ ). D) Existing pores in ß-TCP colonized by DPSCs (scale

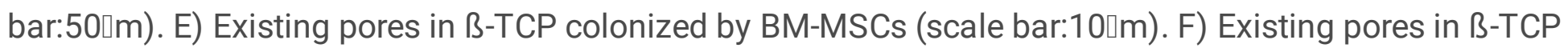
colonized by ASCs (scale bar:200』m).

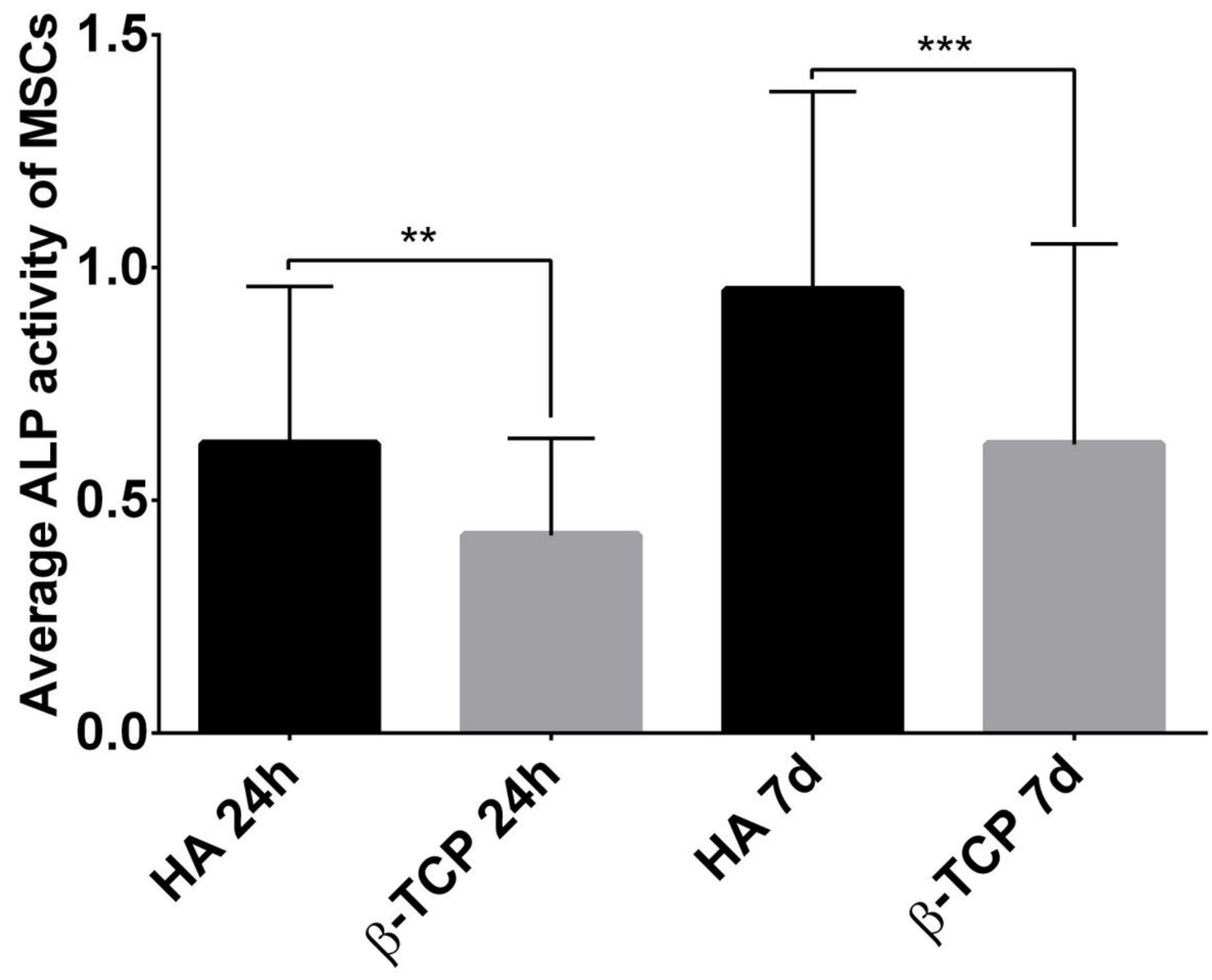

Figure 8

Average ALP activity showed by all MSCs on each CaP. Hydroxyapatite (HA) and ß-tricalcium phosphate $(\beta-T C P)$. All data are shown as mean \pm standard deviation. Significance level: ${ }^{\star \star} \leq 0.01 * \star \star \leq 0.001$. 


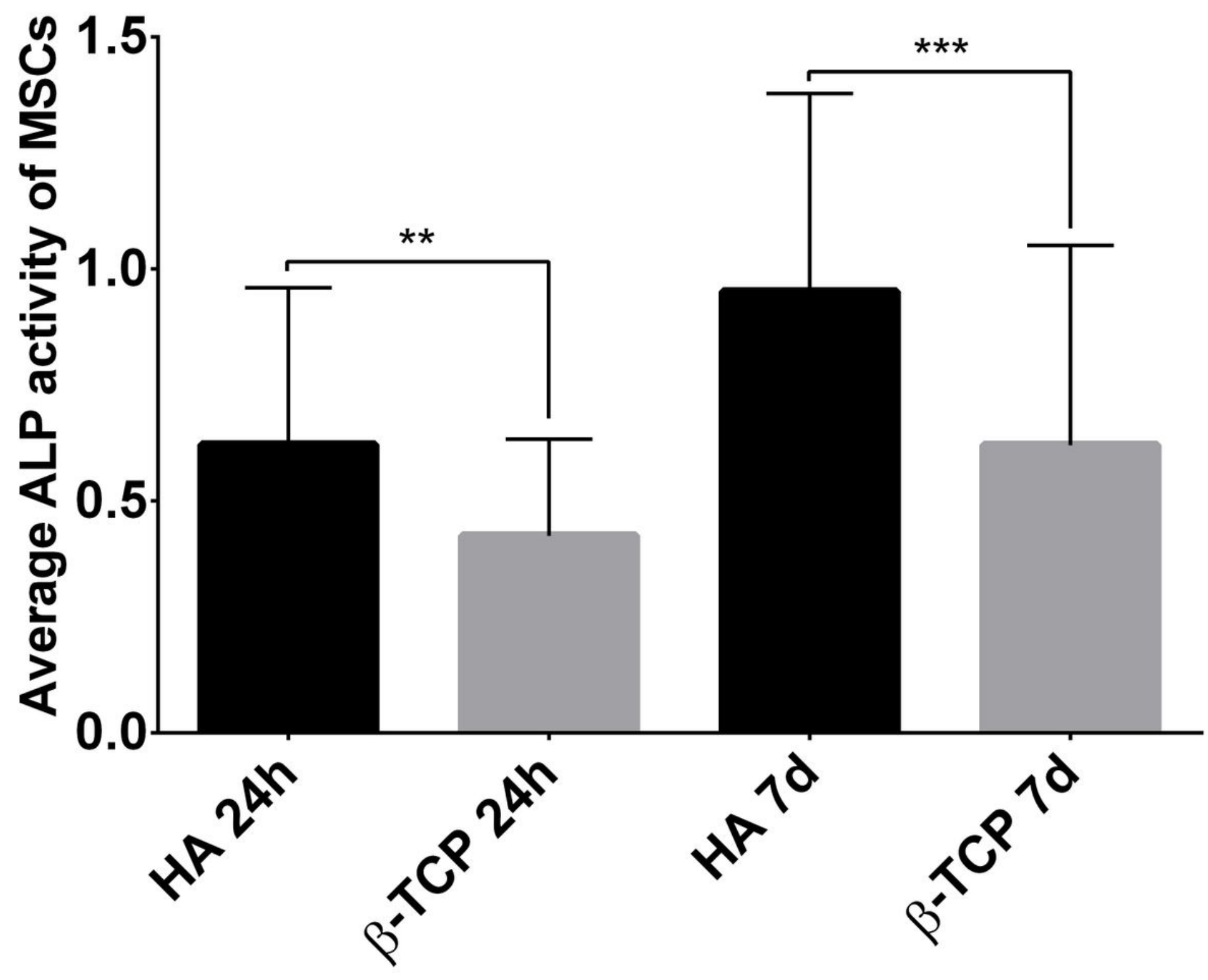

Figure 8

Average ALP activity showed by all MSCs on each CaP. Hydroxyapatite (HA) and ß-tricalcium phosphate $(\beta-T C P)$. All data are shown as mean \pm standard deviation. Significance level: ${ }^{\star \star} \leq 0.01 * \star \star \leq 0.001$. 


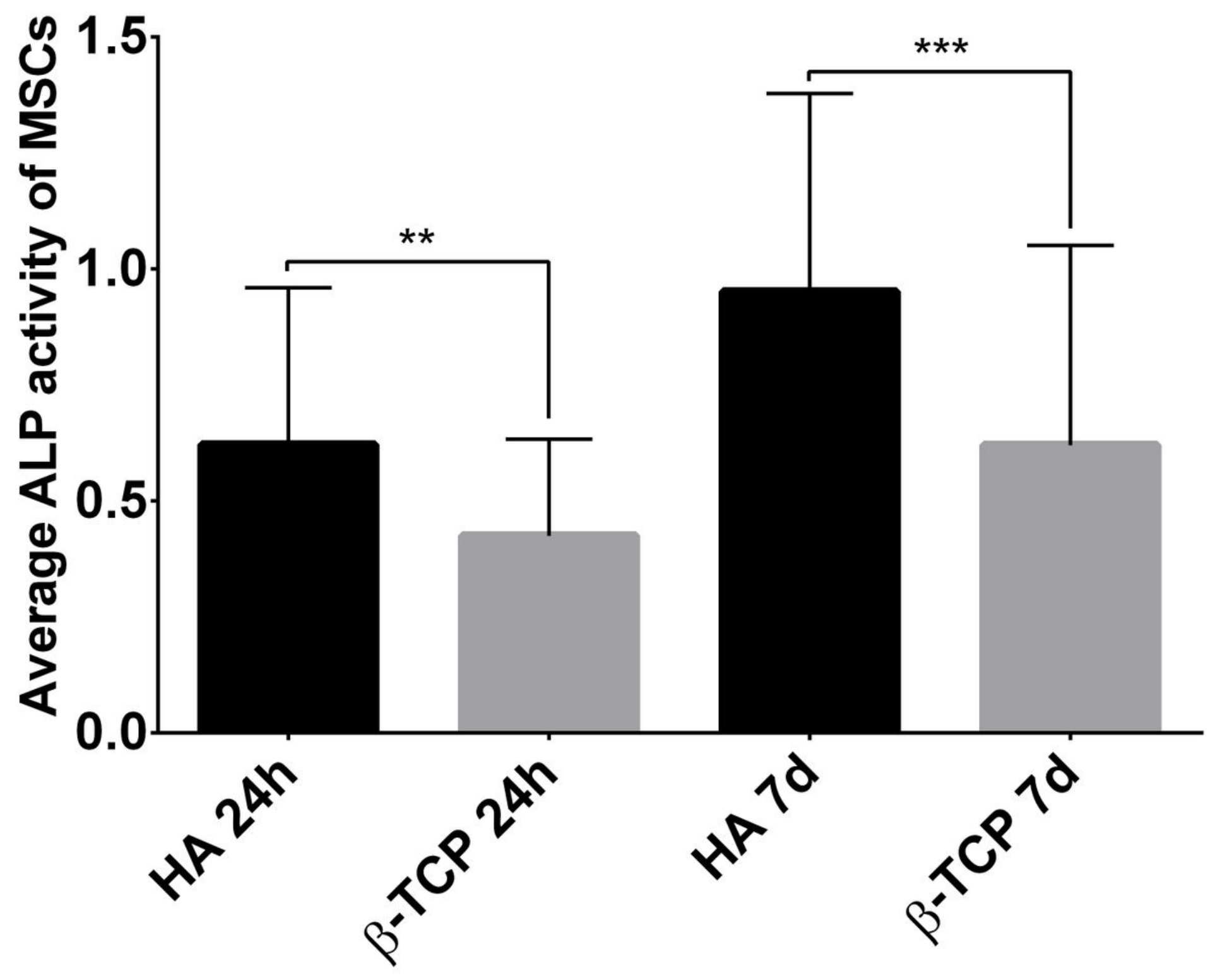

Figure 8

Average ALP activity showed by all MSCs on each CaP. Hydroxyapatite (HA) and ß-tricalcium phosphate $(\beta-T C P)$. All data are shown as mean \pm standard deviation. Significance level: ${ }^{\star \star} \leq 0.01 * \star \star \leq 0.001$. 


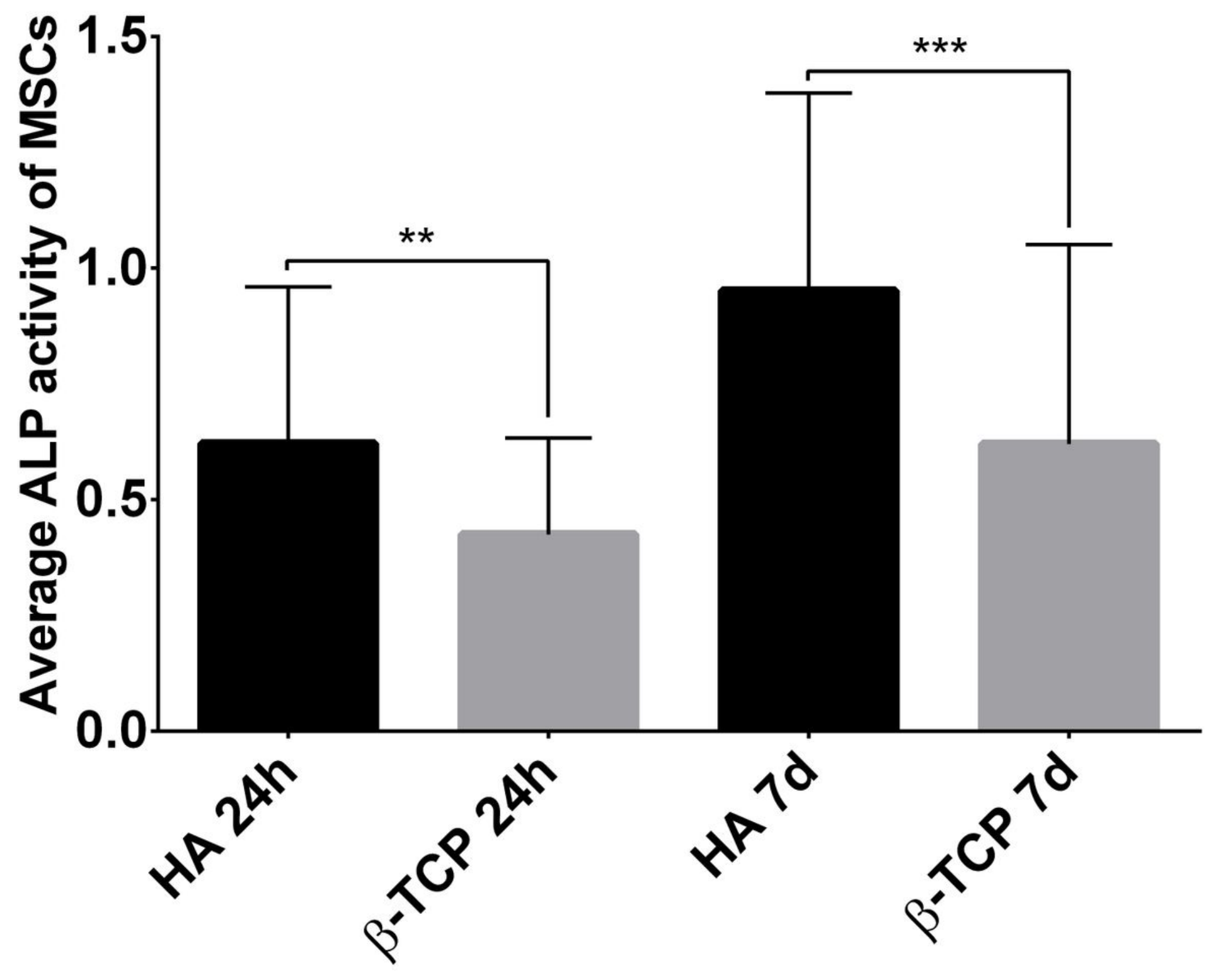

Figure 8

Average ALP activity showed by all MSCs on each CaP. Hydroxyapatite (HA) and ß-tricalcium phosphate $(\beta-T C P)$. All data are shown as mean \pm standard deviation. Significance level: ${ }^{\star \star} \leq 0.01 * \star \star \leq 0.001$. 


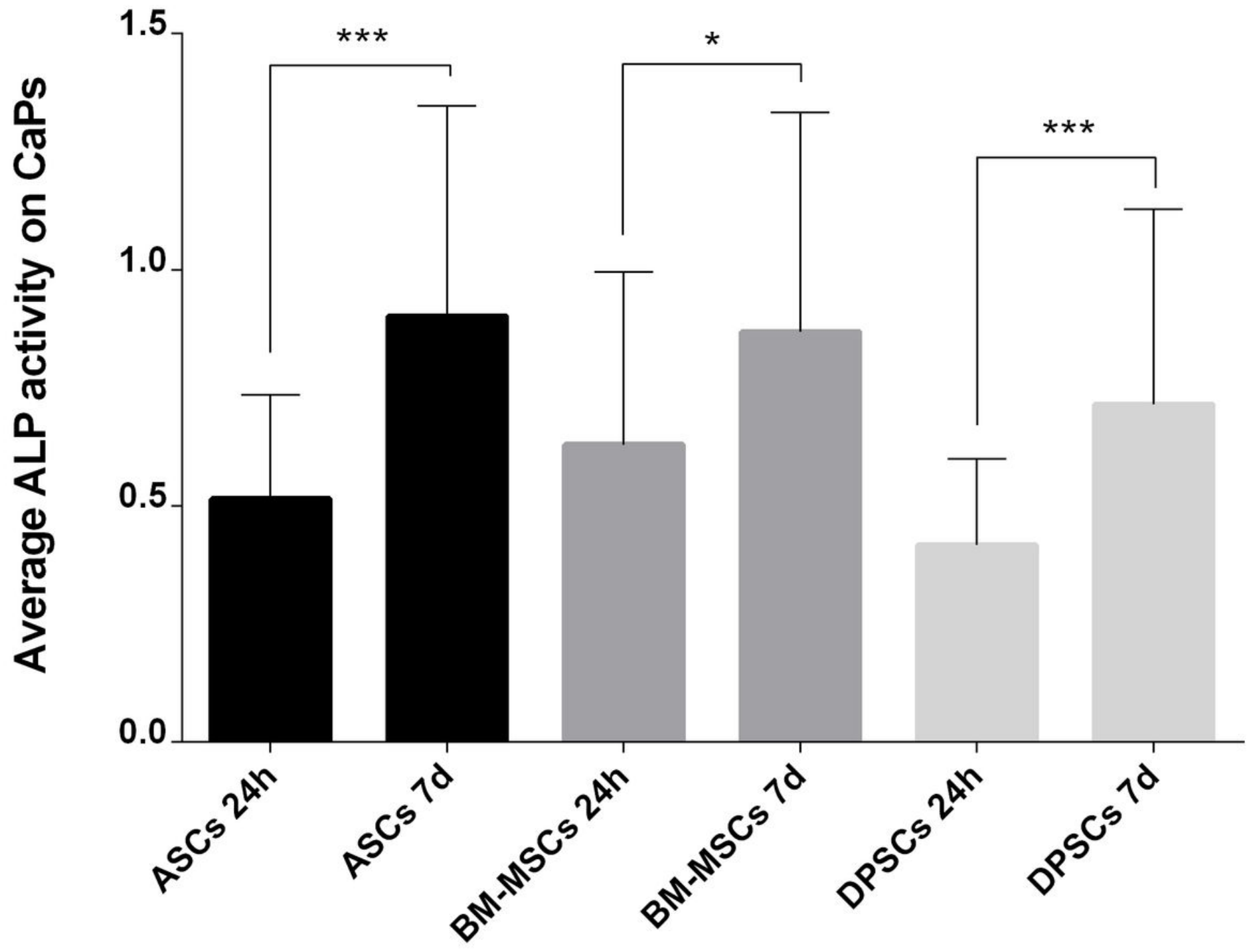

Figure 9

Average ALP activity showed by each MSC on both CaPs. Adipose tissue (ASCs), dental pulp (DPSCs) and bone marrow (BM-MSCs). All data are shown as mean \pm standard deviation. Significance level: * $\leq 0.05^{\star * \star} \leq 0.001$. 


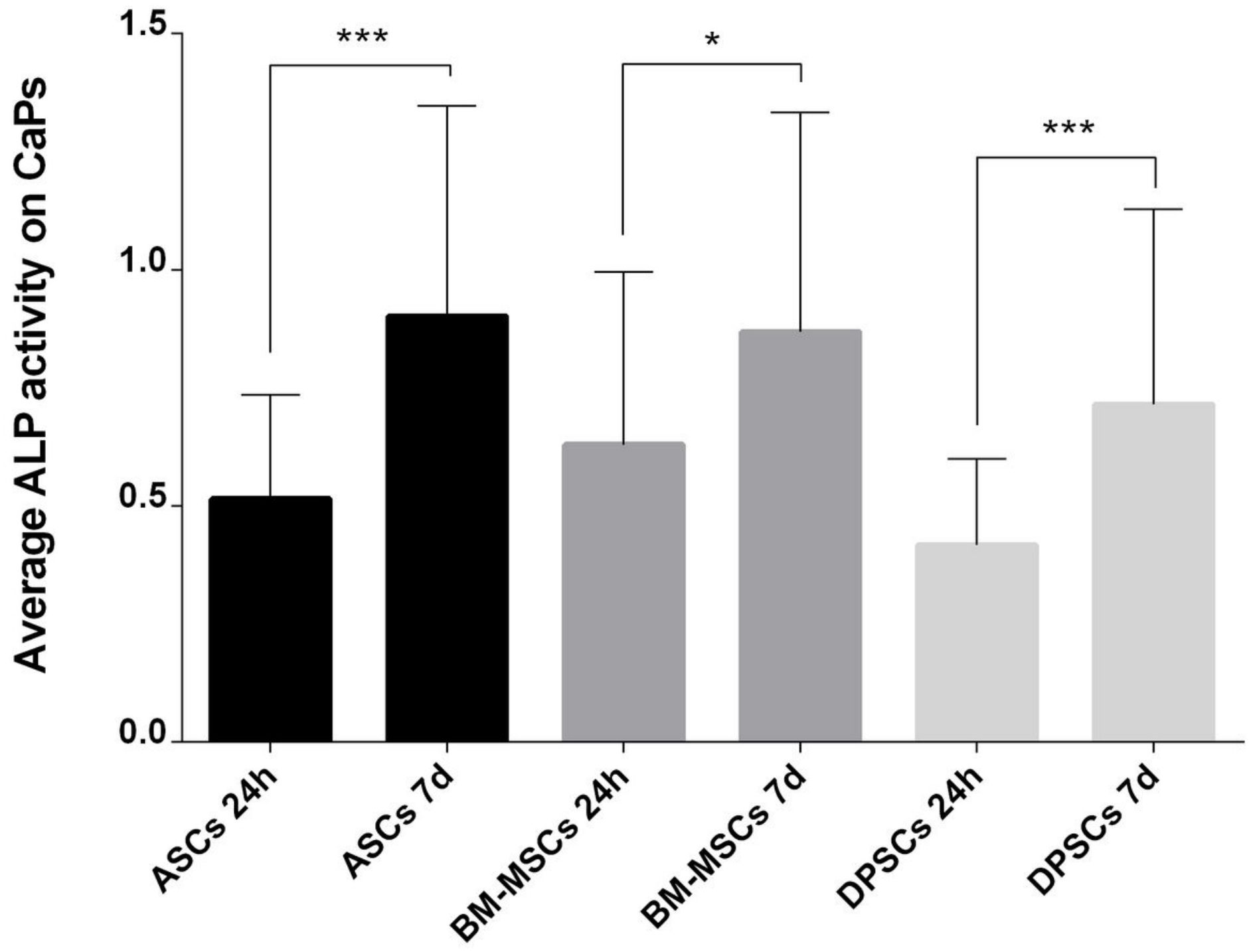

Figure 9

Average ALP activity showed by each MSC on both CaPs. Adipose tissue (ASCs), dental pulp (DPSCs) and bone marrow (BM-MSCs). All data are shown as mean \pm standard deviation. Significance level: * $\leq 0.05^{\star * \star} \leq 0.001$. 


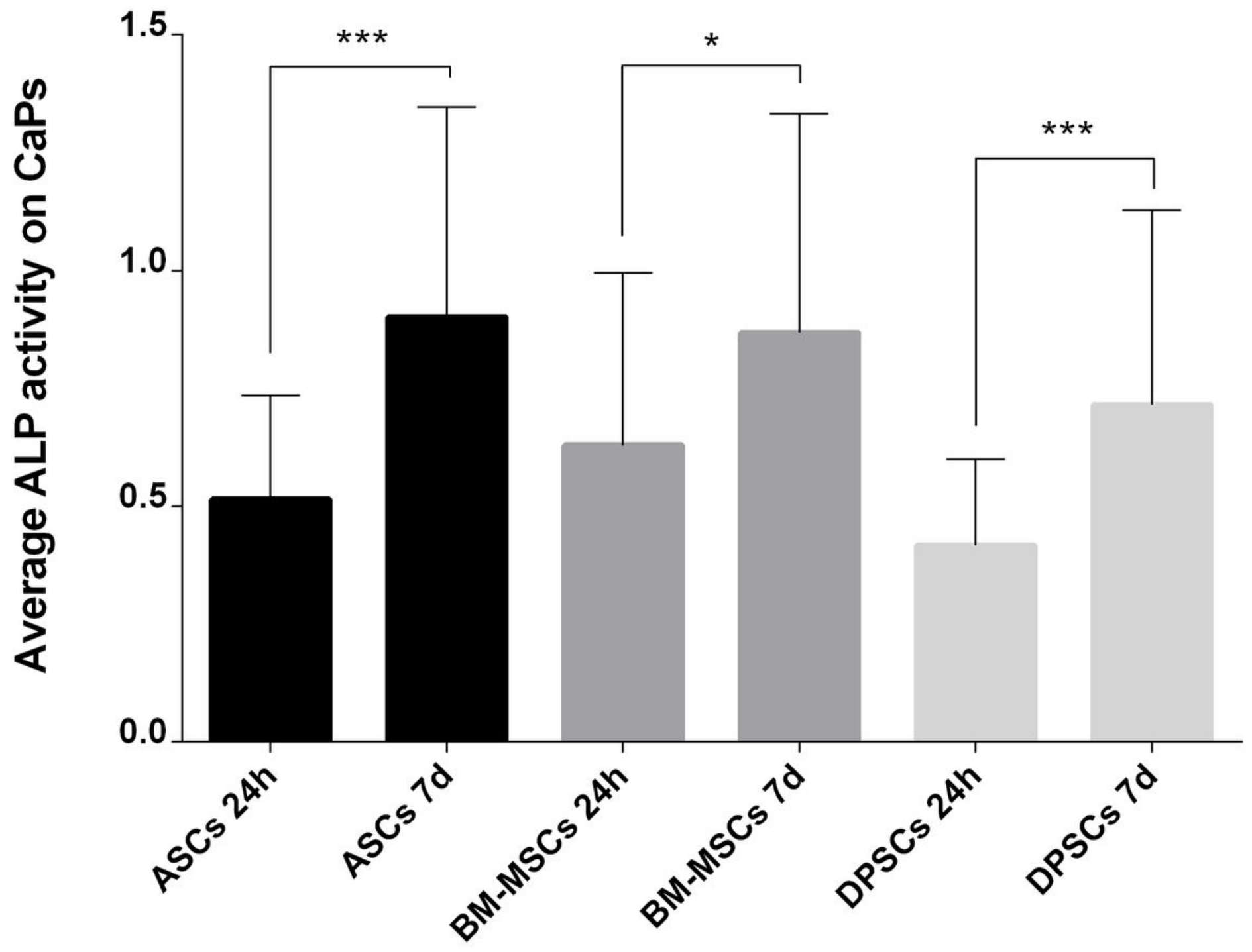

Figure 9

Average ALP activity showed by each MSC on both CaPs. Adipose tissue (ASCs), dental pulp (DPSCs) and bone marrow (BM-MSCs). All data are shown as mean \pm standard deviation. Significance level: * $\leq 0.05^{\star * \star} \leq 0.001$. 


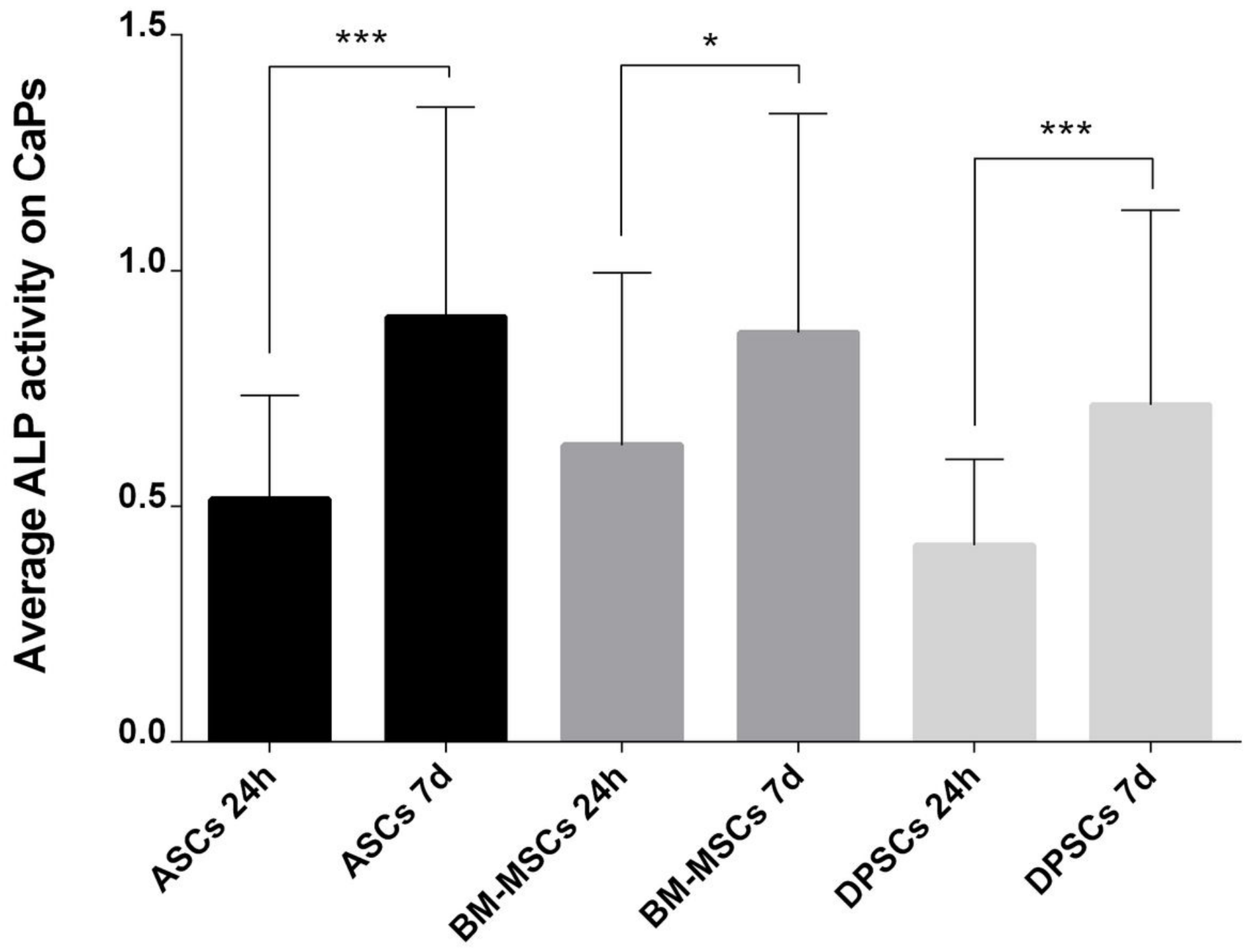

Figure 9

Average ALP activity showed by each MSC on both CaPs. Adipose tissue (ASCs), dental pulp (DPSCs) and bone marrow (BM-MSCs). All data are shown as mean \pm standard deviation. Significance level: * $\leq 0.05^{\star * \star} \leq 0.001$. 


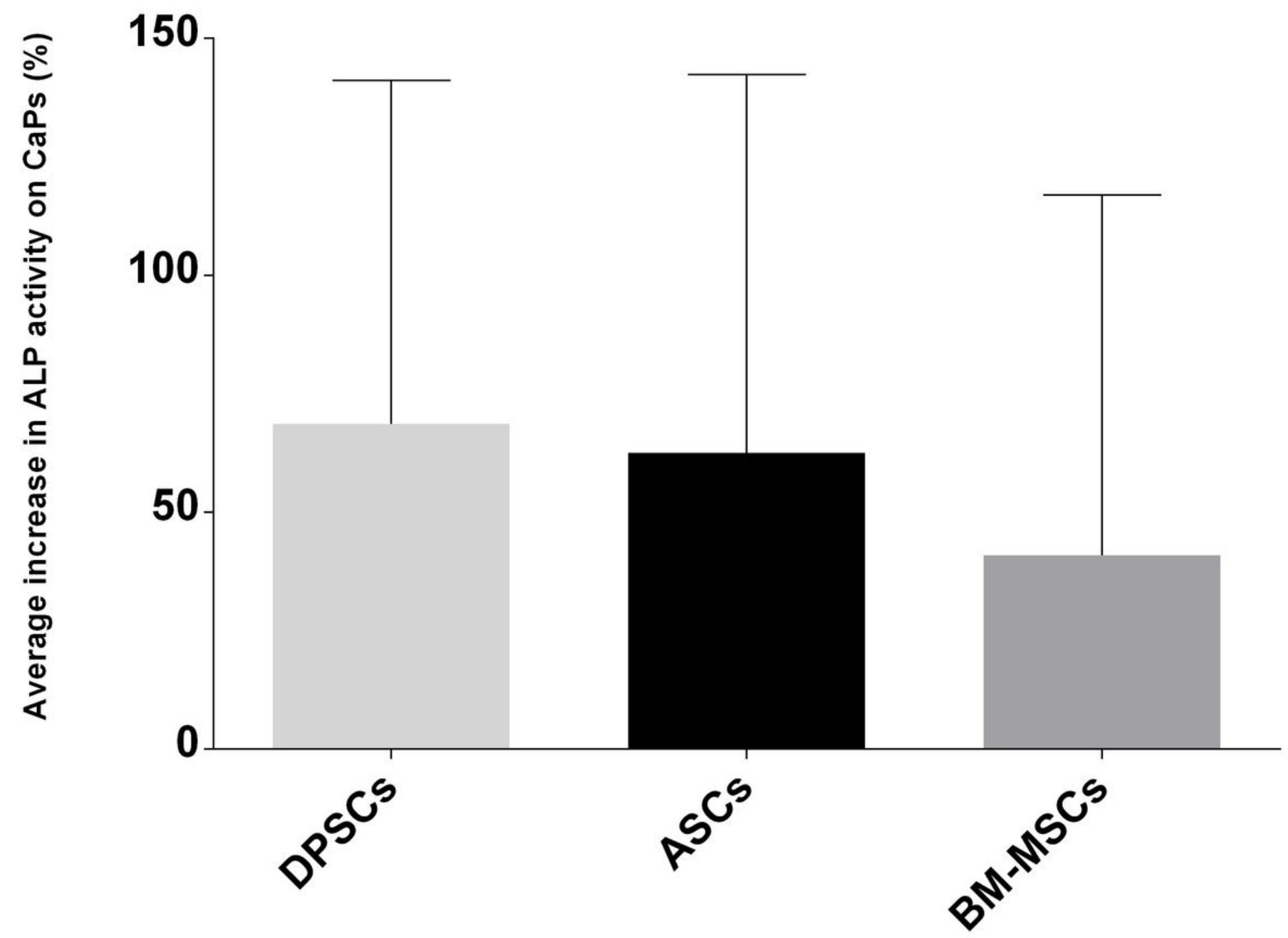

Figure 10

Average increase in ALP activity (in percentage) presented by each MSC on both CaPs. Adipose tissue (ASCs), dental pulp (DPSCs) and bone marrow (BM-MSCs). All data are shown as mean \pm standard deviation. 


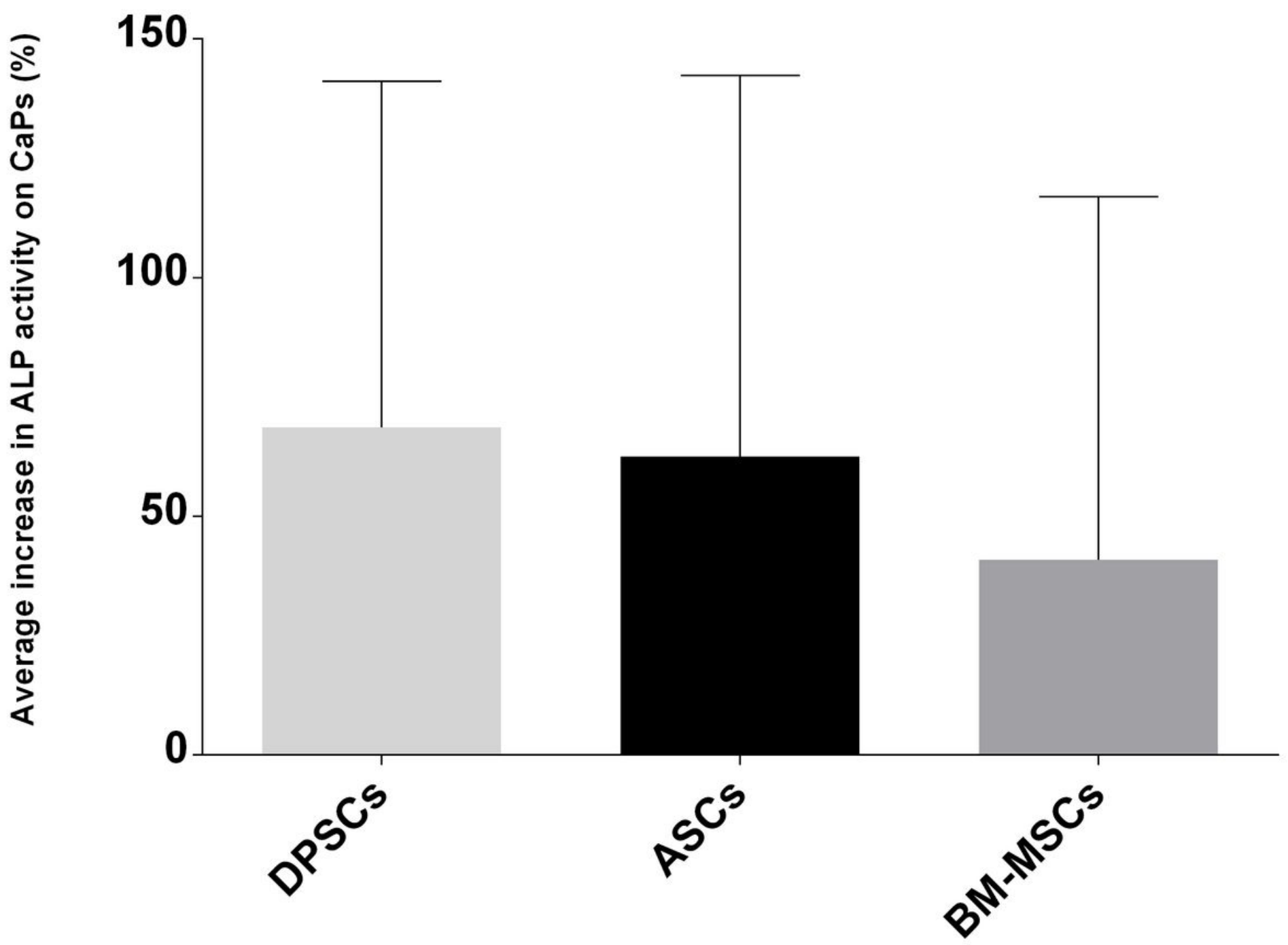

Figure 10

Average increase in ALP activity (in percentage) presented by each MSC on both CaPs. Adipose tissue (ASCs), dental pulp (DPSCs) and bone marrow (BM-MSCs). All data are shown as mean \pm standard deviation. 


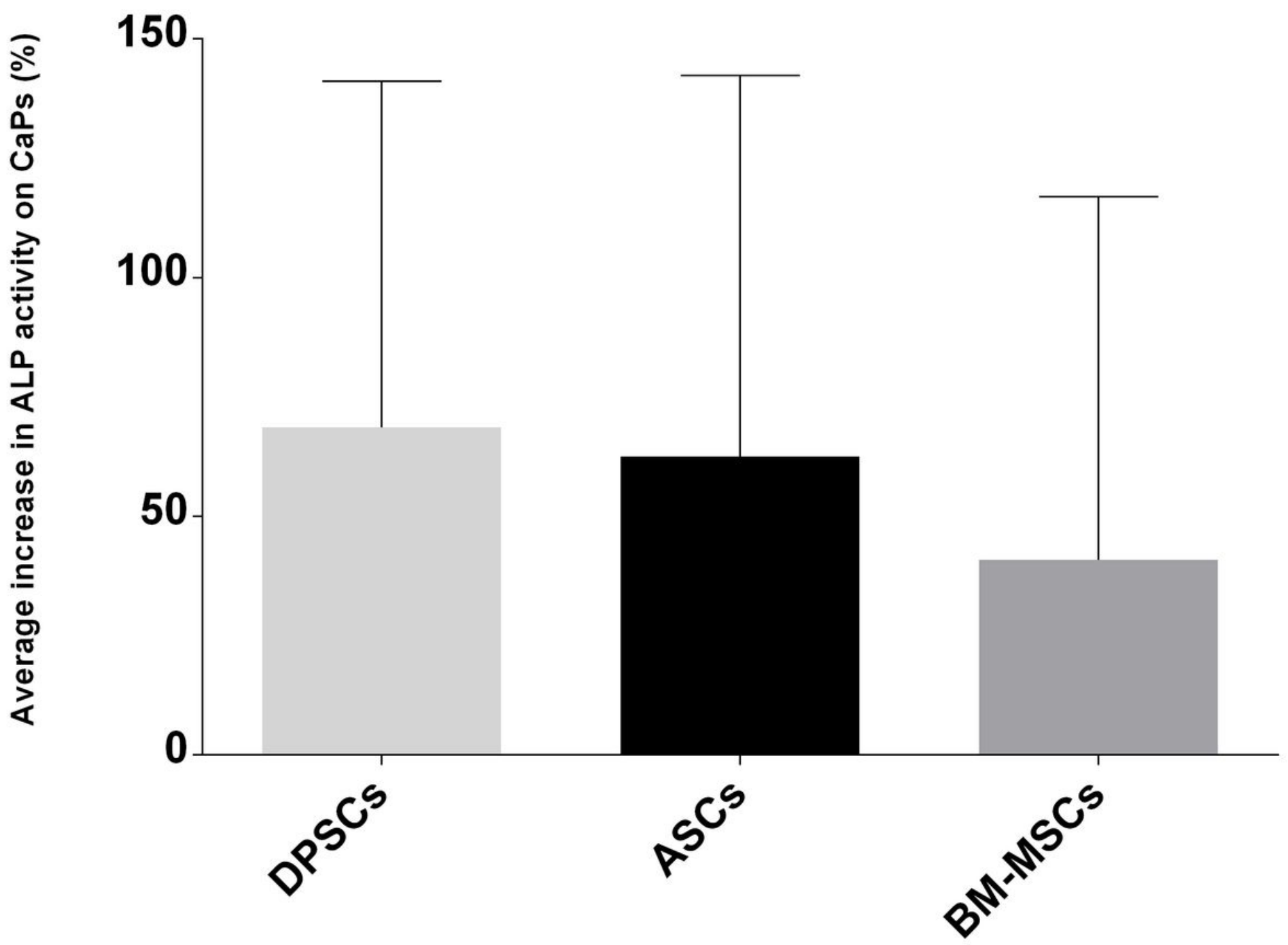

Figure 10

Average increase in ALP activity (in percentage) presented by each MSC on both CaPs. Adipose tissue (ASCs), dental pulp (DPSCs) and bone marrow (BM-MSCs). All data are shown as mean \pm standard deviation. 


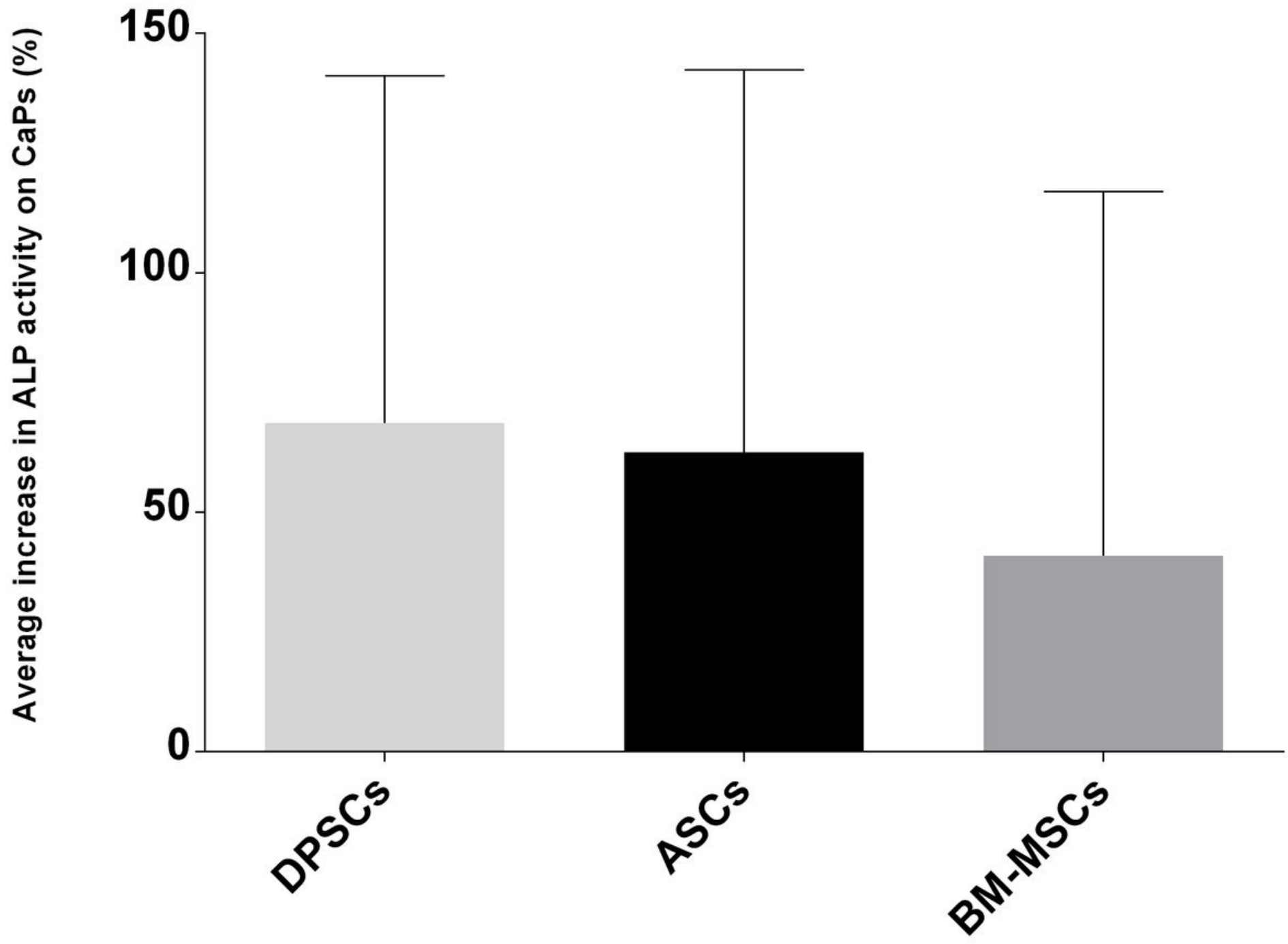

Figure 10

Average increase in ALP activity (in percentage) presented by each MSC on both CaPs. Adipose tissue (ASCs), dental pulp (DPSCs) and bone marrow (BM-MSCs). All data are shown as mean \pm standard deviation. 


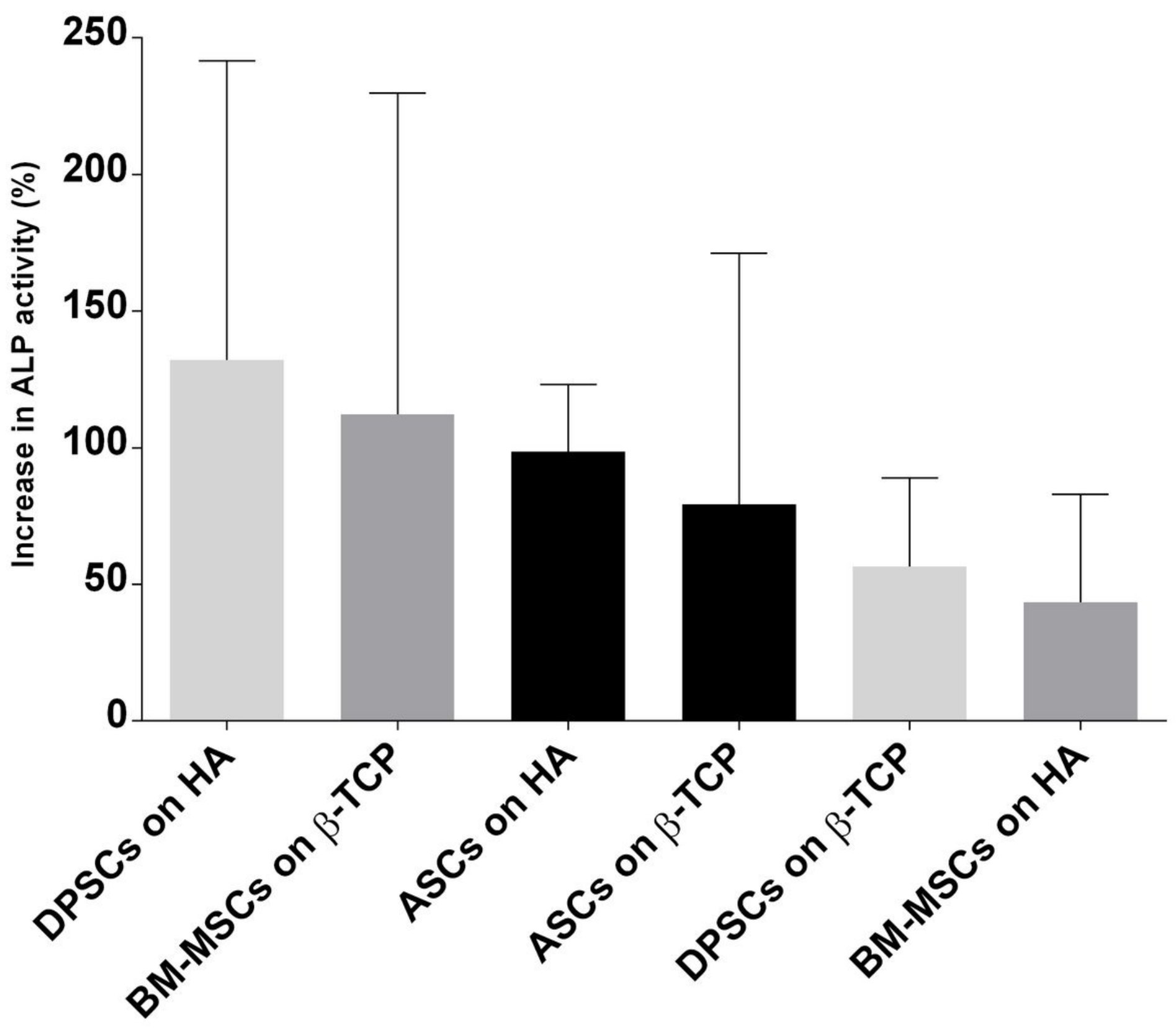

Figure 11

Increase in ALP activity (in percentage) presented by each construct. Hydroxyapatite (HA), ß-tricalcium phosphate ( $\beta$-TCP), adipose tissue (ASCs), dental pulp (DPSCs) and bone marrow (BM-MSCs). All data are shown as mean \pm standard deviation. 


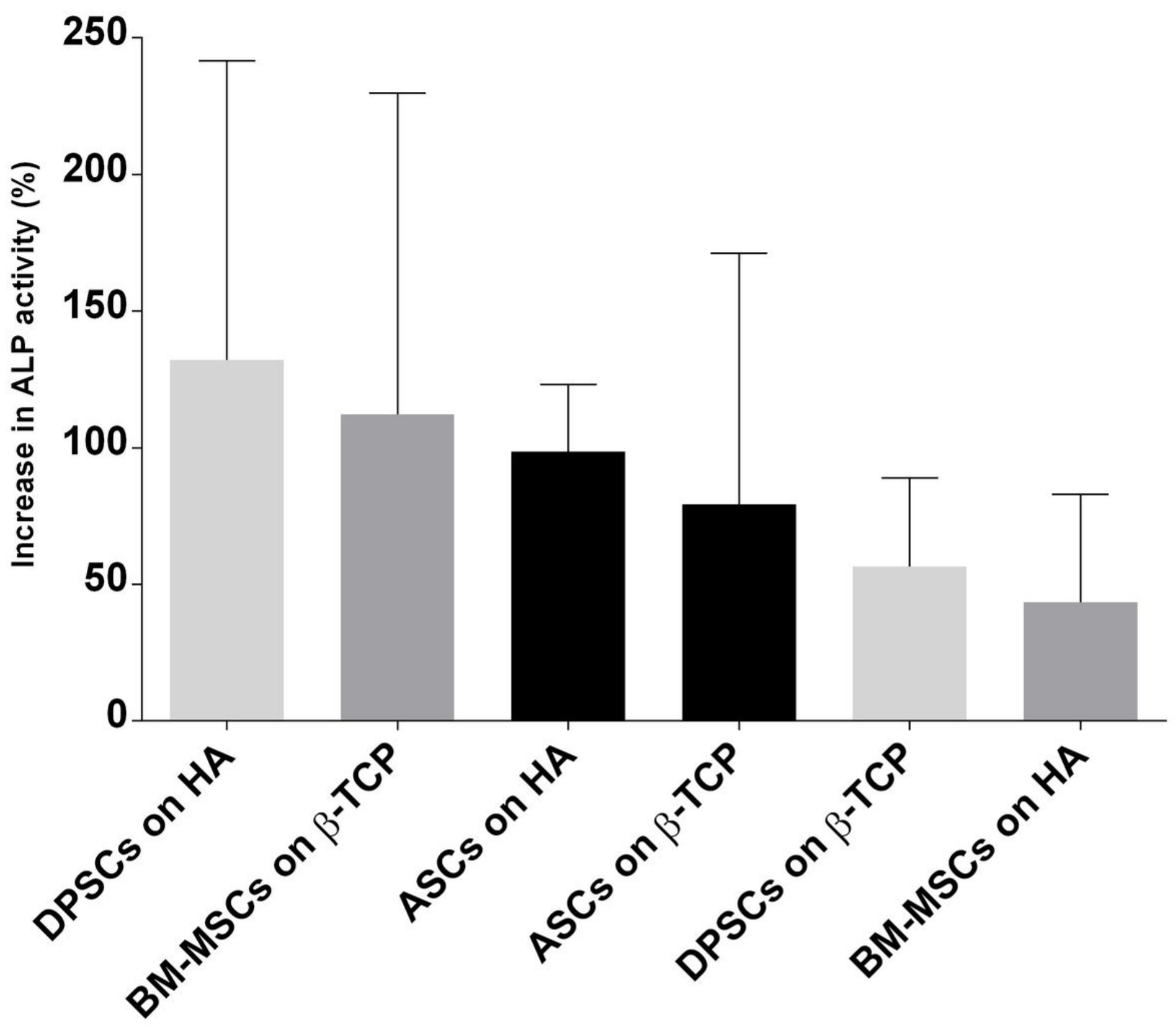

Figure 11

Increase in ALP activity (in percentage) presented by each construct. Hydroxyapatite (HA), ß-tricalcium phosphate ( $\beta$-TCP), adipose tissue (ASCs), dental pulp (DPSCs) and bone marrow (BM-MSCs). All data are shown as mean \pm standard deviation. 


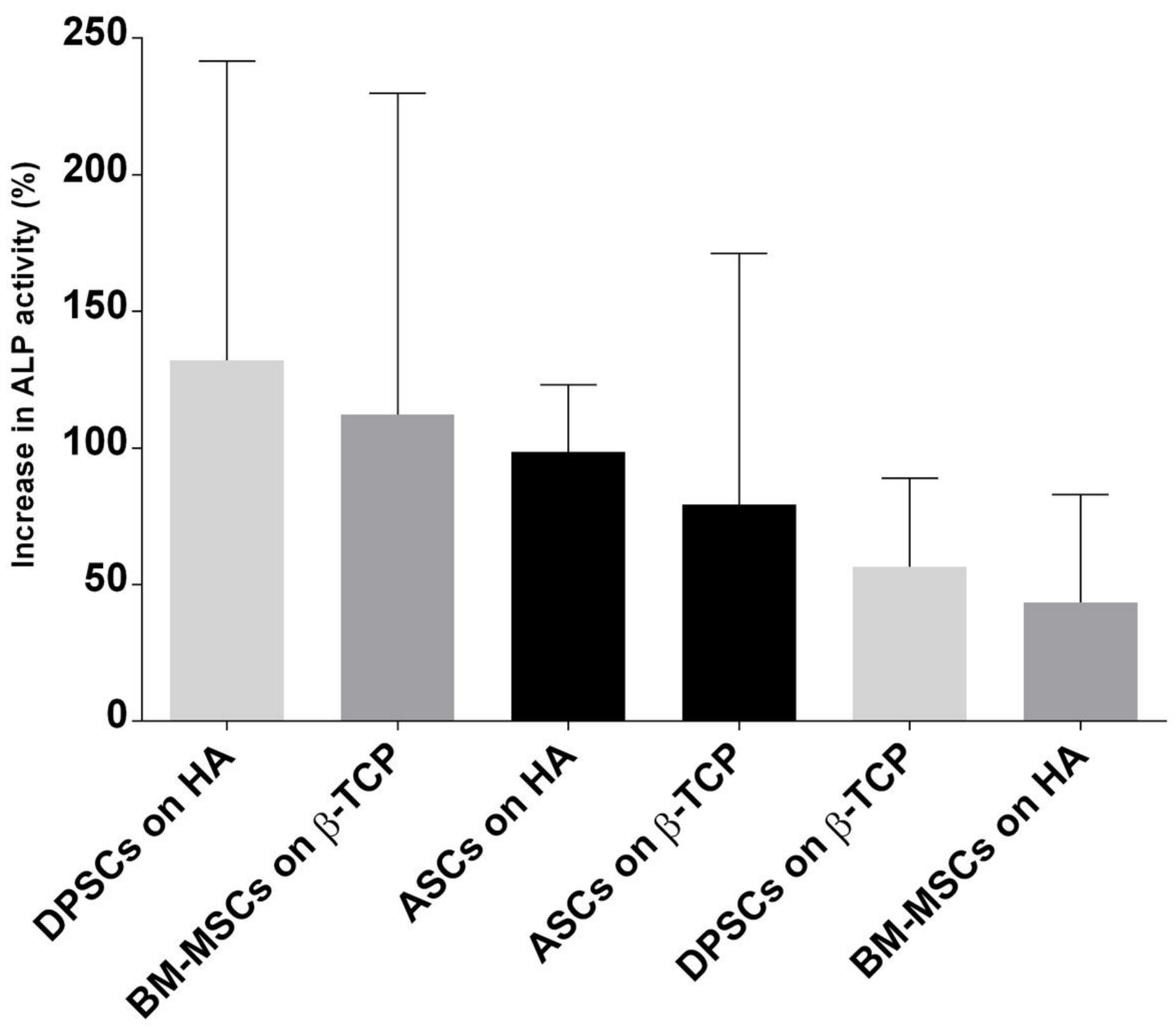

Figure 11

Increase in ALP activity (in percentage) presented by each construct. Hydroxyapatite (HA), ß-tricalcium phosphate ( $\beta$-TCP), adipose tissue (ASCs), dental pulp (DPSCs) and bone marrow (BM-MSCs). All data are shown as mean \pm standard deviation. 


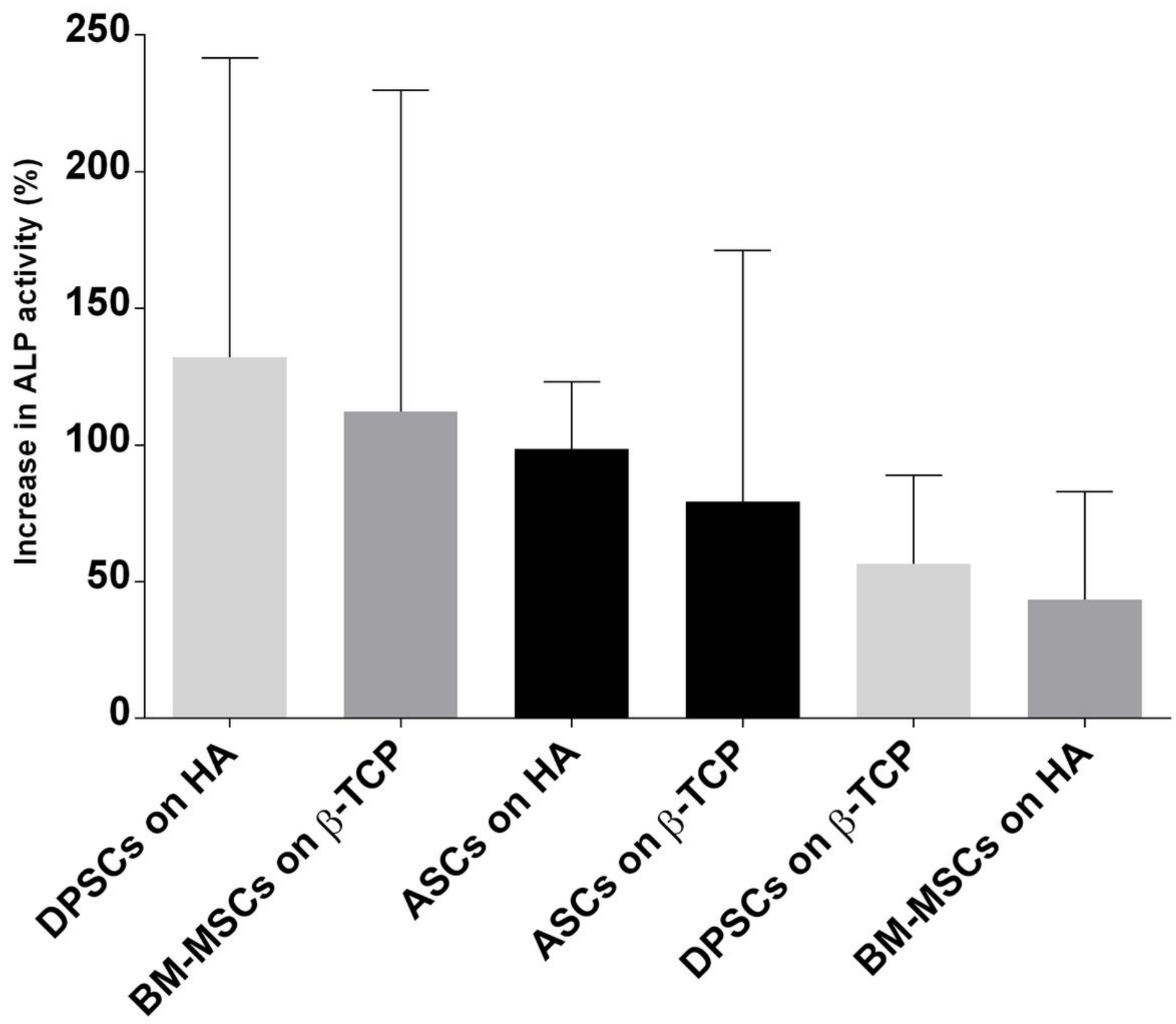

Figure 11

Increase in ALP activity (in percentage) presented by each construct. Hydroxyapatite (HA), ß-tricalcium phosphate ( $\beta$-TCP), adipose tissue (ASCs), dental pulp (DPSCs) and bone marrow (BM-MSCs). All data are shown as mean \pm standard deviation.

\section{Supplementary Files}

This is a list of supplementary files associated with this preprint. Click to download.

- Additionalfile1.tif 
- Additionalfile1.tif

- Additionalfile1.tif

- Additionalfile1.tif

- Additionalfile2.jpg

- Additionalfile2.jpg

- Additionalfile2.jpg

- Additionalfile2.jpg 